\title{
The Effect of Applied Pressure During Feeding of Critical \\ Cast Aluminum Alloy Components \\ With Particular Reference to \\ Fatigue Resistance
}

\author{
Final Report \\ On CMC Project - The Effects of \\ Applied Pressure During Feeding on the Fatigue \\ Properties of Critical Cast Aluminum \\ Alloy Components \\ June 2003 \\ Investigation Supported by the U.S. \\ Department of Energy through the \\ Cast Materials Coalition \\ and \\ The Mississippi State University \\ Monitored by Committee 2-H \\ (Gating and Risering) of the \\ American Foundry Society
}

Report Prepared by

J.T. Berry, R. Luck, B. Zhang, and R.P. Taylor

Department of Mechanical Engineering

Mississippi State University 
FINAL REPORT TO CMC

THE EFFECT OF APPLIED PRESSURE

DURING FEEDING OF CRITICAL

CAST ALUMINUM ALLOY COMPONENTS

WITH PARTICULAR REFERENCE TO FATIGUE RESISTANCE

TABLE OF CONTENTS

1. INTRODUCTION

2. DISPERSED POROSITY AND RELATED PHENOMENA -THEIR EFFECT

ON DUCTILITY AND FATIGUE BEHAVIOR

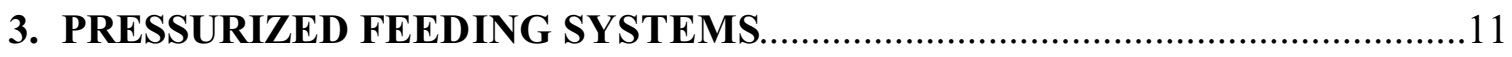

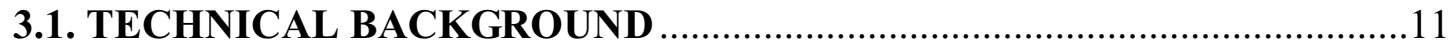

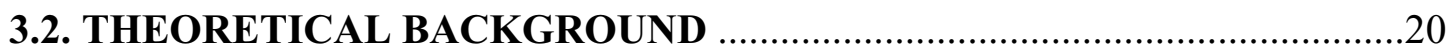

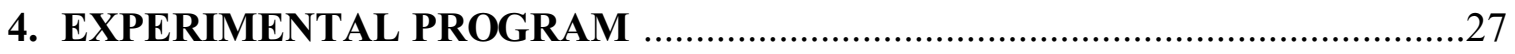

4.1. EXPERIMENTS INVOLVING PRESSURIZATION

AT THE POURING CUP

4.2. EXPERIMENTS INVOVING PRESSURIZATION

AT A BLIND RISER 31

5. RESULTS AND DISCUSSION

5.1. CASTINGS POURED WITH PRESSURIZATION

AT THE POURING CUP .33

5.2. CASTINGS POURED WITH PRESSURIZATION

AT A BLIND RISER .42

6. CONCLUSIONS AND FUTURE WORK .62

7. ACKNOWLEDGEMENTS .65

8. CONTRIBUTORS TO THIS INVESTIGATION AT MSU .66

9. LIST OF ASSOCIATED PUBLICATIONS .67

APPENDIX 1 .68

APPENDIX 2 .73

APPENDIX 3

APPENDIX 4 101 


\section{INTRODUCTION}

The medium to long freezing range alloys of aluminum such as A356, A357, A206, 319

for example are known to exhibit dispersed porosity, which is recognized as a factor affecting ductility, fracture toughness, and fatigue resistance of light alloy castings.

The local thermal environment, for example, temperature gradient and freezing front velocity, affect the mode of solidification which, along with alloy composition, heat treatment, oxide film occlusion, hydrogen content, and the extent to which the alloy contracts on solidification, combine to exert strong effects on the porosity formation in such alloys.

In addition to such factors, the availability of liquid metal and its ability to flow through the partially solidified casting, which will be affected by the pressure in the liquid metal, must also be considered. The supply of molten metal will thus be controlled by the volume of the riser available for feeding the particular casting location, its solidification time, and its location together with any external pressure that might be applied at the riser.

The industrial use of externally applied pressure at the riser has long been referred to in the literature of casting low carbon steels and cast irons. Both compressed air and steam have been applied to blind risers with such alloys, while the incorporation of vaporizing solids also in blind risers has been referred to for both sand and investment castings. 
Aside from the use of squeeze-casting, the use of what might be termed pneumatic aids to feeding aluminum alloy castings appears to be far less common, although the pouring of a mold set in an autoclave was mentioned in the literature of the nineteen thirties and forties. More recent work, which has involved the local application of pressure, appears to hold considerable promise.

The investigation to be described was supported by the U.S. Department of Energy, through the Cast Metals Coalition and Mississippi State University. It was monitored by the AFS Division 2-H Committee, and concerned the application of pressure to the risers of permanent mold castings with a view to the improvement of their fatigue resistance. The project has been concerned with tilt poured castings which have been evaluated using X-ray, pyknometry, image analysis, and a variety of mechanical test methods. 


\section{DISPERSED POROSITY AND RELATED PHENOMENA - THEIR EFFECT ON DUCTILITY AND FATIGUE BEHAVIOR}

It would be expected that the dispersed type of porosity encountered in $\mathrm{Al}-7 \mathrm{Si}-\mathrm{Mg}$ cast alloys affects both ductility and fatigue behavior. A brief review of the effects of porosity and microstructure upon ductility was presented in an earlier publication (1).

The unfortunate interaction between the size, shape, and location effects of porosity with features of microstructure such as the spacing of the secondary arms of the aluminum dendrite, the size, shape, and organization of the eutectic silicon constituents, as well as of any iron containing compounds, has colored a number of experimented investigations of the fatigue properties of cast aluminum alloys. This picture is further confounded by the presence of inadvertently incorporated oxide films, which in turn may influence the nucleation of both the iron containing compounds, and - of course - porosity (2).

Several publications appearing over the last two decades have acknowledged the deleterious effects of porosity on fatigue behavior (3-15). Most authors agree that microporosity, especially the shrinkage dominated variety, has profound effects. However, the proceedings of the ASM Conference on Advances in Aluminum Casting Technology of 1998 contained three excellent accounts of the difficulty in experimentally separating the effects of variables such as dendrite arm spacing and porosity level (1618). 
Earlier, Couper and co-workers (3) and Ozelton and company (4), respectively in 1990 and 1991, were among some of the first researchers to point out that fatigue crack initiation (FCI) in high-cycle fatigue (HCF) almost invariably commenced at pores in Al7Si type alloys. It should be noted, however, that Pitcher and Forsyth at the UK's Royal Aircraft Establishment (5) in 1982 and Stofanak, Hertzberg et al. (6) in 1983 had both cited the initiation potential of such defects.

Ozelton et alia (4) suggested that fatigue crack growth (FCG) is less affected by porosity population than FCI. However, Rading et al.(10) showed, as the porosity level decreases, the threshold stress intensity range increases, and when pores were reduced through Hipping, only the crack propagation resistance close to the stress intensity threshold was improved. Since that time, many others have implied that, in the presence of porosity, FCI is almost instantaneous $(7,9,14)$, and small cracks shorter than a certain length scale will propagate faster.

Most investigations appear to agree that maximum pore size is more important than the level of porosity in controlling FCI. In fact, tentative pore-size effect models, generally derived at least partly from experiment $(9,12,14)$ exist for FCI and FCG. Boileau et alia further indicated that most initiation sites in their studies of cast A356-T6 were at large, irregularly shaped micro-shrinkage pores (of about $300-400 \mu \mathrm{m}$ in average diameter). However, the extent of the interacting contributions of microstructure are difficult to discern with increasing structural coarseness $(16,17)$, this may be especially true for what is termed 'small crack growth', where anomalously high growth rates can occur. 
Since porosity predominates in crack initiation and small-crack propagation, it was also shown the pore size-location influences the total fatigue life (19). For pores with comparable size, the fatigue life increases with distance from the free surface. For pores located a comparable distance from the surface, fatigue life decreases with increasing pore size.

It should be noted that when there are pores present, other effects on the fatigue life such as strontium-modification, grain refining, and heat treatment were overshadowed $(20,21$, 22). Only until pores and oxides are excluded, effects of the microstructures (secondary dendrite arm spacing, grain size, silicon morphology, and heat-treatment) will be apparent $(20,23,24)$.

Campbell, Nyahumwa, and Green come close to separating experimentally porosity, oxide films, intermetallic and microstructural effects on total fatigue life in a paper contained in the ASM proceedings mentioned earlier (18). By examining discontinuities in the Weibull distribution of fatigue life of Al-7Si-Mg test bars together with careful scanning electron fractography, they were able to account respectively for initiation sites involving: 'Young' (thin) oxide films, 'Old' (thick) oxides, pores, and persistent slip bands. (The last category of fatigue initiation site is seen in most wrought aluminum high strength alloys and occurs in the predominantly ductile aluminum-rich phase.) From the above study the authors project that with proper precautions in melting and pouring to insure good (oxide-free) liquid metal quality entering the mold quiescently, a factor of improvement of 100 times might well be achievable in terms of fatigue life. 
Finally, it is significant to mention that few researchers have examined the role of casting surface texture on fatigue behavior; most have tested specimens machined from actual castings. Ting and Lawrence (9) did, however, discuss this factor and observed that fatigue cracks were to initiate from the near-surface casting pore or from discontinuities resulting from the as-cast surface texture. Gungor and Edwards (25) showed that for a squeeze casting the surface character had little effect on the long crack growth rate; instead the reduction in fatigue life was because of the greater small crack growth rate accompanying the rougher surface.

Crack initiation and growth behaviors in conjunction with surface roughness and porosity were examined in A356 alloy in UK by Jiang et al. (26). Surface hollows were found to control crack initiation in as-cast specimens with high surface roughness; it was shown that the period for reaching a crack length of $200 \mu \mathrm{m}$ accounted for $60 \%$ of the total fatigue life for polished specimens but only $\sim 30 \%$ for the as-cast specimens. The fatigue life was significantly improved (in particular, the time period associated with crack initiation and small-crack propagation) with the polished specimens.

Most recently a computational model describing the fracture and fatigue behavior of cast aluminum alloys has made possible the prediction of fatigue life with good accuracy (27 29). The application of this model should do much to enhance our understanding of the relative contributions of porosity and microstructure to controlling fatigue resistance. The multiscale modeling on effects of defects (pores and oxides) and microstructures (SDAS 
and silicon eutectic constituents) on fatigue behavior (crack initiation and small-crack propagation in particular) also contributes in the processing of cast aluminum alloys.

\section{REFERENCES}

1. J.T. Berry, Transaction of American Foundrymen's Society, 1995, (103), 837.

2. J. Campbell, Discussion - Division Two Sessions, AFS Casting Congress, 1999, St. Louis.

3. M.J. Couper, A.E. Neeson, and J.R Griffiths, Fatigue Fracture Engineering Material Structure, 1990, (13), 213.

4. M.W. Ozleton, S.J. Mocarski, and P.G. Porter, Report WL-TR-91-4111, 1991, Materials Directorate, Wright Laboratory, USAF Systems Command (Northrop Corporation, Under Contract.

5. P.D. Pitcher and P. Forsyth, Royal Aircraft Establishment, Technical Report No. 82107, 1982, Farnborough, UK.

6. R. J. Stofanak, R.W Hertzberg, et alia, Engineering Fracture Mechanics, 1987, (17), 527.

7. B. Skallerud, T. Iveland, and G. Hakegard, Engineering Fracture Mechanics, 1993, (44), 857.

8. C.M. Sonsino and J. Ziese, International Journal of Fatigue, 1993, (15), 75.

9. J.C Ting, R.V Lawrence, Fatigue Fracture Engineering Material Structure, 1993, (16), 631.

10. G.O.Rading, J. Li, and J.T. Berry, Transactions of American Foundrymen's Society, 1994, (102), 57.

11. J. Conley, B. Moran, et alia, Report to National Institute Standards and Technology, 1996.

12. J.M. Boileau, J.W. Zindel, and J.E Allison, SAE Paper 970019, 1997, SAE International, Warrendale, PA.

13. J.F. Major, Transactions of American Foundrymen's Society, 1998, (106), 901.

14. A.J. Hinkle, J.R. Brookenbrough, and J.T. Burg, SAE Paper 960161, SAE International, Warrendale, PA. 
15. G.R. Wakefield and R.M. Sharp, Materials Science and Technology, 1992, (8), 1125.

16. W. Chen, B. Zhang, T. Wu, D. R. Poirier, and Q. T. Fang, in Advances in Aluminum Casting Technology, (M. Tiryakoiglu and J. Campbell, Eds.), ASM., 1998, 207.

17. Q.G. Wang, D. Apelian, and J.R. Griffiths, ibid, 217.

18. J. Campbell, C. Nyahumwa, and N.R. Green, ibid, 225.

19. J.G. Conley, B. Moran, SAE Technical Paper Series, 980455, SAE International, Warrendale, PA, 1998, 25.

20. B. Zhang, Ph.D Dissertation, The University of Arizona, Tucson, AZ, 2002.

21. G.E. Byczynncki and D.A. Cusinato, International Journal of Cast Metals Research, $2002,14,315$.

22. C.J. Davidson, J.R. Griffith, M. Badiali and A. Zanada, Metallurgical Science and Technology, 2000, 18(2), 27.

23. Q.G. Wang, D. Apelian, D.A. Lados, Journal of Light Metals, 2001, (1), 73.

24. Q.G. Wang, D. Apelian, D.A. Lados, Journal of Light Metals, 2001, (1), 85.

25. S. Gungor, and L. Edwards, Materials Science and Engineering, 1993, (A160), 17.

26. H. Jiang, P. Bowen, and J. F. Knott, Journal of Materials Science, 1999, (34), 719.

27. M. Horstemeyer, D.L. McDowell, J.H. Fan, Sandia Report, SAND 2000-8661, March 2001.

28. J.H. Fan, D.L. McDowell, M. Horstemeyer, K. Gall, Engineering Fracture Mechanics, 2001 (68), 1687.

29. D.L. McDowell, K. Gall, M. Horstemeyer, J.H. Fan, Engineering Fracture Mechanics 2003, (70), 49. 


\section{PRESSURIZED FEEDING SYSTEMS}

\subsection{TECHNICAL BACKGROUND}

The success of the technique of applying external pressure during the solidification of metals and alloys depends upon two principles:

a. Suppressing the nucleation and growth of bubbles formed as a result of the expulsion of dissolved gases from the melt, or from reactions in the melt which form gaseous products.

b. Enhancing the action of feeding as solidification contraction takes place. This would be especially important with long freezing range (LFR) alloys where liquid metal must be made to flow through a mushy zone separating the totally liquid metal from the completely solid metal.

Occluded oxide films will also play an important part in determining the location and type of pore that will form (1). External pressure will also play a part here.

It is often suggested that the dispersed type of porosity forming in LFR alloys arises as the joint result of the phenomena described above. Consequently, rather than describe pores forming during solidification as either "gas porosity" or "shrinkage porosity", it is perhaps more appropriate to term such pores as "gas driven" or "shrinkage driven." 
The condition for gaseous bubble formation and growth in a liquid have been described quantitatively (2) as:

$$
P_{g}=P_{L}+P_{A}+\frac{2 \sigma}{r}
$$

where $P_{g}$ is the pressure within the gas bubble; $P_{L}$ is the metallostatic head; $P_{A}$ is the atmospheric or external pressure; $\sigma$ is the surface tension; $r$ is the bubble radius.

Consequently, bubble (i.e. gaseous driven porosity) growth may be minimized by increasing $P_{L}$ or $P_{A}$ or both. Through the years, practicing foundry engineers have followed a variety of paths to minimize troubling dispersed porosity, which occurs in LFR alloys, especially in those of aluminum. In addition to the occasional use of pressurization, careful degassing, controlled pouring, and the provision of steep temperature gradients have customarily been employed. Steep temperature gradients are associated with narrow mushy zones and thus short feeding distances. Many premium quality aerospace castings produced in the USA more than forty years ago can be characterized as heavily chilled, well degassed, and quiescently poured (3).

It is difficult to determine the exact date at which pressurized feeding came into common practice. This report next discusses the industrial background of the current practice.

A text by Harbard and Hall published in 1923 (4) carries an account of a technique involving the pressurization of large steel ingots or billets in refractory lined molds which Whitworth patented in the 1850 s. Similar practices were mentioned as taking place in France and Germany. It would appear that such activity was associated with the 
production of quality, "blow-hole" free billets suitable for the production of naval gunbarrels.

By the 1950s the local pressurization of risers in steel and iron castings was being practiced in Eastern Europe and in the UK $(5,6,7)$ in certain steel and iron foundries. The senior author (JTB) also recalls witnessing the production of aluminum match-plate patterns at that time using plaster molds, where risers were pressurized with compressed air.

The beginning of the more truly systematic work applying pressure during the solidification of aluminum alloys appears to spring from the 1930's when Hanson and Slater (8) in the UK solidified a number of sand castings under pressers up to levels of $700 \mathrm{psi}(4.826 \mathrm{MPa})$ of nitrogen in a small autoclave.

Both stock melted and deliberately gassed metal of an $8 \%$ copper-aluminum base alloy were involved. It was found that a pressure of $50 \mathrm{psi}(0.345 \mathrm{MPa})$ was sufficient to prevent the formation of what was termed 'pinholes' by the authors in the non-gassed (Stock) melted batch. However, assuming that the quoted density of 2.862 grams per cc of the 'stock' casting solidified under a pressure of $700 \mathrm{psi}(4.826 \mathrm{MPa})$ approaches the maximum theoretical density, at $50 \mathrm{psi}(0.345 \mathrm{MPa})$ their results suggest a porosity level of about $0.94 \%$, a level of porosity which would be unacceptable by today's standards. Not surprisingly, the elongation measurements of only $2 \%$ were recorded on test bars cut from 1.5 inch sand cast bars for pressure levels of zero, $50 \mathrm{psi}(0.345 \mathrm{MPa})$, and $200 \mathrm{psi}$ 
(1.379 MPa). It must be pointed out, however, that the authors specifically mention the entrapment of dross and oxide occurring during pouring through the teeming funnel applied to the neck of the autoclave which was positioned some twelve-inches above the top of the mold concerned. It would seem the oxide film formation are entrainment effects similar to those described more recently by Campbell (9) probably obscured any advantages of the pressurization.

Subsequently, work by Parker, Cox, and Turner (10) also in the UK in 1946 utilizing a $10 \%$ magnesium-aluminum base alloy showed exceptionally encouraging results in terms of elongation improvement, both in terms of level and consistency. Again autoclaving, this time at $100 \mathrm{psi}(0.689 \mathrm{MPa})$ was used. However, more attention appears to have been paid to precluding oxide incorporation in the metal during pouring into the autoclave where the sand mold was located.

In 1958, Uram, Flemings, and Taylor at MIT (11) working with well degassed 356 and 195 alloys again used the autoclave technique during the solidification of eleven-inch deep sand castings. Pressures of $15,60,100,160$, and $250 \mathrm{psi}(0.103,0.414,0.689$, 1.103, and $1.724 \mathrm{MPa}$ ) were maintained. However, extremely low values of elongation were recorded for all levels of pressurization. For example, all 356 samples tested showing values of only $2 \%$. Again, it is suggested that the excessive fall during pouring and concomitant oxide films incorporated into the stream probably biased the results, as was mentioned by the earlier workers in 1935 with the $8 \% \mathrm{Cu}$ alloy. 
However, a recent successful commercial application concerning total casting pressurization is the work of Donahue at Mercury Marine (12), where the lost foam casting, of engine blocks in B391 have been involved. With the equipment described pressures up to 10 atmospheres ( 1.034 MPa) can be applied. The author reports a low level of porosity. It is suggested here that the attenuation in the rate of fall of the molten metal by the melting/evaporation of the foam may well have had a desirable effect on decreasing the quantity of entrapped oxides and hence the amount of oxide related porosity.

In 1960, T. Watmough, a colleague of one of the authors (JTB) at the Armour Research Foundation (now IITRI) in Chicago, suggested a radically different series of experiments, whereby end-fed two-inch and four-inch square sectioned sand-cast bars were poured into three aluminum base alloys and plaster sleeved risers pressurized. The work, reported in the $1961 \mathrm{Tr}$. AFS, compared the effects of 0, 10, $20 \mathrm{psi}(0,0.069$, and 0.138 $\mathrm{MPa}$ ) pressure levels on the X-ray soundness of vertical slices taken along lengths of the bars concerned (7).

In addition to the above examination of casting slices, sectioning of the risers of the $5 \%$ silicon alloy bars revealed an interesting effect, Figure 3-1. The contrast between the non-pressurized and the pressurized risers was striking; that associated with the pressurization piped in the fashion of a short freezing range alloy, the non-pressurized riser did not - as would be expected. 
In 1969, Irani and Kondic working at Birmingham University conducted experiments similar to Berry and Watmough, along with a variety of other combinations of rigging

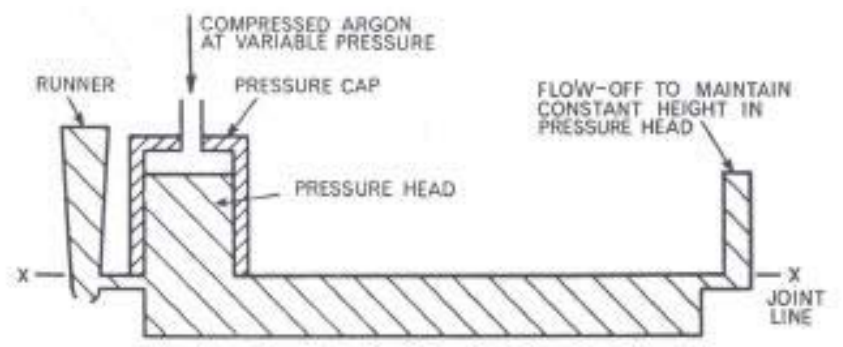

SECTION A-A

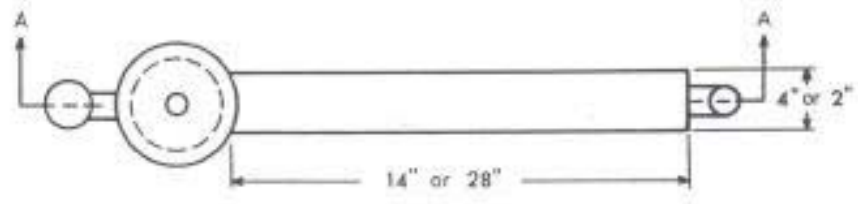

(a)

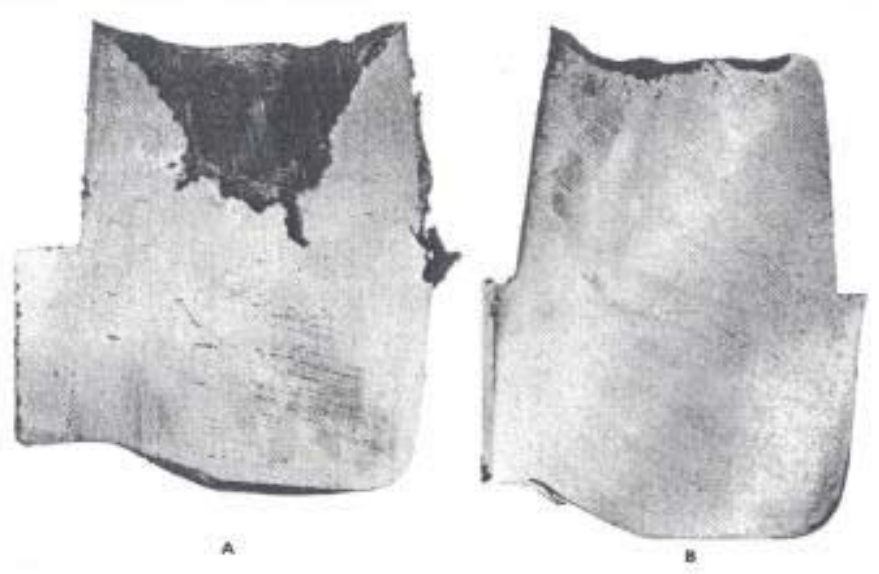

Figure 3-1. (a) Method of pressurizing bar castings; (b) Sectioned feeders from 2" $\times 2$ " $\times$ $14 " \mathrm{Al}-5 \% \mathrm{Si}$ sand cast bars. A) gas pressure $10 \mathrm{psi}$; B) no applied gas.

(chills, insulating sleeves and pads, etc.) in an aluminum-silicon-copper alloy (13). It is interesting to note that, of all the experiments performed, the flattest porosity distribution, 
together with the lowest average porosity level was seen in the casting attached to the riser pressurized at $15 \mathrm{psi}(0.103 \mathrm{MPa})$, Figure 3-2.

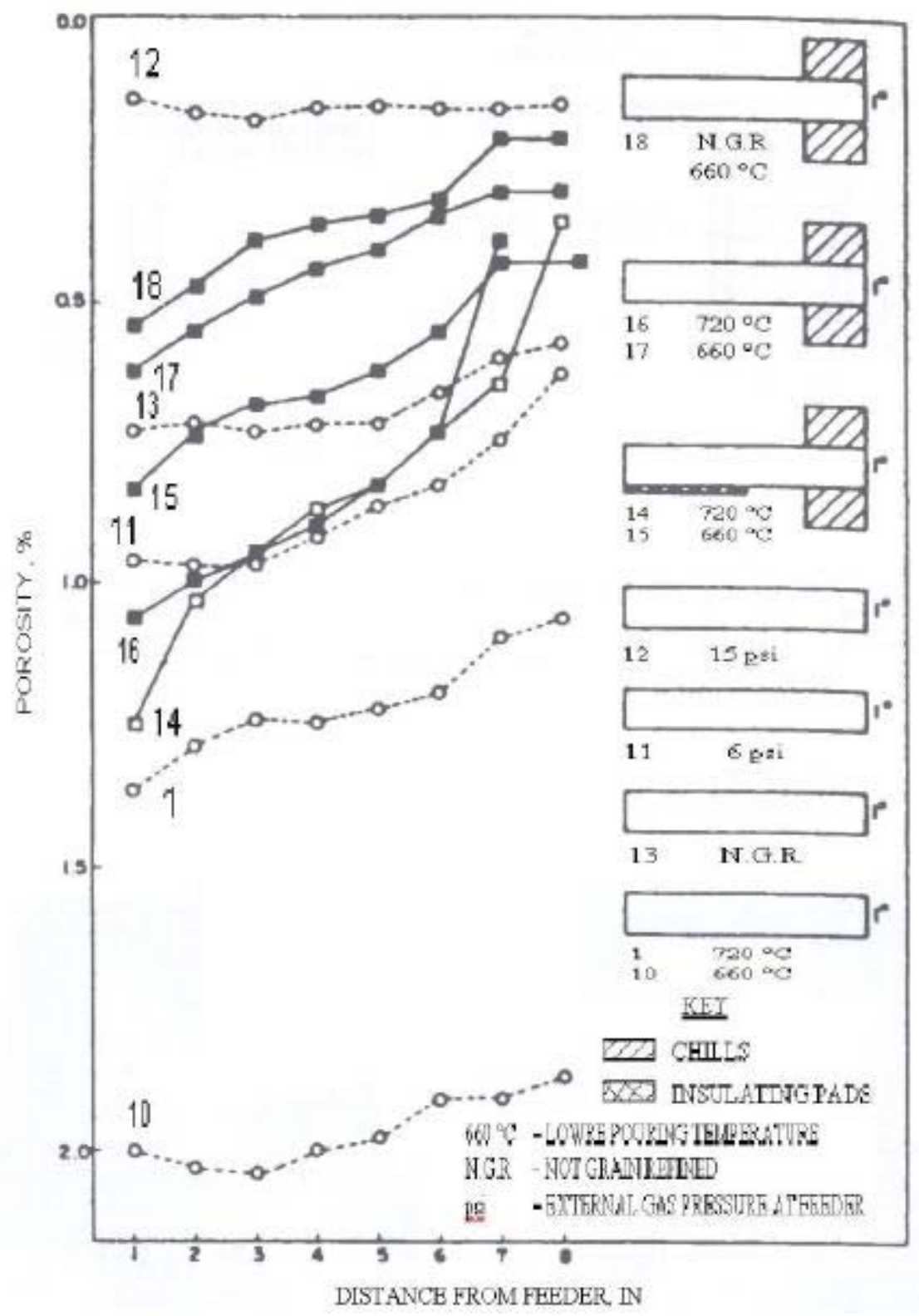

Figure 3-2. Porosity distribution for $1^{\prime \prime} \times 7^{\prime \prime} \times 8^{\prime \prime}$ plates in an $\mathrm{Al}-5 \mathrm{Si}-3 \mathrm{Cu}-0.25 \mathrm{Mg}$ alloy. Plates 11 and 12 were pressurized.

Both sets of experiments involved sand-cast end-fed bars or plates. Berry and Watmough specifically mention three problems with pressurization. The first is peculiar to sand 
molding, where penetration of the mold occurs. The second necessitates avoiding blowing the liquid metal out through the gating system. The third requires no pressurization of the riser until a point in the solidification where a layer of reasonably non-permeable solid metal has formed. The first problem was solved by the application of a zircon wash to the internal mold surface, the second by ensuring that the gating system had solidified prior to the pressurization, while the third problem is clearly going to be influenced by the freezing range of the alloy concerned. Consequently, the technique of the riser pressurization would not be expected to be particularly effective for alloys described as possessing a "pasty" mode of solidification - clearly where a combination of a very long freezing range and shallow temperature gradients are present. Additionally it would be highly desirable to be able to predict the precise point in time at which external pressure should be applied.

Frueh et al. conducted experiments and simulations on the effect of pressure on porosity in cast A356.2 plates in 2002 (14). The alloy was melted under vacuum and pressured with $0.2 \mathrm{~atm}$ hydrogen and argon to a total overpressure of 1, 10, and $20 \mathrm{~atm}$; bottom cooling in ceramic mold was induced to effect a directional solidification. Image analysis result showed that the area percentage of pores is $0.4 \%$ for an over pressure of $1 \mathrm{~atm}$, and very efficiently, an increase in overpressure of $10 \mathrm{~atm}$, and $20 \mathrm{~atm}$ reduces the amount of porosity to $0.09 \%, 0.02 \%$, respectively; the pore size distribution was shifted to smaller pores as the overpressure increases. 
The later work of Dahle et al. in Norway (1997) differs from preceding investigations in that a permanent mold (die) was used, although the end-fed bar configuration was retained (15). Again a flat distribution, this time of density rather than porosity, was observed with the pressurized riser, as opposed to a distribution which contained a marked minimum where the non-pressurized riser was employed.

An investigation involving the mechanical pressurization of the upper portions of small ingot like castings from Taiwan (16) published in 2002 has indicated that with rapidly solidifying castings poured in metallic molds, the sphere of action of the applied pressure will be linked closely with the location of the pressurization point with respect to that of a particular zone of the casting. These workers showed that porosity in regions remote from the pressurization, that might have solidified soon after pouring, was not reduced by the application of pressure.

Thus the importance of the extent of solidification at a particular point in a casting (that is the volume fraction solid at a specific location at a particular time) in relation to the success of any riser pressurization treatment is borne out. The precise role of volume fraction solidified at a particular time and casting location was borne out effectively in a 2003 paper from Lee and co-workers (17). Working in New Zealand with low pressure permanent mold castings of automotive wheels, this group's work clearly emphasizes the need for accurate solidification modeling in connection with pressurizing sequence planning, as well as pressurization location. 
Independent of the above investigations involving local pressurization, experiments at Fischer-Disa with both aluminum alloys and ductile iron, indicate how the pressurization of the riser in vertically-gated sand molds may be undertaken successfully on a commercial basis (18).

Herron (19) has suggested an extension of this application of pressure in the production of aluminum castings in vertically-parted sand molds using a two-stage approach. In the first stage metal is delivered into the mold cavity from below at low pressure. This is followed by a second stage where the delivered metal is pressurized again from below the mold. Clearly, accurate solidification and filling simulations will be needed if such a system is to succeed.

\subsection{THEORETICAL BACKGROUND TO THE PRINCIPLE OF RISER PRESSURIZATION}

Figure 3-3 shows a schematic view of a plate casting. Microshrinkage or feedingresistance porosity occurs when the pressure in the mushy zone, $P_{0}$, becomes negative (positive tensile stress). Liquids can sustain negative pressures when they are confined. Gas-dominated porosity occurs when $P_{0}$ falls below the nucleation pressure for gas bubbles. For aluminum alloys, gas-dominated porosity is primarily the result of dissolved hydrogen, coming out of solution on solidification. 


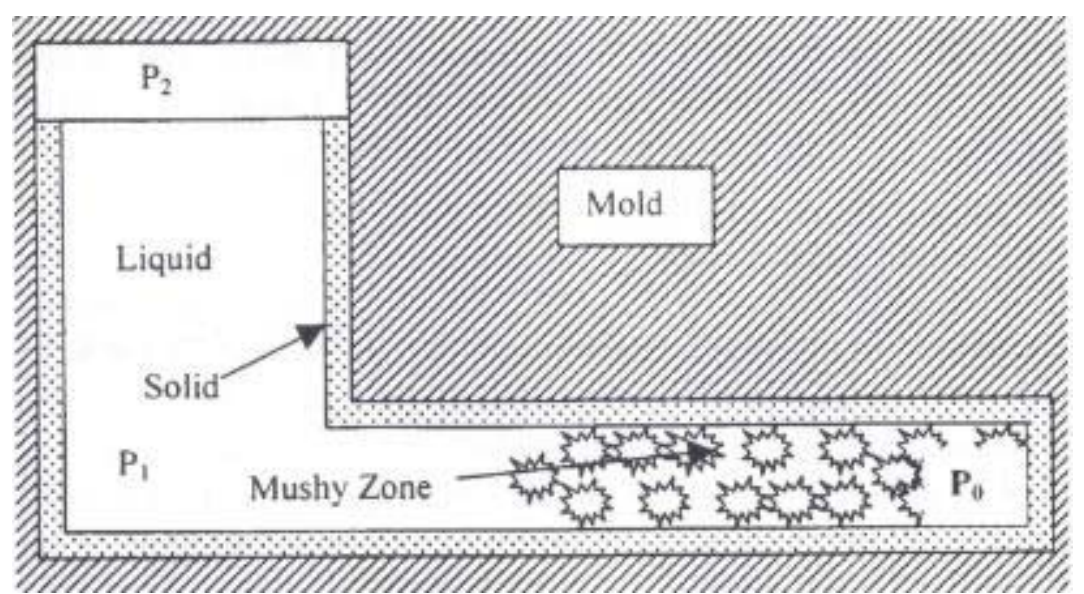

Figure 3-3. Schematic of a plate casting.

Consider the nomenclature given in Figure 3-4. The feeding rate $V(\xi)$ required to compensate for the solidification shrinkage $\beta=\left(\rho_{s}-\rho_{L}\right) / \rho_{L}$ is (20)

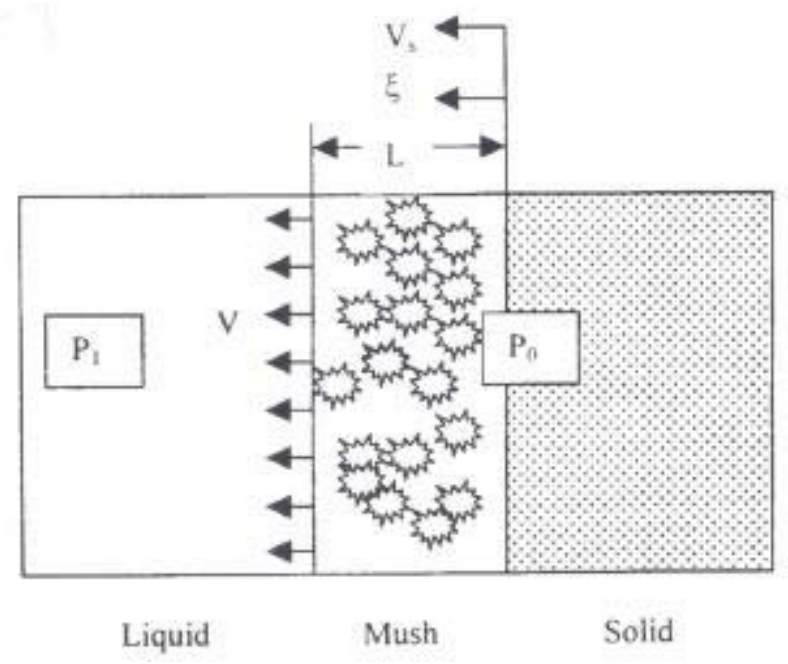

Figure 3-4. Schematic illustrating nomenclature.

$$
V(\xi)=-\beta \cdot V_{s} \cdot f_{L}(\xi)
$$

where $V_{s}$ the solidus-front velocity, $f_{L}(\xi)$ is the fraction liquid, and $\xi$ is the distance from the solidus front. $V(\xi)$ is the velocity of liquid needed to overcome the shrinkage. The 
negative sign results from the fact that the liquid metal must feed into the mushy zone.

This feeding-rate velocity is related to the pressure gradient by Darcy's Law.

$$
\frac{d P}{d \xi}=\frac{-\mu}{K} \cdot V(\xi)
$$

where $K$ is the permeability of the mushy zone and $\mu$ is the liquid viscosity. If $K$ is

proportional to the liquid fraction $K=\alpha f_{L}$ equations (3-1) and (3-2) can be combined to give

$$
\frac{d P}{d \xi}=\frac{\mu \cdot \beta \cdot V_{s}}{\alpha}
$$

Integrating and applying the boundary conditions $P=P_{0}$ at $\xi=0$ and $P=P_{1}$ at $\xi=L$ yields

$$
P_{1}-P_{0}=\frac{\mu \cdot \beta \cdot V_{s}}{\alpha} \cdot L
$$

Using the relationships

$$
\begin{gathered}
L=\frac{\Delta T}{G} \\
V_{S}=\frac{R}{G}
\end{gathered}
$$

where $\Delta T$ is the liquidus-solidus temperature difference, $G$ is the local temperature gradient, and $R$ is the local cooling rate, gives

$$
P_{0}=P_{1}-\left(\frac{\mu \cdot \beta \cdot \Delta T}{\alpha}\right) \frac{R}{G^{2}}
$$

The pressure $P_{1}$ is related to the riser pressure $P_{2}$ and the metallostatic head h

$$
P_{1}=P_{2}+\gamma \cdot h
$$


where $\gamma$ is the specific weight of the liquid metal. $P_{2}$ is equal to atmospheric pressure plus any additional pressurization $P^{\text {star }}$

$$
P_{2}=P_{a t m}+P^{s t a r}
$$

Therefore,

$$
P_{0}=P_{a t m}+\gamma \cdot h+P^{s t a r}-\left(\frac{\mu \cdot \beta \cdot \Delta T}{\alpha}\right) \cdot \frac{R}{G^{2}}
$$

For aluminum castings, $h=1 \mathrm{ft}$ and $\gamma=150 \mathrm{lbf} / \mathrm{ft}^{3}$; so

$$
P_{a t m}+\lambda \cdot h=14.7+\frac{150.1}{144}=15.7 p s i \quad(0.1083 \mathrm{MPa}) \quad(3-12
$$

Therefore, a riser pressurization of $P^{\text {star }}=15 \mathrm{psi}(0.1083 \mathrm{MPa})$ will effectively double the available feeding pressure potential of the casting.

Thus an applied pressure of roughly one atmosphere is actually addionally equivalent to decreasing the critical Niyama criterion value at which porosity is expected to form by a factor of the square root of 2 . This can be established by evaluating the $G / \sqrt{R}$ value in

$$
\frac{G}{\sqrt{R}}=\sqrt{\frac{\frac{\mu \cdot \beta \cdot \Delta T}{\alpha}}{\left(P_{a t m}+\gamma \cdot h+P^{s t a r}-P_{0}\right.}}
$$

Clearly, increasing $P^{\text {star }}$ decreases $G / \sqrt{R}$.

Figure 3-5 shows porosity data plotted against Niyama's Criterion, $G / \sqrt{R}$, by Huang et alia (21) for A356 aluminum alloy plate castings. The data indicates that the porosity in these castings is correlated with the criterion. For low values of the criterion, less than 
500 , the percent porosity rises rapidly. Therefore it is desirable to set a critical value of the criterion $G / \sqrt{R}$ and design the riser and rigging such that the predicted values of the criterion are great than this number. Berry (22) recommends a critical value of 2700 $\sqrt{{ }^{\circ} \mathrm{C} \cdot \mathrm{s}} / \mathrm{m}$ for aluminum plate castings with hydrogen content less than $0.2 \mathrm{cc} / 100 \mathrm{~g}$. As seen in the figure the porosity is more or less constant for criterion values above this critical value. Below this critical value, the porosity begins to increase. As can be seen in equation (3-13), the effect of the riser pressurization $P^{\text {star }}$ is to reduce this critical value and shift the data in Figure 3-5 to the left allowing a wider range of riser/rigging designs to yield low levels of porosity.

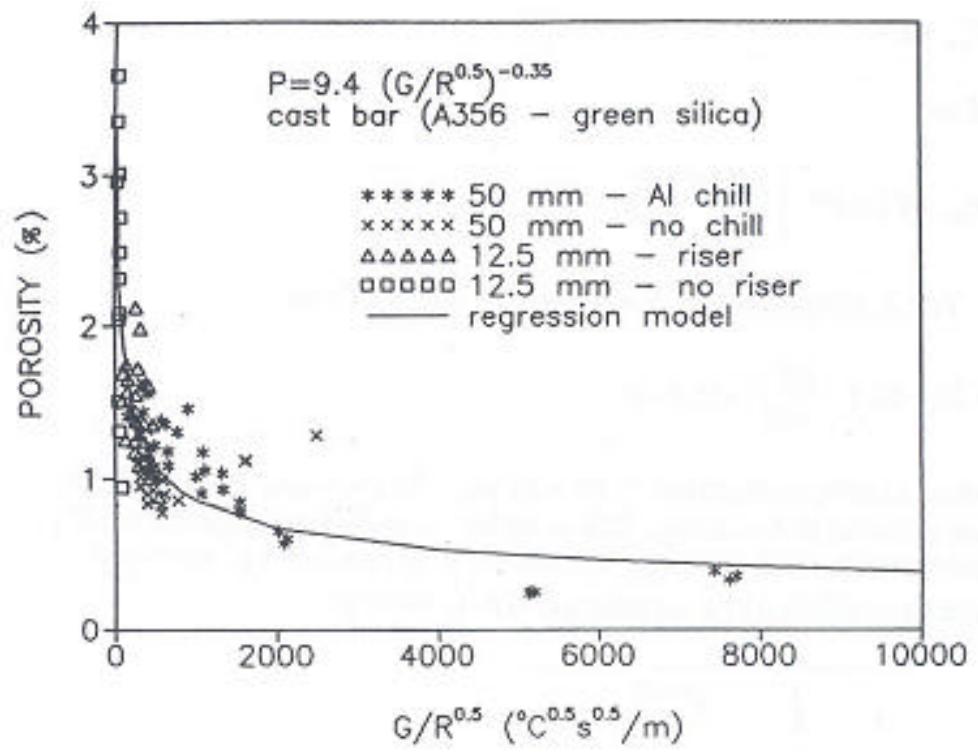

Figure 3-5. Porosity data for A356 aluminum alloy castings in green silica sand plotted versus Niyama's Criterion.

\section{REFERENCES}

1. Campbell. Castings, Butterworth-Heinemann, Oxford, U.K., 1, 1991.

2. Flemings M.C., Solidification Processing, McGraw-Hill, N.Y., 237, 1974. 
3. J.T. Berry, G. Jalewalia and R. G. Kumble, Transactions of American Foundrymen's Society, 2000, 108.

4. F.W. Harbard and J. W.Hall, The Metallurgy of Steel, Vol. II, Mechanical Treatment, 1923, C. Griffin, London.

5. W. Desnizki, Iron and Steel, February 1958, 58.

6. S. Jaswinski, Archiwum Hutnictwa, 1959, 4, 45.

7. J.T. Berry, T. Watmough, Transactions of American Foundrymen's Society, 1961, 69, 11.

8. D. Hansen and I Slater, Jnl. Inst. Metals, 1935, 56, 103.

9. J. Campbell, C. Nyahumva, and N.R. Green, in Advances in Aluminum Casting Technology, M. Tiryakioglo and J. Campbell (eds.), ASM International, Materials Park, OH, 225-234, 1998

10. R. Parker, G. Cox and A. Turner, JnL. Inst. Metals, 1946, 73, 175.

11. S. Uram, M.C. Flemings and H. F. Taylor, Transactions of American Foundrymen's Society, 1958, 66, 129.

12. A. T. Spada, Modern Casting, 91 (5), 2001, 27.

13. D.R. Irani and V. Kondic, Transactions of American Foundrymen's Society, 1969, 77, 208.

14. C. Frueh, P.K. Sung, D.R. Poirier, R.G. Erdmann, and M.E. Miszkiel, in Proceedings from the $2^{\text {nd }}$ International Aluminum Casting Technology Symposium, 7-9 October, Columbus, OH, ASM International, 2002, 99.

15. A. Dahle, L. Arnberg and D. Apelian, Transactions of American Foundrymen's Society, 1997, 105.

16. KD. Li, and E. Chang, Transactions of American Foundrymen's Society, 2002, paper 02-069.

17. J.R. Lee, D.P.K. Singh, and Z.W. Chen, Transactions of American Foundrymen's Society, 2003, paper 03-016

18. N. W. Rasmussen, R. Aagaard and P. N. Hansen, Transactions of American Foundrymen's Society, 2001. 
19. D.J. Herron, Trans. Transactions of American Foundrymen's Society, 2003, paper 03138.

20. P.N. Hansen, presentation at May 1997 meeting, Birmingham Chapter American Foundrmen's Society.

21. T.S. Piwonka, N. El-Kaddah and J.T. Berry, Patent disclosure, University of Alabama, 1978.

22. R.P. Taylor, J.T. Berry and R. A. Overfelt, ASME Proceedings of the $31^{\text {st }}$ national Heat transfer Conference, 1996 (HTD-Vol.323) 69; TMS. 


\section{EXPERIMENTAL PROGRAM}

The experimental program has involved the production of two small tilt-poured permanent mold castings. The subject castings were poured in the plants of two of the collaborating foundries (Stahl Specialty Co. and Metalloy Inc.). Each phase of the experimental program will be described separately.

\subsection{EXPERIMENTS INVOLVING PRESSURIZATION AT POURING CUP}

The castings involved in this phase of the investigation were of a small-pressure-tight configuration with several integral bosses. Four such castings were gated through individual risers to a common pouring cup (Figure 4-1). Tooling previously used on a NIST supported project was made available by Stahl Specialty. The tooling was such that air pressure could be applied at the pouring cup and also at two of the integral bosses by pneumatically activated mechanical 'squeeze pins'.

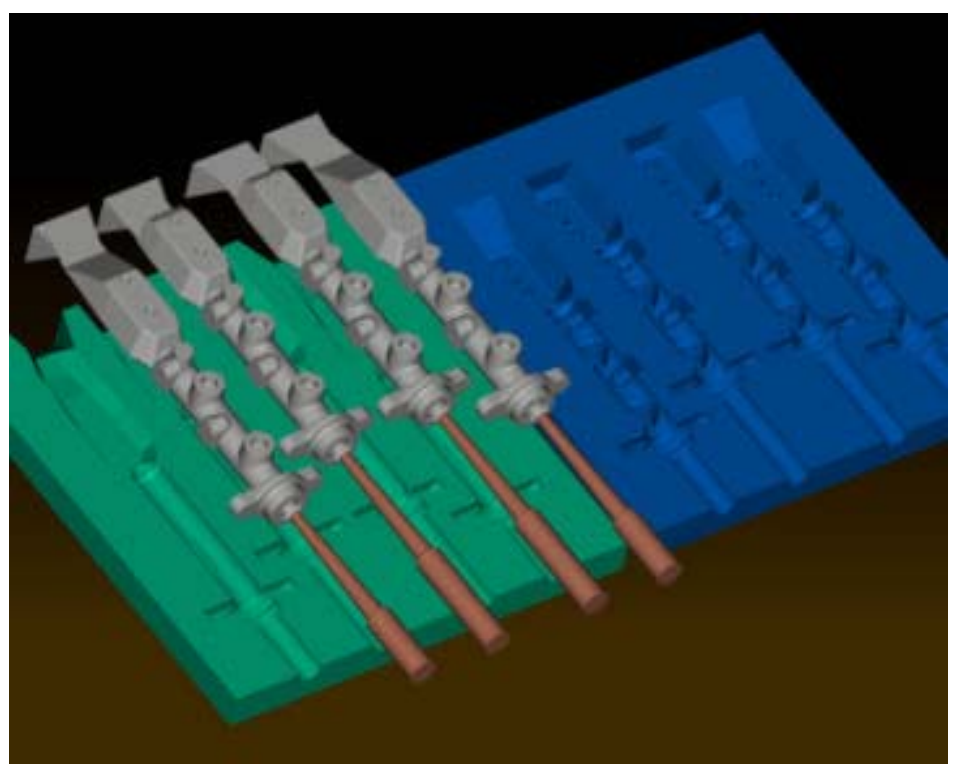

Figure 4-1. Casting, risers and pouring cup diagram for initial study. 
The action of the pins was at right angles to the axis of the roughly cylindrical casting. Castings poured both in Alloy 319 and A356 were involved.

The different casting procedures are described below. For each group, sixteen castings were produced; Groups A-G were 319 with a core and Groups I-O were A356 without a core.

(1) Group A castings (319) were poured without pressure applied to the pouring cup or squeeze pins.

(2) Group B castings (319) were poured with pressure (52 psi gage) applied only to the pouring cup once the mold completed the tilt-cycle.

(3) Group C castings (319) were poured without pressure applied to the pouring cup but pressure (82 psi gage) applied to the squeeze pins once the mold completed the tilt-cycle.

(4) Group D castings (319) were poured with pressure applied to the pouring cup (52 psi gage) and squeeze pins (82 psi gage) once the mold completed the tilt-cycle.

(5) Group E castings (319) were same as Group B, but the pressure was reduced to 25 psi gage and only eight castings were produced.

(6) Group F castings (319) were poured with pressure (52 psi gage) applied only to the pouring cup when the mold was half-way through the tilt-cycle.

(7) Group G castings (319) were poured with pressure applied to the pouring cup (52 psi gage) and squeeze pins ( 82 psi gage) once the mold was half-way through the tilt-cycle. 
(8) Group H castings (A356) were poured without pressure applied to the pouring cup or squeeze pins.

(9) Group I castings (A356) were poured with pressure (52 psi gage) applied only to the pouring cup once the mold completed the tilt-cycle.

(10) Group J castings (A356) were poured with no pressure applied to the pouring cup (52 psi gage) but squeeze pins ( 82 psi gage) once the mold completed the tiltcycle.

(11) Group K castings (A356) were poured with pressure applied to the pouring cup (52 psi gage) and squeeze pins (82 psi gage) once the mold completed the tiltcycle.

(12) Group L castings (A356) were poured with pressure applied to the pouring cup (52 psi gage) once the mold was 90 percent through the tilt cycle.

(13) Group M castings (A356) were poured with pressure applied to the pouring cup (52 psi gage) once the mold was 80 percent through the tilt cycle.

(14) Group N castings (A356) were poured with pressure applied to the pouring cup (52 psi gage) once the mold was half-way through the tilt cycle.

(15) Group O castings (A356) were poured with pressure applied to the pouring cup (52 psi gage) once the mold was 67 percent through the tilt cycle.

(Note: $52 \mathrm{psi}=0.3588 \mathrm{MPa}, 82 \mathrm{psi}=0.5658 \mathrm{MPa}$ )

After pouring, sample castings were subject to X-ray inspection and castings poured during the same cycle were sectioned and porosity levels determined by pyknometry (Archimedes based methods). 
The tilt cycle was approximately 25 seconds. The castings were poured mechanically from the dip-well of a reverbatory furnace (Temperature of metal at dip well $1440^{\circ} \mathrm{F}$ $\left.\left(780{ }^{\circ} \mathrm{C}\right)\right)$. The molds were maintained at $800^{\circ} \mathrm{F}\left(425^{\circ} \mathrm{C}\right)$ through the process of pouring. The tilt cycle was maintained at 28 seconds. The chemical analysis for the two heats concerned is given in Tables 4-1.

Table 4-1 Chemical Analyses of 319 Heat and A356 Heat

\begin{tabular}{|c|c|c|}
\hline \multirow{2}{*}{ Element } & 319 & A356 \\
\cline { 2 - 3 } & \multicolumn{2}{|c|}{ Percent, \% } \\
\hline $\mathrm{Mg}$ & 0.08 & 0.38 \\
\hline $\mathrm{Sr}$ & 0.03 & 0.02 \\
\hline $\mathrm{Ti}$ & 0.14 & 0.12 \\
\hline $\mathrm{Cu}$ & 3.42 & 0.00 \\
\hline $\mathrm{Fe}$ & 0.55 & 0.08 \\
\hline $\mathrm{Si}$ & 5.97 & 7.01 \\
\hline $\mathrm{Cr}$ & 0.06 & 0.001 \\
\hline $\mathrm{Mn}$ & 0.3 & 0.001 \\
\hline $\mathrm{Ni}$ & 0.04 & 0.003 \\
\hline $\mathrm{Pb}$ & 0.03 & 0.00 \\
\hline $\mathrm{Sn}$ & 0.01 & 0.00 \\
\hline $\mathrm{Zn}$ & 0.86 & 0.003 \\
\hline $\mathrm{H}_{2}(\mathrm{cc} / 100 \mathrm{~g})$ & $\sim 0.11$ & 0.11 \\
\hline $\begin{array}{l}\text { Note: Both 319 and A356 melts were modified with strontium and refined with TiBor. } \\
\text { The modification was accomplished by adding the modifier to the melted metal } \\
\text { present in the dip well. }\end{array}$ & \\
\hline \multicolumn{2}{|c|}{} \\
\hline
\end{tabular}

After cooling castings were heat treated to the T6 condition. Selected castings were Xrayed and also sectioned for density based porosity determination.

Finally, it should be noted that considerable difficulty was experienced in sealing the pouring cup for pressurization. Thus the stated pressure levels may only be taken as approximate. 


\subsection{EXPERIMENTS INVOLVING PRESSURIZATION AT A BLIND RISER}

The castings in this phase of the investigation were small bracket castings in Alloy $356^{\#}$.

They were poured four at one time from a common pour cup using tilt-pour tooling made available by Metalloy Inc. The tooling permitted the pressurization of each of the individual blind risers adjacent to the castings concerned. The tilt-pour platform was kindly donated by Hall Corporation. Simulation of the freezing of the bracket castings are contained in Appendix 2

The pouring temperature was maintained $1290^{\circ} \mathrm{F}\left(700{ }^{\circ} \mathrm{C} \pm 5^{\circ} \mathrm{C}\right)$ while the mold temperature was held at $780^{\circ} \mathrm{F}\left(415^{\circ} \mathrm{C}\right)$. Both a non-pressurized (base-line) and pressurized riser was involved. Pressure was applied by a shop air line which was regulated to permit a variety of pressure levels, given in Table 4-2. The cycle time was at 28 seconds. It was noted that above about $10 \mathrm{psi}(0.069 \mathrm{MPa})$ there was a distinct tendency to both replicate closely and lift off the mold coating. The chemical analysis of the heat concerned is shown in Table 4-3.

Each of the castings was sectioned into eleven (11) portions (See Figure 4-2). The various sections were subject to the porosity evaluation as well as microstructure characterization. The surface roughness of some castings around the elbow portion where cracks initiated was measured using a standard roughness measuring device (TaylorHobson Surtronic $3^{+}$). Certain portions of selected castings were also subjected to hot isostatic pressurization. The hipping conditions were 2 hours at $540{ }^{\circ} \mathrm{C}$ and $100 \mathrm{MPa}$.

\footnotetext{
\# For illustration see next section.
} 
Table 4-2. Riser Pressurization Levels Associated with Individual Casting Sets.

\begin{tabular}{|c|c|}
\hline Casting Set Designations & Pressurization Treatment psi (MPa) \\
\hline $16-11,12,15,16$ & $0(0)$ \\
\hline $18-11,12,15,16$ & $0(0)$ \\
\hline $19-11,12,15,16$ & $0(0)$ \\
\hline $21-11,12,15,16$ & $2(0.0138)$ \\
\hline $22-11,12,15,16$ & $4(0.0276)$ \\
\hline $23-11,12,15,16$ & $4(0.0276)$ \\
\hline $25-11,12,15,16$ & $8(0.0552)$ \\
\hline $26-11,12,15,16$ & $10(0.0689)$ \\
\hline $28-11,12,15,16$ & $14(0.0966)$ \\
\hline $32-11,12,15,16$ & $20(0.1378)$ \\
\hline \multicolumn{2}{|c|}{ Note: The figure after the hyphen indicates the die cavity impression from where the } \\
casting was taken for testing.
\end{tabular}

Table 4-3. Chemical Analysis of 356 Heat

\begin{tabular}{|c|c|}
\hline Element & Percent, \% \\
\hline $\mathrm{Si}$ & 6.78 \\
\hline $\mathrm{Cu}$ & 0.07 \\
\hline $\mathrm{Mg}$ & 0.25 \\
\hline $\mathrm{Fe}$ & 0.32 \\
\hline $\mathrm{Mn}$ & 0.1 \\
\hline $\mathrm{Ni}$ & 0.01 \\
\hline $\mathrm{Zn}$ & 0.05 \\
\hline $\mathrm{Ti}$ & 0.12 \\
\hline $\mathrm{Sr}$ & 0.031 \\
\hline $\mathrm{H}_{2}(\mathrm{cc} / 100 \mathrm{~g})$ & $\sim 0.20$ \\
\hline Note: $\mathrm{H}_{2}$ content was estimated from reduced pressure testing. \\
\hline
\end{tabular}

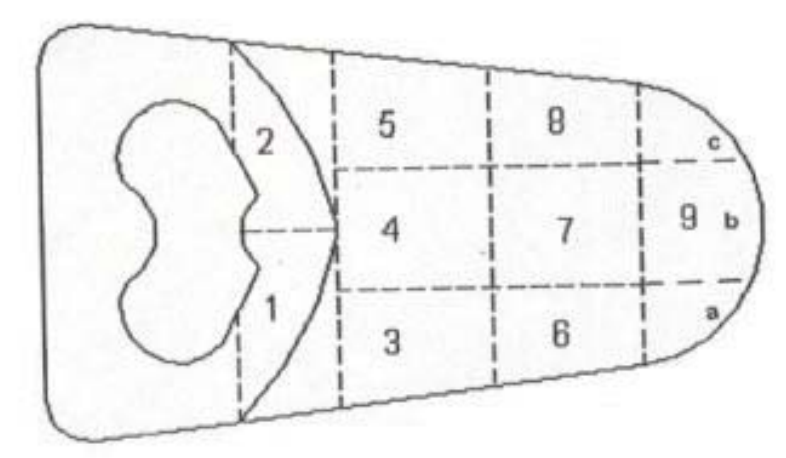

Figure 4-2. Locations of sections used in porosity determination by both pyknometry and image analysis (Location 1 and 2 covers where fatigue cracks initiated). 


\section{RESULTS AND DISCUSSION}

\subsection{CASTINGS POURED WITH PRESSURIZATION AT POURING CUP}

As indicated in the previous section (4.1) castings representative of each group were Xrayed and sectioned in preparation for density measurement and subsequent porosity determination. The theoretical density for the particular heat of material was determined by the method of McClain, McClain and Berry (1). Utilizing this figure, the difference between the theoretical density less the measured density of the subject sample, divided by the theoretical density, yields the porosity.

The samples taken along the lengths of the castings were carefully deburred before the Archimedes-method based porosity determination was conducted. This precaution removed the possibility of air bubbles remaining attached to the samples concerned. At least five samples were taken along the length of the castings concerned. Each sample encompassed the whole of the diametral cross section.

No systematic trends of porosity variation along any of the sets of casting were found ${ }^{*}$. Consequently, an average value for each of the groups examined was determined. Approximately 180 data points were involved for each group of castings. Tables 5-1 and 5-2 summarize the results for the groups of castings sampled. These groups were selected on the basis of the X-ray examinations referred to earlier. The X-ray examinations had revealed microporosity near the four integral boss locations.

\footnotetext{
* See selected data in Appendix 1.
} 
Table 5-1. 319 Porosity Data

\begin{tabular}{|c|c|c|c|c|}
\hline \multirow{2}{*}{ Group } & \multicolumn{2}{|c|}{ Pressure Location } & \multirow{2}{*}{$\begin{array}{c}\text { Time Applied } \\
\text { during Tilting }\end{array}$} & \multirow{2}{*}{ Porosity (\%) } \\
\cline { 2 - 3 } & Pouring Cup & Pins & N/A & 0.567 \\
\hline A & $\times$ & $\times$ & $100 \%$ & 0.627 \\
\hline D & $\vee$ & $\vee$ & $50 \%$ & 0.534 \\
\hline G & $\vee$ & $\vee$ & & \\
\hline
\end{tabular}

Table 5-2. A356 Porosity Data

\begin{tabular}{|c|c|c|c|c|}
\hline \multirow{2}{*}{ Group } & \multicolumn{2}{|c|}{ Pressure Location } & \multirow{2}{*}{$\begin{array}{c}\text { Time Applied } \\
\text { during Tilting }\end{array}$} & \multirow{2}{*}{ Porosity (\%) } \\
\cline { 2 - 3 } & Pouring Cup & Pins & N/A & 0.546 \\
\hline $\mathrm{H}$ & $\times$ & $\times$ & $100 \%$ & 0.530 \\
\hline $\mathrm{J}$ & $\times$ & $\vee$ & $100 \%$ & 0.436 \\
\hline $\mathrm{K}$ & $\vee$ & $\vee$ & $100 \%$ & 0.460 \\
\hline $\mathrm{I}$ & $\vee$ & $\times$ & $80 \%$ & 0.505 \\
\hline $\mathrm{M}$ & $\vee$ & $\times$ & $50 \%$ & 0.493 \\
\hline $\mathrm{N}$ & $\vee$ & $\times$ & &
\end{tabular}

The results in Table 5-1 indicate that overall, as far as porosity percentage is concerned, the technique leads to only small improvement for the (cored) 319 castings for the case of pressurizing at $50 \%$ of the tilt-cycle only. The negative effect (increase in porosity) observed in pressurizing at $100 \%$ of the tilt-cycle required further investigation (See comments on surface condition). At this juncture it should be pointed out that the standard rigging design for this particular casting was well established and under normal (non-pressurized) conditions worked well, permitting the production of acceptable castings.

The results for the A356 castings (where the core was not present and where the original rigging was unchanged with this shorter freezing range alloy) indicate some advantage of 
pressurizing the castings at the pouring cup ${ }^{*}$. The improvements are small $(\sim 16 \%)$, however, and would seem to suggest that pressurization of blind risers near to critical casting locations might lead to further improvement.

The effects of applied pressure on surface integrity and mechanical behavior were also investigated. During the pouring of the 319 castings involved with the initial stages of the investigation it was noticed that the surfaces of the pressurized castings appeared 'frosty' rather than 'shiny', as were the non-pressurized castings. The mold-fill was also enhanced by the pressurization, as evidenced by the replication of lettering on the castings.

Subsequently, both SEM examinations of the surface quality, and metallographic sectioning have revealed some interesting features heretofore not mentioned in the literature. These examinations revealed minute intrusions in the surfaces of the 319 pressurized castings. Figure 5-1 and 5-2 show respectively a micro-section through the surface and a scanning electron micrograph of surface on one of the 319 castings.

The intrusions are thought to be a result of the pressurizing medium (compressed air) flowing into the gap between the mold and the partly solidified skin and subsequently pushing the still liquid interdendritic materials into the interior of the casting. A similar effect was described by Campbell in 1969 (2) explaining surface defects in intermediate

\footnotetext{
* Raw data for selected casting groups appear in Appendix 1.
} 
section sand castings, where normal atmosphere pressure can result in surface rupture (Fig. 5-3).

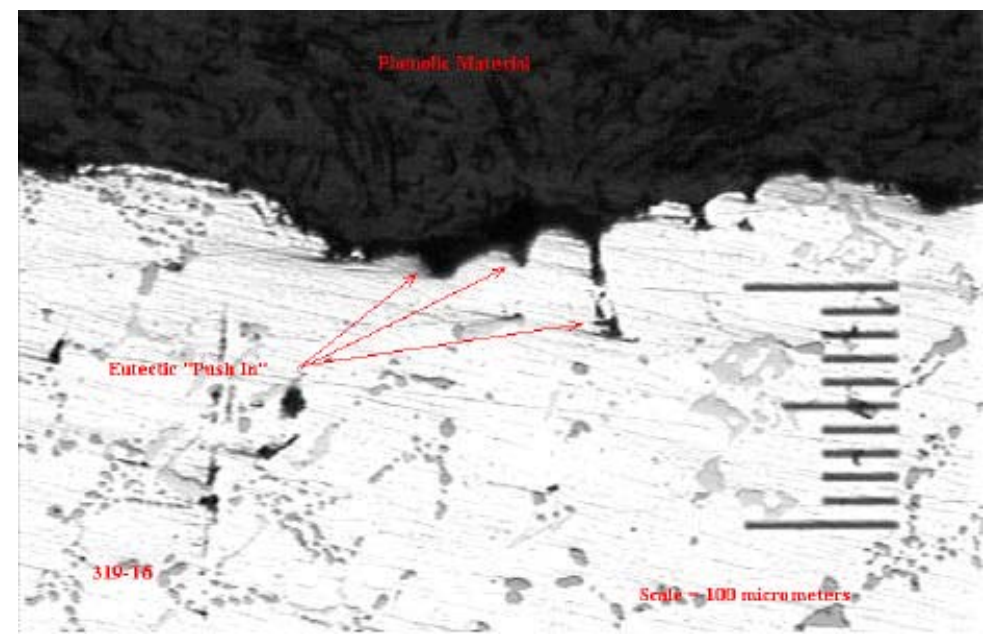

Figure 5-1: Optical image of a section through a tilt-poured 319-T6 casting pressurized at $45^{\circ}$ (half-way) in the tilt sequence. The Figure illustrates the nature of the 'intrusions' referred to in the text, i.e. Eutectic push-in or primary aluminum push-out.

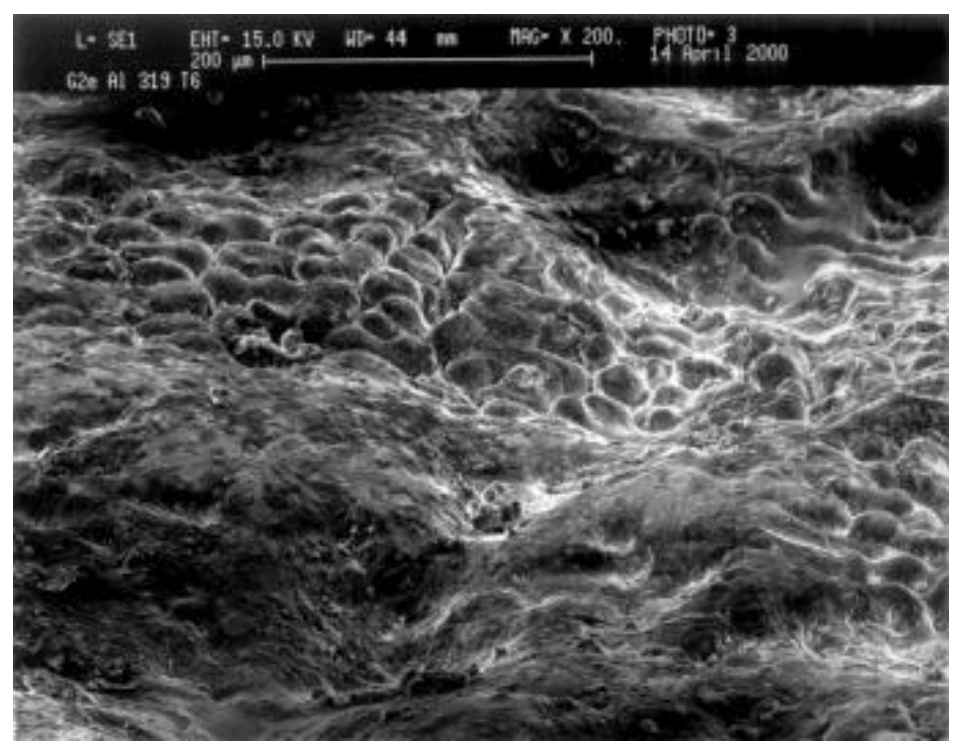

Figure 5-2: Scanning Electron Microscope (SEM) Shot at $200 \times$ of surface of casting llustrated in Figure 5-1. The overall surface roughness appears to follow the mold-coat. However, the 'valleys' appear to be the regions associated with the 'intrusions' of Figure 5-1. 

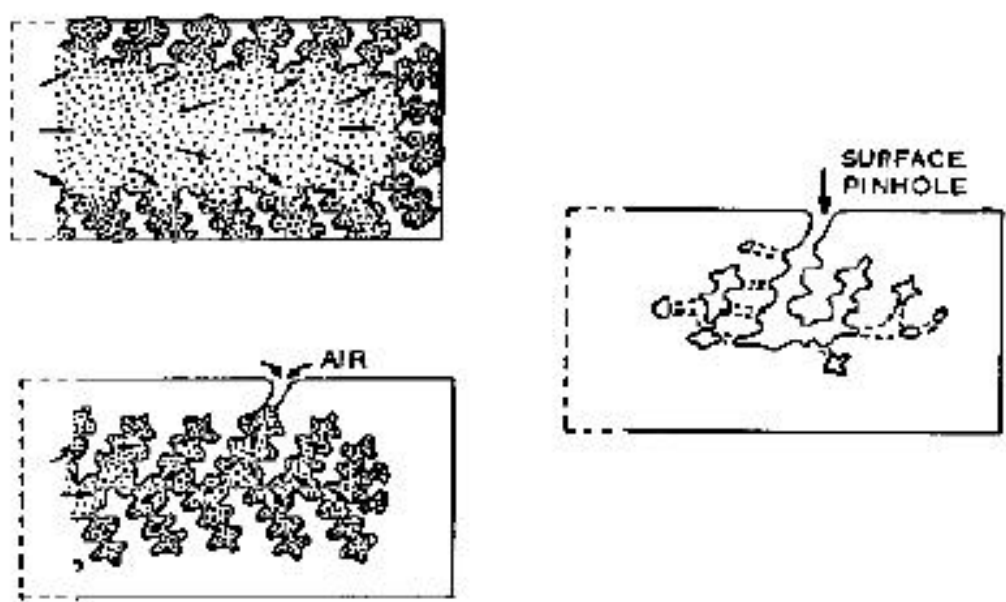

Figure 5- 3: Campbell's explanation of surface defects in intermediate section castings, Poured without riser pressurization (Ref. 6).

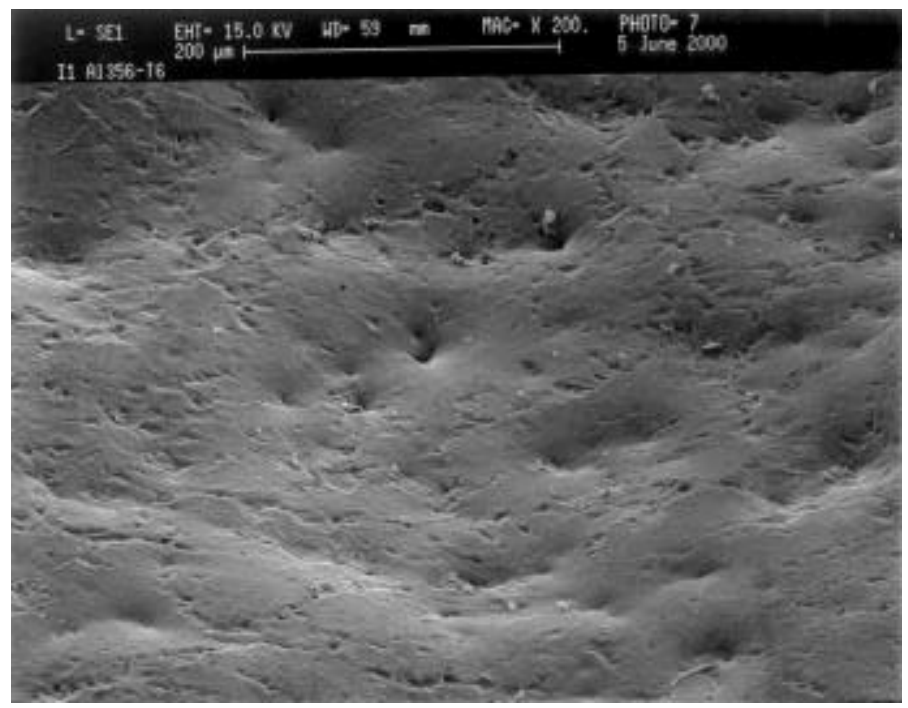

Figure 5-4: Scanning Electron Microscope (SEM) shot at $200 \times$ of surface of A356.

Notice there is no evidence of a surface intrusions structure as shown in Figure 5-2.

An alternative theory would suggest that the overall pressurization of the castings has pushed the primary dendrites through the partially liquid surface. Whether the intrusions (or 'extrusions') initiate at incipient hot tears associated with the long freezing range alloy (319) is still a matter requiring investigation. Interestingly, the castings of A356 did 
not show this type of surface defect, possibly in line with the shorter freezing range (Fig.

5-4). This was also confirmed on examination of an A356 tilt-poured casting of different design (small structural casting) made from a separate heat at a separate location.

Because of these intrusions acting as local stress raisers, which would clearly affect fatigue crack initiation, a series of four-point bend tests were conducted from samples cut from the tilt-poured castings where the cast surface is loaded in tension. The samples were cut from castings in the heat-treated (T-6) condition. Table 5-3 contains the results for 319 .

Table 5-3. 319 Four Point Bend test Average Results

\begin{tabular}{|c|c|c|c|}
\hline Group & $\begin{array}{c}\text { Flexural Modulus } \\
(\mathrm{GPa})\end{array}$ & $\begin{array}{c}\text { Maximum Load } \\
(\mathrm{kg})\end{array}$ & $\begin{array}{c}\text { Flexural Strength } \\
(\mathrm{MPa})\end{array}$ \\
\hline $\mathrm{A}$ & $67.28 \pm 3.41$ & $69.11 \pm 4.85$ & $563.39 \pm 41.45$ \\
\hline $\mathrm{D}$ & $64.51 \pm 4.05$ & $68.51 \pm 6.05$ & $559.20 \pm 48.0$ \\
\hline $\mathrm{G}$ & $60.89 \pm 3.21$ & $63.12 \pm 3.82$ & $519.68 \pm 33.44$ \\
\hline
\end{tabular}

In order to obtain a true representation of the effects of this problem, six replicates of each processing procedure and sample location within the castings were machined from a casting and tested on a four point bend apparatus in accordance with ASTM D 790M \# . In all some fifty-one samples were machined out and tested for the 319 alloy alone.

Similar bend tests were performed upon samples located at exactly similar locations for selected A356-T6 castings (Table 5-4). These results will be compared with those for the alloy 319-T6 samples (discussed above) next.

\footnotetext{
\# ASTM D 790 M was utilized, as there exist no standard for bend tests on cast aluminum alloys. This particular specification was designed for ceramic and similar low ductility materials.
} 
Table 5-4. A356 Four Point Bend Test Average Results

\begin{tabular}{|c|c|c|c|}
\hline Group & $\begin{array}{c}\text { Flexural Modulus } \\
(\mathrm{GPa})\end{array}$ & $\begin{array}{c}\text { Maximum Load } \\
(\mathrm{kg})\end{array}$ & $\begin{array}{c}\text { Flexural Strength } \\
(\mathrm{MPa})\end{array}$ \\
\hline $\mathrm{H}$ & $68.28 \pm 2.15$ & $73.41 \pm 2.13$ & $600.93 \pm 16.02$ \\
\hline $\mathrm{I}$ & $67.18 \pm 2.20$ & $72.85 \pm 3.56$ & $596.61 \pm 29.26$ \\
\hline $\mathrm{N}$ & $68.13 \pm 2.05$ & $74.55 \pm 2.57$ & $610.90 \pm 21.95$ \\
\hline
\end{tabular}

In order to properly compare and contrast the results of the above bend test plots were made of the cumulative distribution of the flexural (failure) strength of samples excised from casting groups A, D, and G (319 alloy) and group H, I and N (A356). The data is presented in Figures 5-5 and 5-6 for 319 and A356 in the T6 condition, respectively.

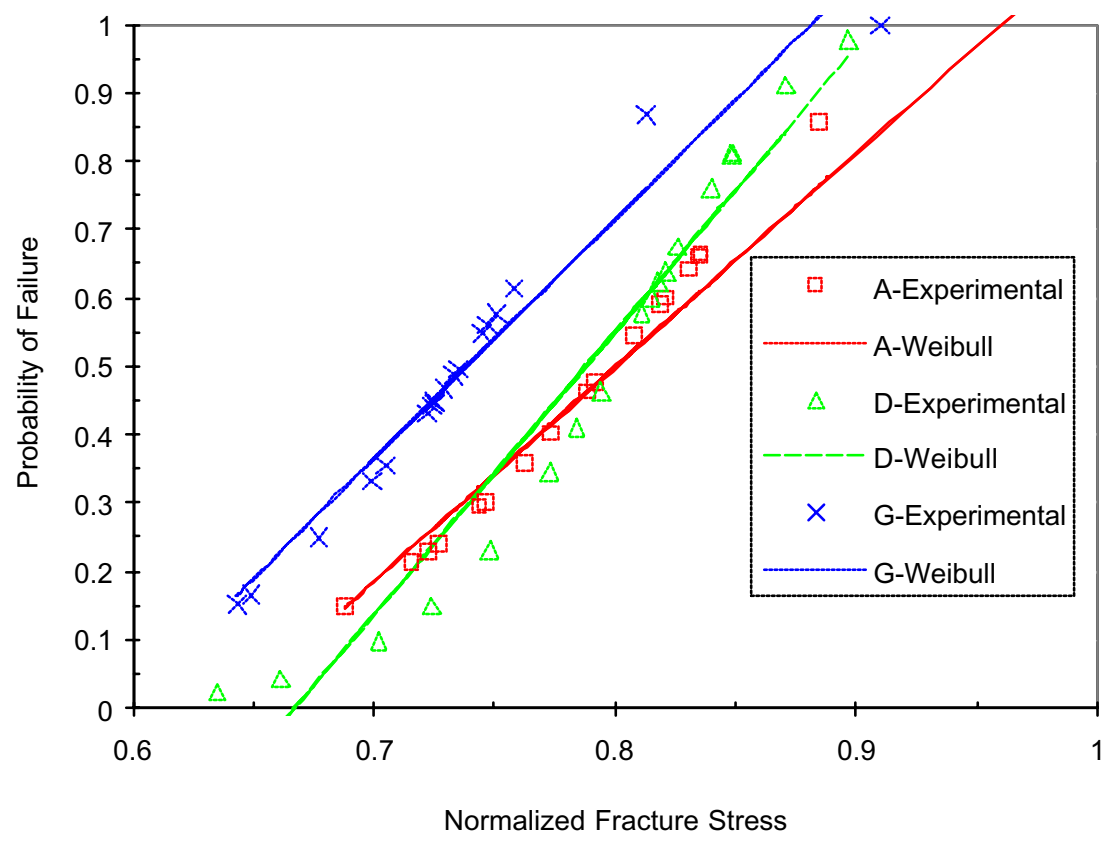

Figure 5-5: Weibull plot of probability of failure versus fracture strength for Groups A, D and $\mathrm{G}$ castings (319). The circles, crosses and squares represent experimental data and the lines were obtained using a Weibull analysis. (A-No Pressure, DFull Tilt, G-Half Tilt) 


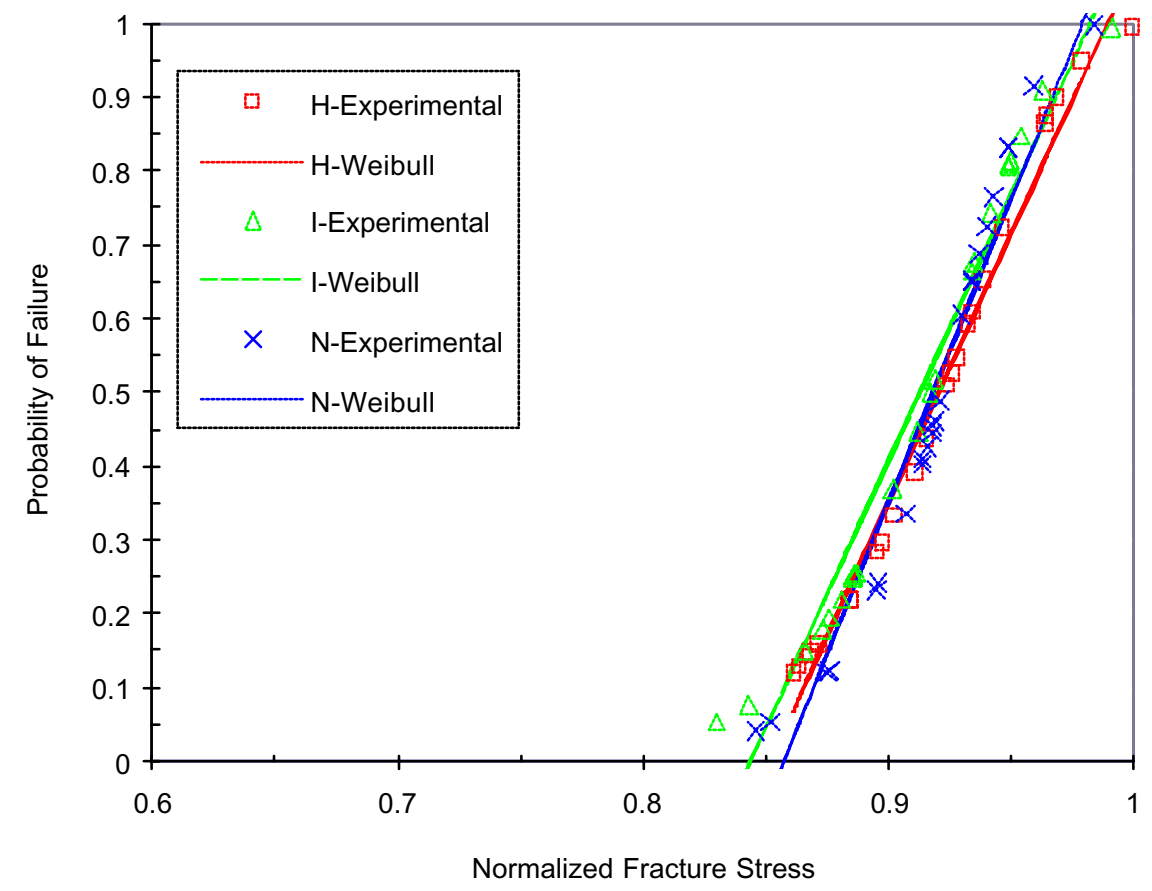

Figure 5-6: Weibull plot of probability of failure versus fracture strength for Groups H, I and $\mathrm{N}$ castings (A356). The circles, crosses and squares represent experimental data and the lines were obtained using a Weibull analysis. (H-No Pressure, I-Full Tilt, N-Half Tilt)

There will be seen a major difference in the width of the strength distribution, reflecting the effects of the intrusions present in the 319 castings and the lack of these notch-like features in the A356 surface.

It should be mentioned at this point that the principal virtue of using the four point bend test is that the constant bending moment present between the two inner points of load application removes the necessity of these notch-like surface features having to be present at the exact mid-point of the lower (tension) surface - the cast surface- of the sample. In other words an intrusion located off-center will have the same deleterious effect as one located precisely at the center of the lower surface of the bend sample. 
It will also be seen that the pressurization of the 319 casting at the $50 \%$ of tilt position increased the probability of failure in flexure. It may be presumed that this arises because of the still semi-solid nature of then surface at that point, which facilitates the formation of the notch-like intrusions during solidification (Figs. 5-1 and 5-2).

The results for the samples drawn from the 319 castings that were not pressurized and those which were pressurized at full-tilt are close together, although both show the wide distribution of strength referred to earlier. All three groups showed surface intrusions, however, even those castings which were non-pressurized, where atmospheric pressure is most likely responsible in line with Campbell's observation (2).

As mentioned above and in contrast, the distributions of strength data for the A356 samples which is much narrower than that for 319 , shows a common distribution for samples excised from castings which were not pressurized, pressurized at half-tilt and pressurized at full-tilt (Groups H, I and N).

Finally, examination was made of the effects of the 'squeeze pin' action for alloy 319 by removing the areas containing the integral bosses and subjecting these to porosity determination. The results are indicated on the Figure 5-7, which indicates that the effects are measurable but at the same time modest ( 10\% diminution in porosity level)

Inall results of the both density-based porosity estimation and the four point bend flexural strength tests for castings pressurized at the pouring cup are somewhat disappointing, and 
as pointed out earlier would seem to recommend a more localized pressurization at the blind riser, for example.

\section{EFFECT OF SQUEEZE PINS (ALLOY 319)}
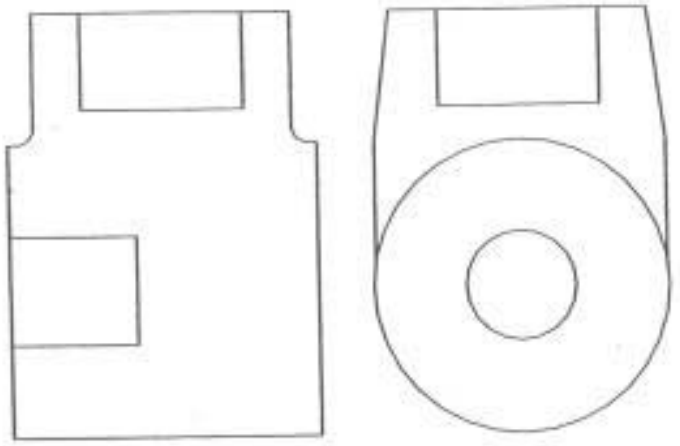

Local Porosity Levels

No pressure on pins (A)

$0.63 \%$

Squeeze pins only (C)

$0.56 \%$

(means of 10

determinations)

REDUCTION Approx. 11\%

(a) Pieces as cut from pressure vessel used for first porosity calculations.
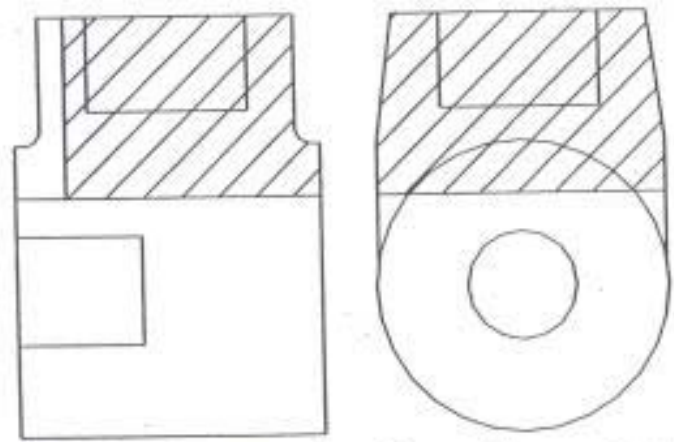

No pressure on pins (A)

$0.37 \%$

Squeeze pins only (C)

$0.34 \%$

(means of 10

determinations)

REDUCTION Approx. $9 \%$

(b) Hatched section shows pieces used for second porosity calculations.

Figure 5-7. Effects of squeeze pins on porosity in 319 alloy.

\subsection{CASTINGS POURED WITH PRESSURIZATION AT THE BLIND RISER}

The small bracket castings, the pouring of which was described in section 4-2, were selected on the bases of their being readily subjected to rig testing under repeated loading. Figure 5-8 illustrates a casting attached to a portion of the test rig that was mounted in a fatigue test frame. 
In order to determine the location at which fatigue failures was likely to initiate, a set of (Non-pressurized) bracket castings previously poured by the co-operating foundry were tested at two local stress levels. The local stresses were determined by undertaking a finite element based analysis of the bracket under load. The computed local stress levels were then validated using strain gages located in the area where failure was contemplated to be initiated (viz. within the 'elbow' of the bracket)

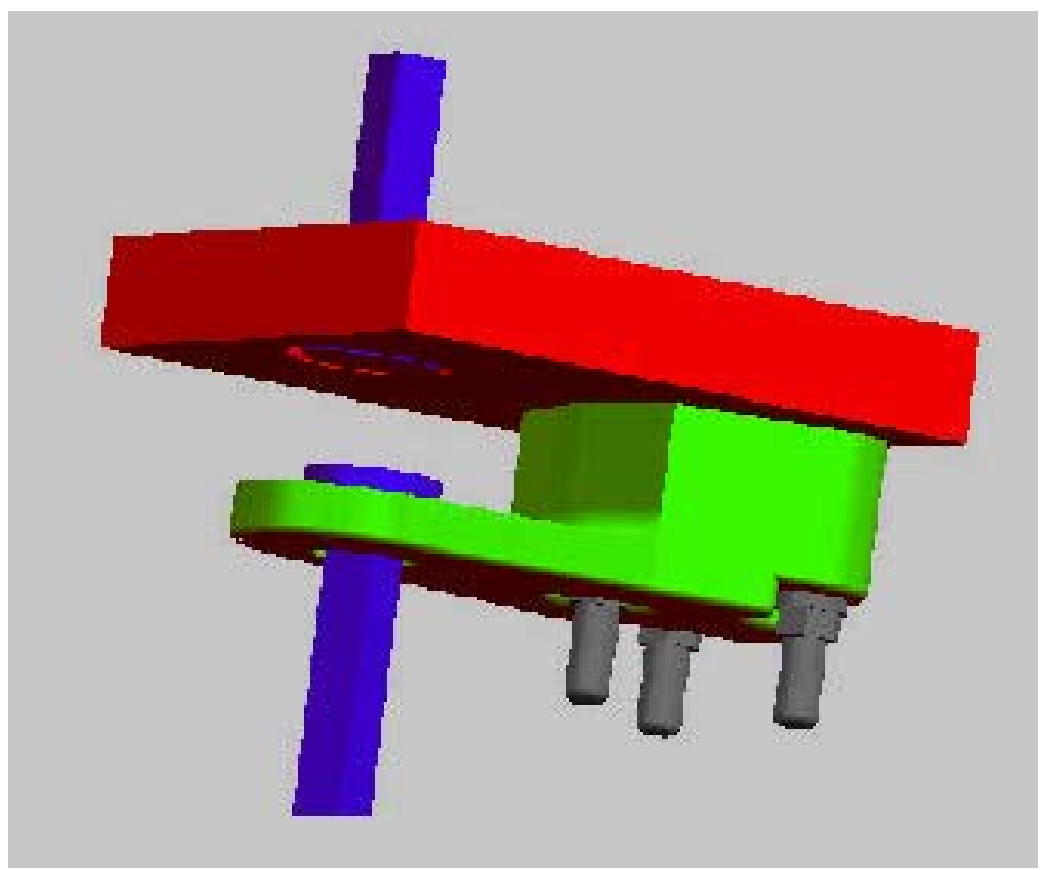

Figure 5-8: Structural casting and fatigue test assembly.

The results of the preliminary fatigue tests on the previously poured non-pressurized castings showed a population of fatigue life which appeared to be sensitive to surface finish. At this point it should be noted that this series of castings (poured in A 356-T6, 
for chemical analysis see Tables 5-5) were poured in a different die-set than those which were the subject of the later pressurized tests. Results are tabulated (Table 5-5)

Table 5-5. Chemical Analysis of A356 Heat

\begin{tabular}{|c|c|}
\hline Element & Percent, \% \\
\hline $\mathrm{Si}$ & 6.85 \\
\hline $\mathrm{Cu}$ & 0.02 \\
\hline $\mathrm{Mg}$ & 0.38 \\
\hline $\mathrm{Fe}$ & 0.11 \\
\hline $\mathrm{Mn}$ & 0.004 \\
\hline $\mathrm{Ni}$ & 0.003 \\
\hline $\mathrm{Zn}$ & 0.01 \\
\hline $\mathrm{Ti}$ & 0.14 \\
\hline $\mathrm{Sr}$ & 0.017 \\
\hline
\end{tabular}

Table 5-6. Fatigue Life Data from A356 Bracket Casting Rig-Tests.

\begin{tabular}{|c|c|c|c|c|c|c|c|}
\hline Casting & $\mathrm{F}_{\max }(\mathrm{lb})$ & $\mathrm{F}_{\mathrm{a}}(\mathrm{lb})$ & $\mathrm{F}_{\mathrm{m}}(\mathrm{lb})$ & $\begin{array}{c}\text { Max. } \\
\text { Stress } \\
(\mathrm{ksi})\end{array}$ & $\begin{array}{c}\text { Stress } \\
\text { Amplitude } \\
(\mathrm{ksi})\end{array}$ & $\begin{array}{c}\text { Stress } \\
\text { Mean (ksi) }\end{array}$ & $\mathrm{N}$ (cycles) \\
\hline $\mathrm{A}$ & 2000 & 900 & 1100 & 36.03 & 17.09 & 20.32 & 101809 \\
\hline $\mathrm{B}$ & 2000 & 900 & 1100 & 36.03 & 17.09 & 20.32 & 82701 \\
\hline $\mathrm{C}$ & 2000 & 900 & 1100 & 36.03 & 17.09 & 20.32 & 90919 \\
\hline $\mathrm{D}$ & 1750 & 787.5 & 962.5 & 31.64 & 15.25 & 18.1 & 82784 \\
\hline $\mathrm{E}$ & 1750 & 787.5 & 962.5 & 31.64 & 15.25 & 18.1 & 157311 \\
\hline $\mathrm{F}$ & 1750 & 787.5 & 962.5 & 31.64 & 15.25 & 18.1 & 158272 \\
\hline $\mathrm{G}$ & 1750 & 787.5 & 962.5 & 31.64 & 15.25 & 18.1 & 101062 \\
\hline $\mathrm{H}$ & 2000 & 900 & 1100 & 36.03 & 17.09 & 20.32 & 87554 \\
\hline $\mathrm{I}$ & 1750 & 787.5 & 962.5 & 31.64 & 15.25 & 18.1 & 123436 \\
\hline
\end{tabular}

Note: 1 . Stress was calculated using a strain gauge mounted on a single casting loaded to maximum for a given test. Stress was not measured on actual fatigue tested specimens.

2. Heat was grain refined with TiAl and Sr-modified, and tilt-poured.

3. Heat treatment: Solution treatment for 8 hours at 1000 F; Water quench; Natural aging at room temperature for 24 hours; Aging at $350 \mathrm{~F}$ for $6 \mathrm{hrs}$; Air cooling.

Fig 5-9 compares the results of the preliminary tests with those of an investigation conducted at Birmingham University (UK) where a similar sensitivity to surface finish, 
especially surface roughness, was noted (3). The R-ratio employed in the Birmingham tests $(0.1)$ was approximately the same as that maintained in the MSU tests (0.06). This difference is judged to be insignificant.

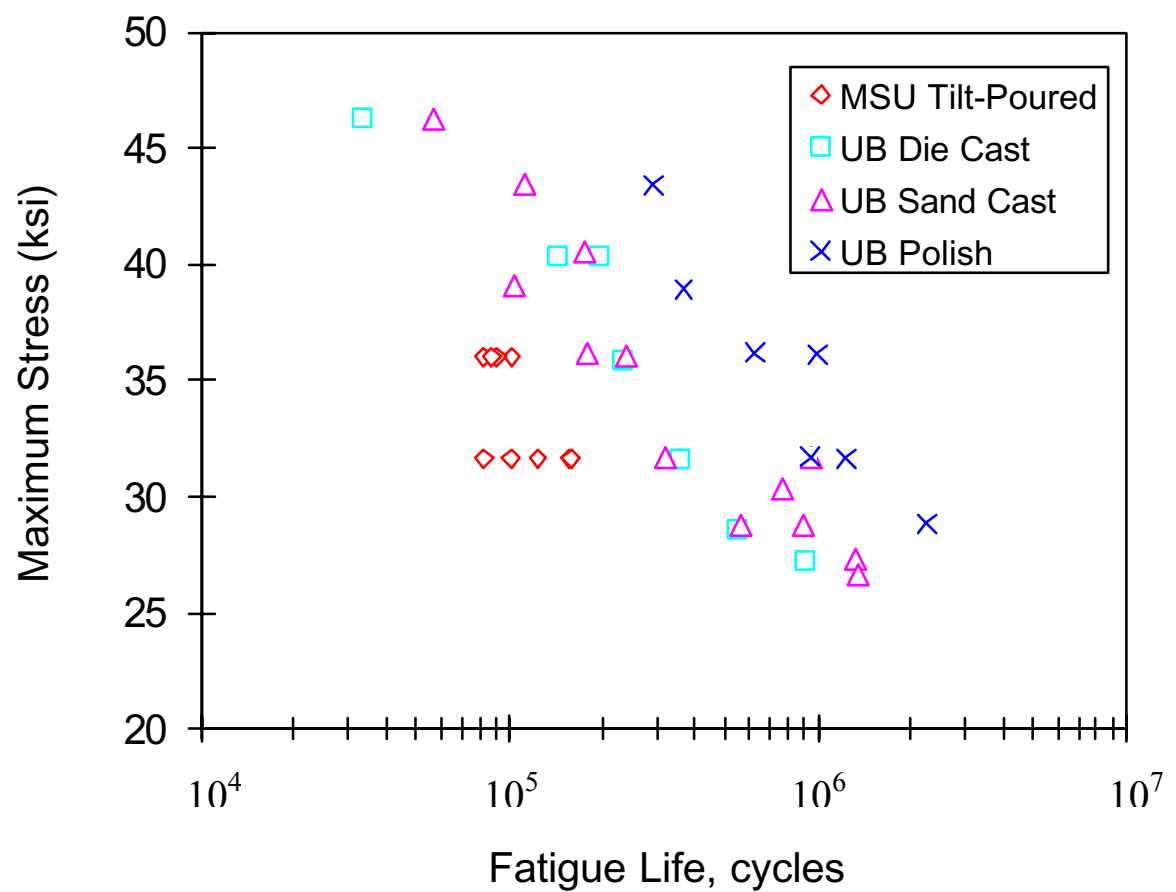

Figure 5-9. Comparison of fatigue life test data, MSU tilt-poured castings and UB test bar castings.

Figs 5-10 and 5-11 show the appearance of the surfaces of the castings showing the shortest and longest fatigue life at $\sim 32$ psi maximum local stress. It was observed that the roughness was probably more related to either die-coating roughness or the actual die roughness. It was not of the character of that observed with the 319 castings referred to in section 4.1 of this report (That is, not of a metallurgical but a mold-replication related character). 


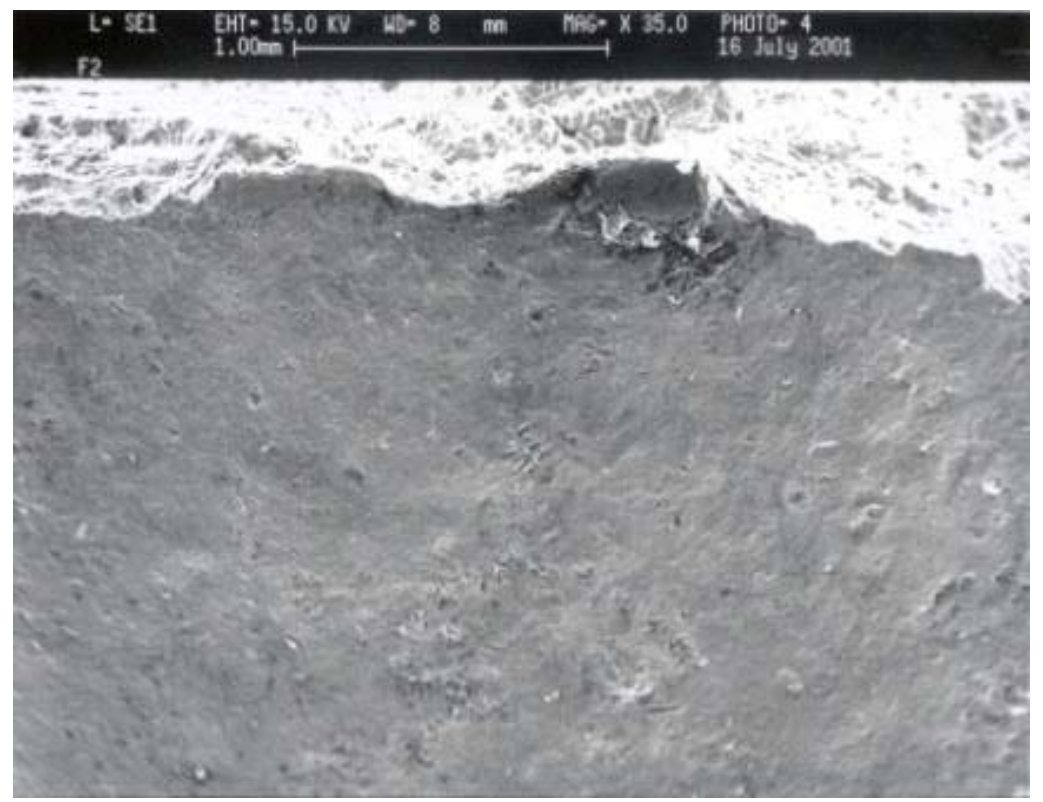

Figure 5-10. Sample F, lower foreground (dark) is casting surface, upper portion is fracture surface. ( $\mathrm{F}$ has finest surface roughness at closer to where crack initiated, $211 \mu \mathrm{in}, \mathrm{Ra}$, and has the longest fatigue life)

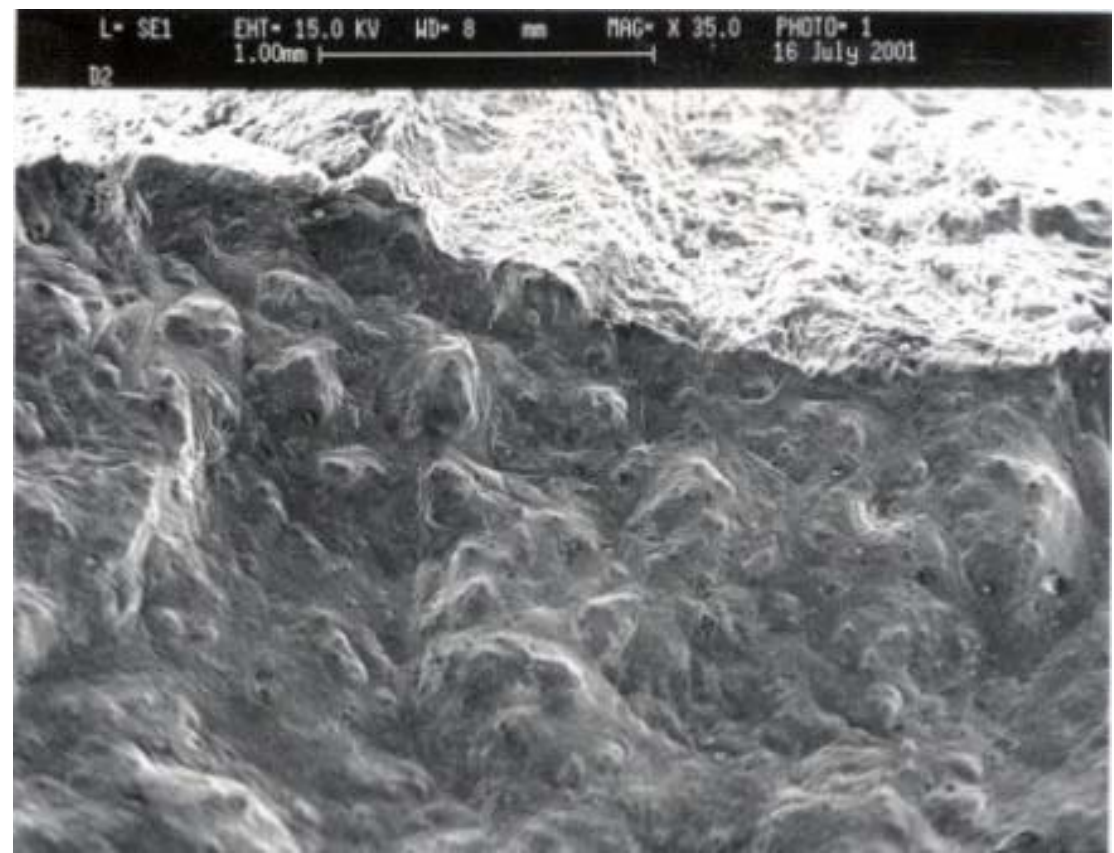

Figure 5-11: Sample D, lower foreground (dark) is casting surface, upper portion is fracture surface. (D has the roughest surface at closer to where crack initiated, $370 \mu \mathrm{in}, \mathrm{Ra}$, and has the shortest fatigue life). 
The bracket castings which were the subject of the riser pressurization experiments (see Tables 4-3 and 4-4 for pressurizing treatment and heat analysis respectively) conform to the 356 specifications, rather than the A356 of the preliminary fatigue tests. The difference in the chemical analysis revolves around the iron and magnesium levels (compare Tables 4-3 and 5-5).

Each casting was sectioned into 11 portions, as per the illustration (Fig. 4-2). The sections extended around the location of the fatigue cracks observed in the preliminary tests to the end ('toe') of the casting.

The densities of the individual portions were determined from the separate sets of weighings (i.e., three repeats, to ensure that no bubbles are attached to the samples during the weighing in water). The method of theoretical density determination was again that described elsewhere by McClain, McClain and Berry (1).

The results obtained are shown in Figures 5-12 (a) -(d). Figure 5-13 represents a summary of the results. Results for sections 1 and 2; 3, 4 and 5; 6, 7 and 8, 9a, b and c represent mean or averaged values across those sections. 


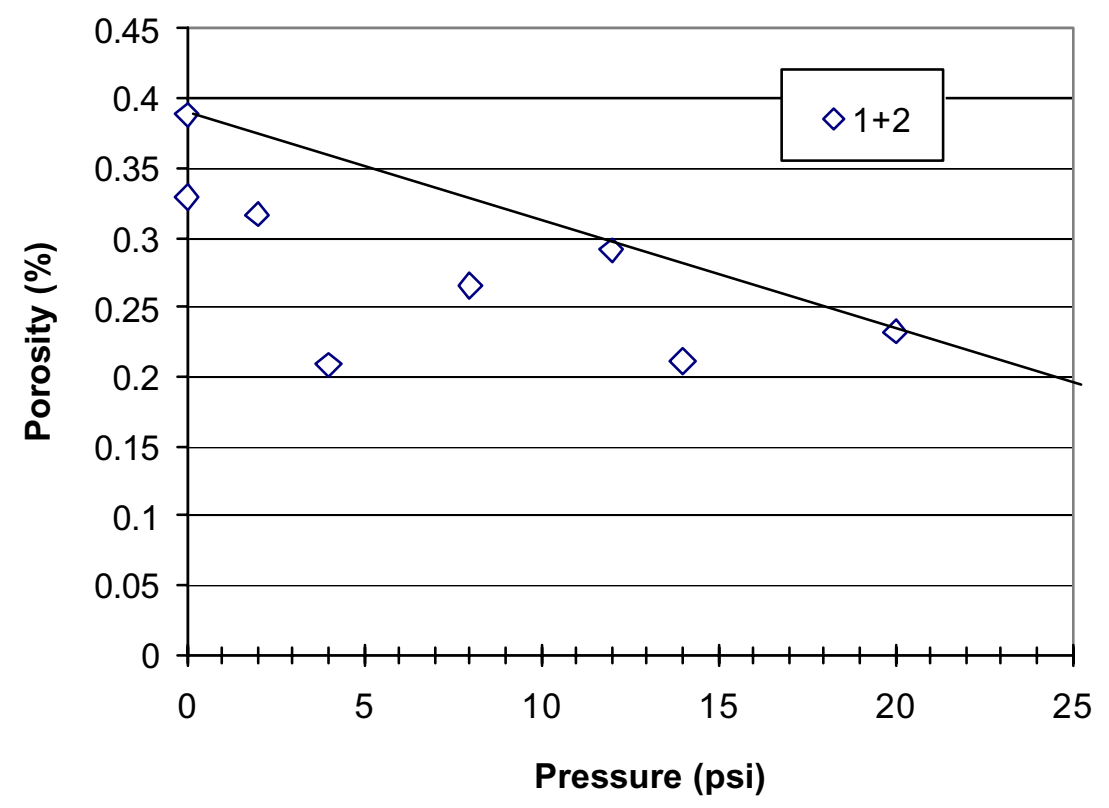

(a)

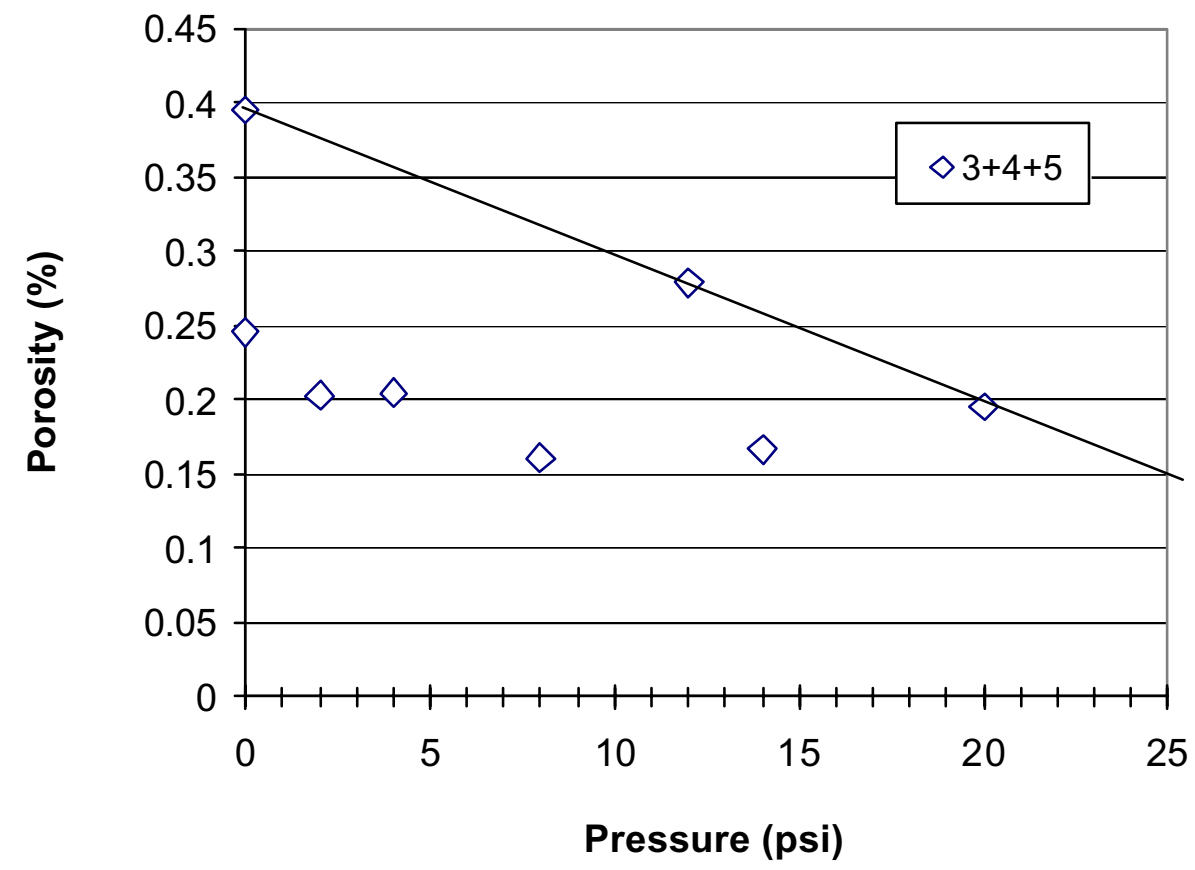

(b)

Figure 5-12. Showing the effect of applied pressure to the riser upon porosity level. The line represents the upper-bound of the averaged results of the 356 alloy bracket castings (Castings (\#11) were away from the pouring cup on the right side of the gating system): (a) sections 1 and 2; (b) sections 3, 4 and 5; (c) 6, 7 and 8; (d) 9a, 9b and 9c. 


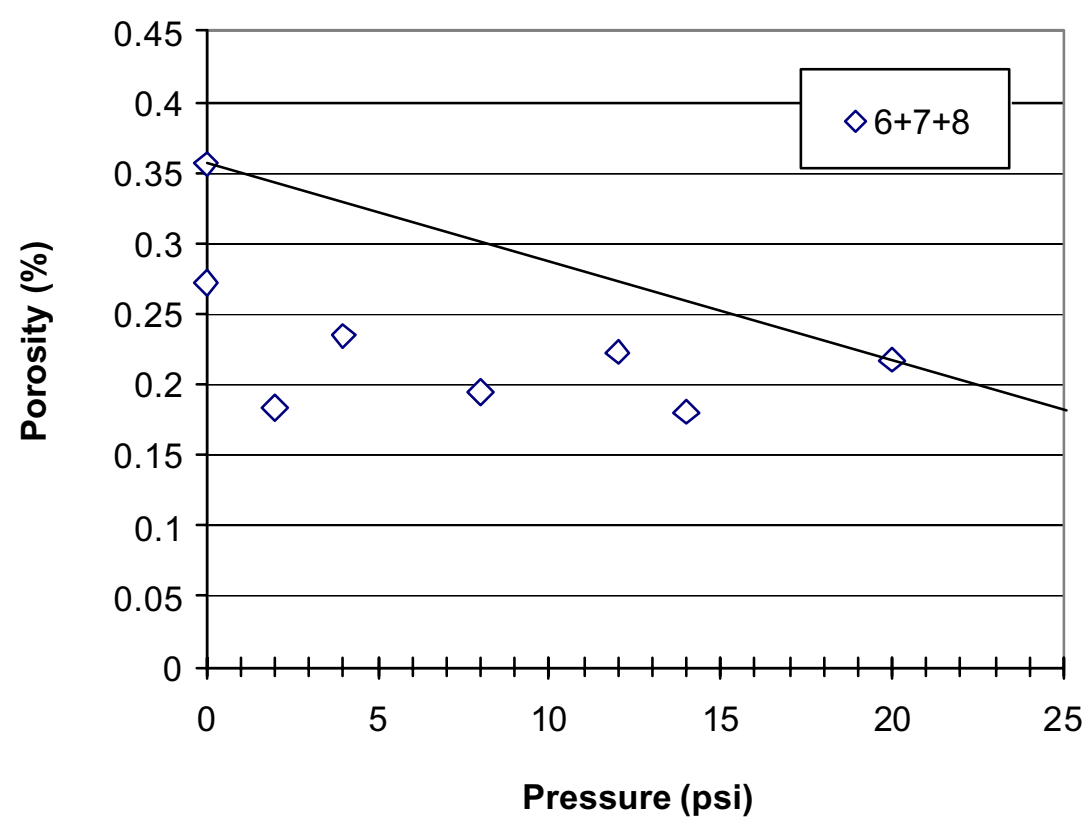

(c)

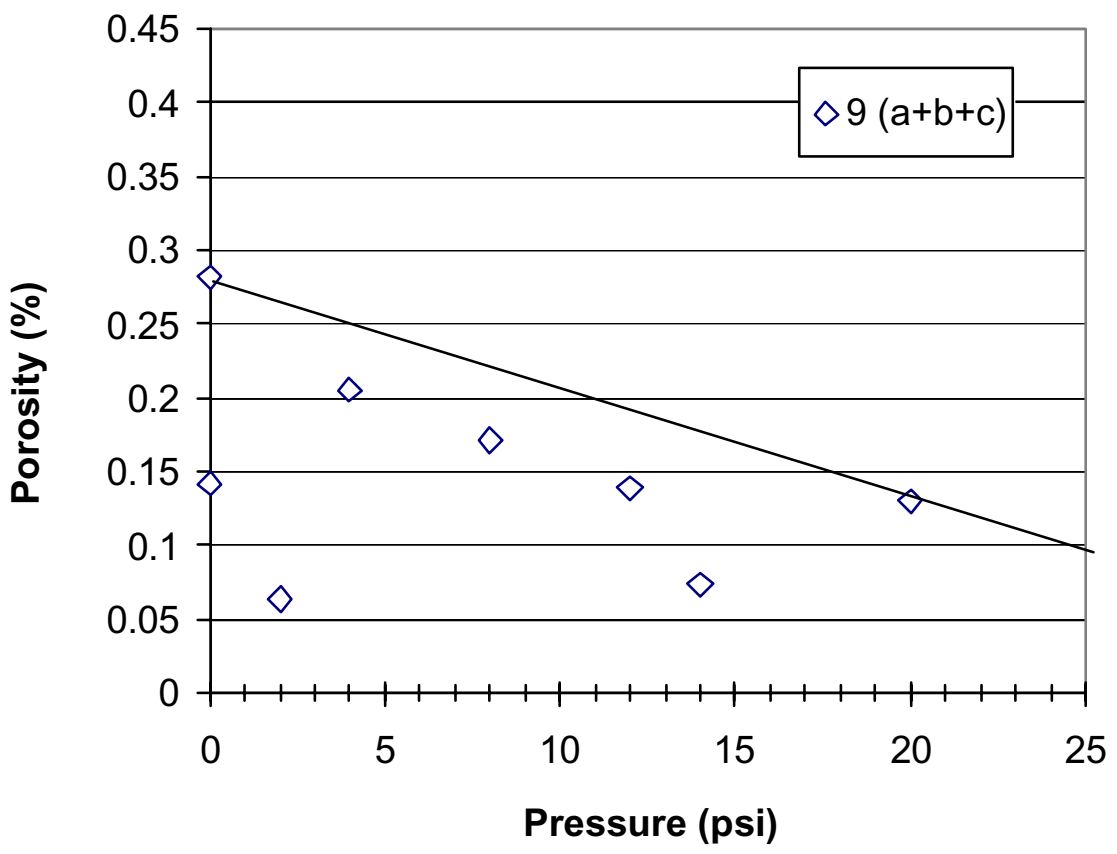

(d)

Figure 5-12. (Continued). 


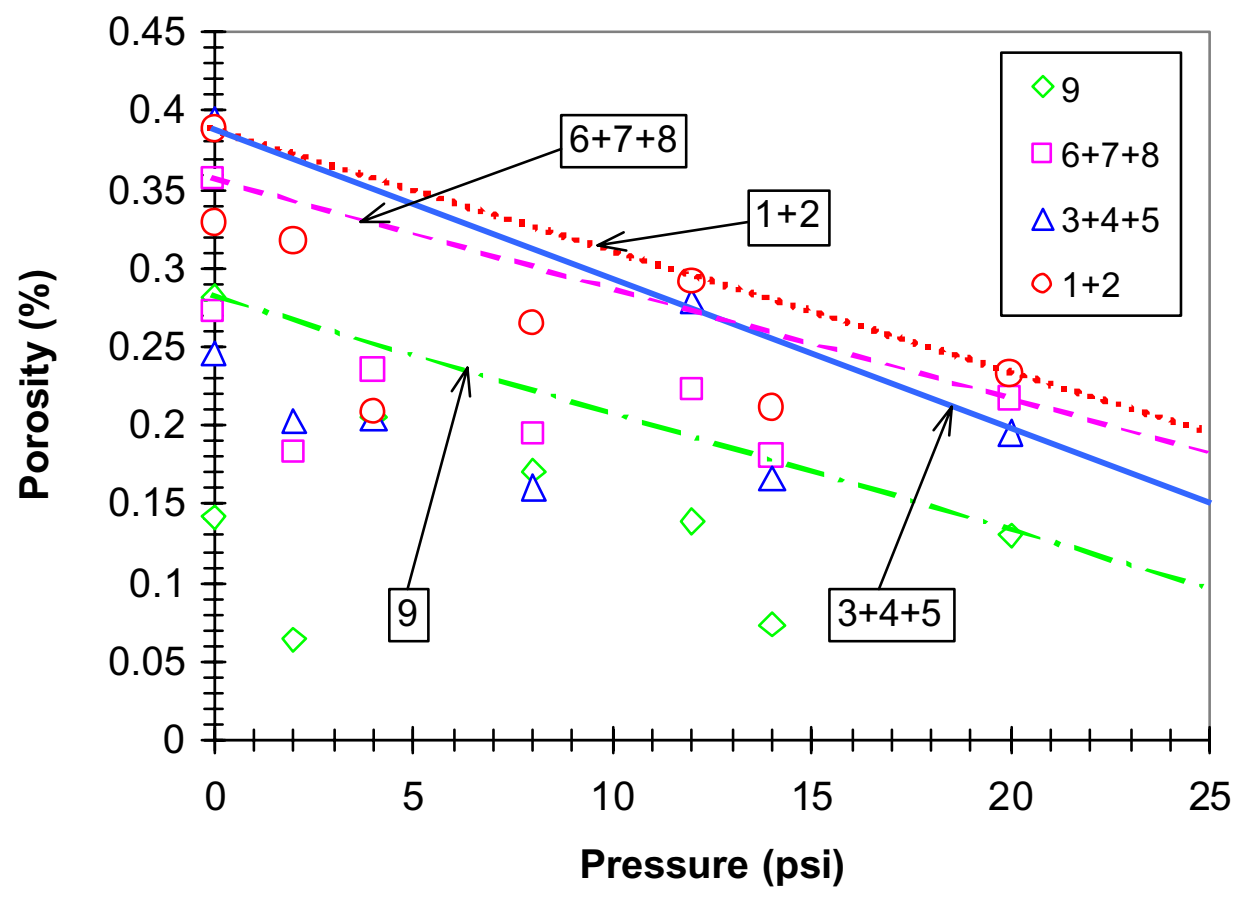

Figure 5-13. Showing the trends indicated by the various upper-bounds. Note the upper bounds for section 9 (means of $9 a+9 b+9 c$ ) lies below those of the remaining sections.

The lines drawn above the results are upper bounds above which no porosity values appear. The need to employ such a method of presentation arises since in each of the individual casting locations sampled, the probability of there being a source of pore nucleation will vary greatly, especially if the theory of Campbell (4) concerning the role of unfurling bifilms is to be believed. (Campbell suggests that these bifilms provide the sites for embryo type pores to nucleate and grow.). Thus the upper bound presents a worst-case situation where oxides are readily available to facilitate pore nucleation. Points below this upper-band represent areas in the casting where fewer oxides are available to facilitate pore nucleation. 
Returning to Figure 5-13, which summarizes the results of the present experiments, with the pressurized bracket castings, here the upper-bounds are again shown for each of the section sets $(1+2,3+4+5,6+7+8,9 a+9 b+9 c)$. The figure shows two interesting trends:

a. The reduction of maximum porosity level with the increase of externally applied pressure.

b. The upper-bound for the 'toe' section of the casting $(9 a+9 b+9 c)$ falls below those of the other section sets $(1+2,3+4+5,6+7+8)$

The first trend would seem to indicate that riser pressurization is capable of reducing maximum porosity level, whereas the second, while indicating this same trend also suggests an added effect of efficient feeding action in this toe region because of marked sequential solidification. (See results of solidification modeling experiments, Appendix 2).

In order to confirm these important results and to further examine the generation of surface roughness variation, the following supplemental checks were undertaken:

(a) Image analysis of porosity level variation

(b) Image analysis of pore shape and diameter variation

(c) Image analysis of secondary dendrite arm spacing (SDAS)

(d) Analysis of surface roughness on the region of the casting where fatigue cracks are known to initiate

Furthermore, a selected numbers of the bracket castings were divided longitudinally and casting halves were sent for hot isostatic pressing (services kindly provided by Kittyhawk 
Products). The corresponding portions of each of the castings concerned were subject to both image analysis and porosity evaluation.

The area percentage and number density of porosity in castings at different pressurizations are shown in Fig. 5-14 (a) and (b), respectively. The sampling area of $300 \mathrm{~mm}^{2}$ for each A356 bracket castings is around the elbow area where fatigue cracks were initiated in fatigue testing. When the pressure is increased from 0 to $20 \mathrm{psi}$ ( 0 to $0.138 \mathrm{MPa}$ ), as shown in Fig. 5-14 (a), the porosity area fraction decreases from $0.172 \%$ to $0.013 \%$, and $0.243 \%$ to $0.086 \%$ for castings located further from the pouring cup on the left side of the gating and the one closer to the pouring cup on the right side of the gating, respectively; as is shown in Fig. 5-14 (b). The porosity area density decreases from 0.169 number $/ \mathrm{mm}^{2}$ to 0.023 number $/ \mathrm{mm}^{2}$, and 0.234 number $/ \mathrm{mm}^{2}$ to 0.137 number $/ \mathrm{mm}^{2}$ for casting located further from the pouring cup in the left and the one closer to the pouring cup in the right, respectively. Apparently, the effect of pressurization on decreasing porosity is very effective, confirming the trends of the density based upper bound data. The application of pressure up to $20 \mathrm{psi}(0.138 \mathrm{MPa})$ at the blind riser feeding the small bracket casting shows a distinct porosity diminution of over $50 \%$ from image analysis.

In Figs 5-14 (a) and (b), it is also shown that the casting further from the pouring cup on the left side of the gating contained fewer pores than the one closer to the pouring cup in the right. The shorter local solidification time as later shown by the smaller $S D A S$ might contribute to the lower porosity in the casting further from the pouring cup on the left 


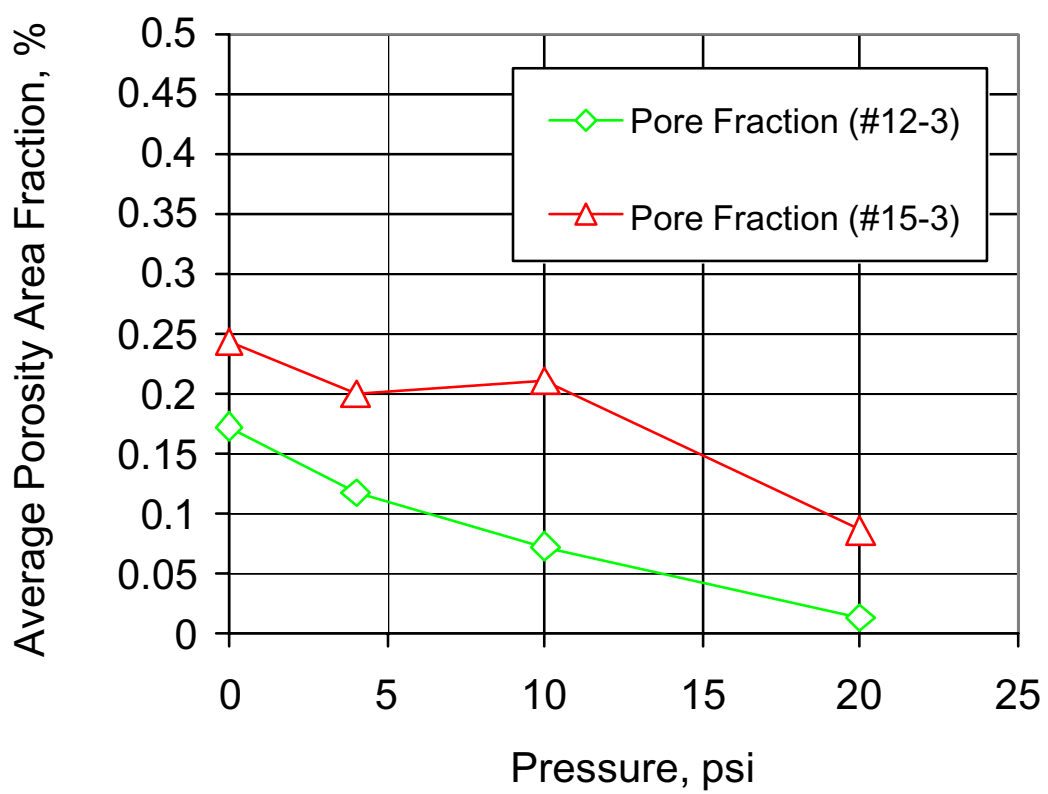

(a)

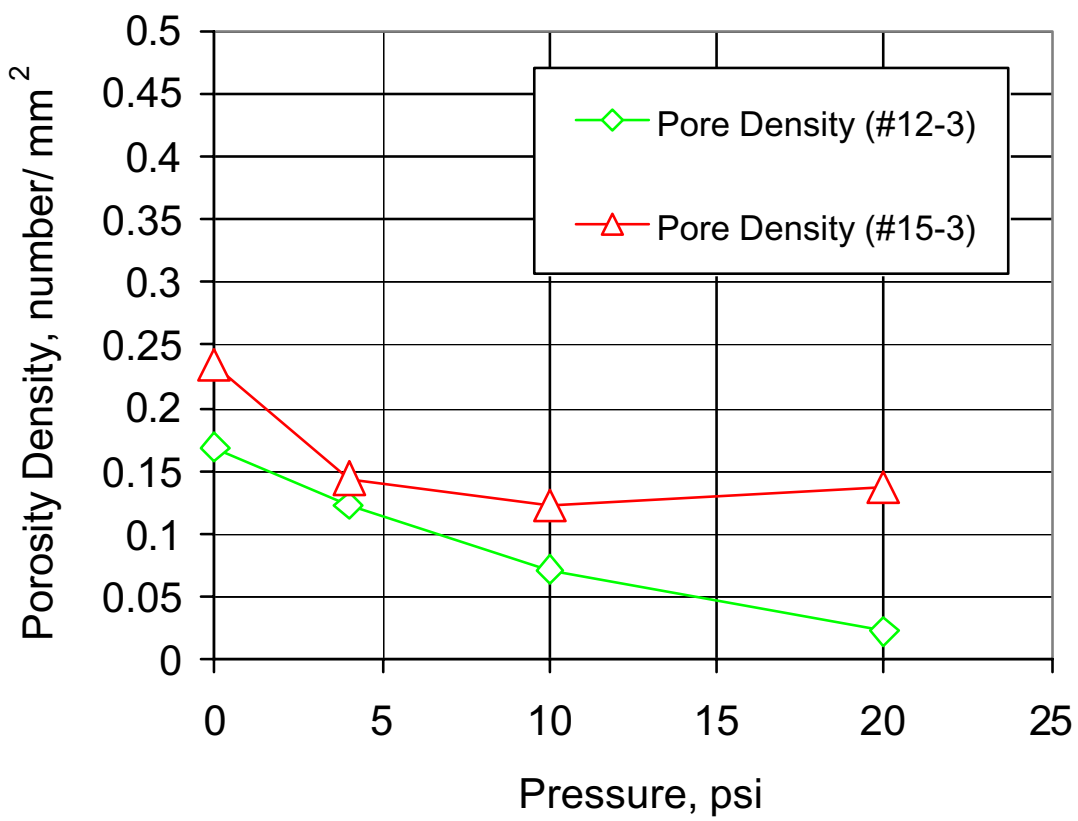

(b)

Figure 5-14. Effect of pressure on the porosity (Image analysis result): (a) average area fraction of porosity; (b) number density of porosity. \# 12-3 was from castings further from the pouring cup to the left, and \#15-3 was from castings closer to the pouring cup to the right of the gating system. 
side of the gating. It is possible that the temperature drop of the melt during the filling to castings further from the pouring cup decreased the local solidification time. Further precise simulations of the filling and solidification process might help clarify this.

Pore shape factors are shown in Figures 5-15 (a) and (b) for pores in the sampling areas in castings located at two positions in the casting tree. It is seen that the effect of pressurization on the pore shape is not significant. The general trend shown is that smaller pores tend to be more spherical.

The average $S D A S$ in castings at different pressurizations are shown in Fig. 5-16 (a) and (b), respectively. Three positions that are closer to the top surface, in the middle and closer to the bottom surface of the bracket castings were examined. The measurements were on the same samples used for porosity determination.

As is shown in Fig. 5-16 (a), the SDAS in castings further from the pouring cup on the left of the die are independent of the pressurization (from 0 psi to $20 \mathrm{psi}$ ), an average of SDAS of $\sim 34 \mu \mathrm{m}$ in the middle, and $\sim 27 \mu \mathrm{m}$ around both the top and the bottom are seen. As is shown in Fig. 5-16 (b), although there is some difference of the SDAS with the pressurization in the middle and at the top for castings closer to the pouring cup on the right of the die, considering the errors in measurements and the variation of SDAS in the same dendrite, it is believed the effect of pressurization on the SDAS is not significant; thus an average of SDAS are $\sim 40 \mu \mathrm{m}$ in the middle and $\sim 33 \mu \mathrm{m}$ around both the top and the bottom in the casting closer to the pouring cup to the right, for example. 


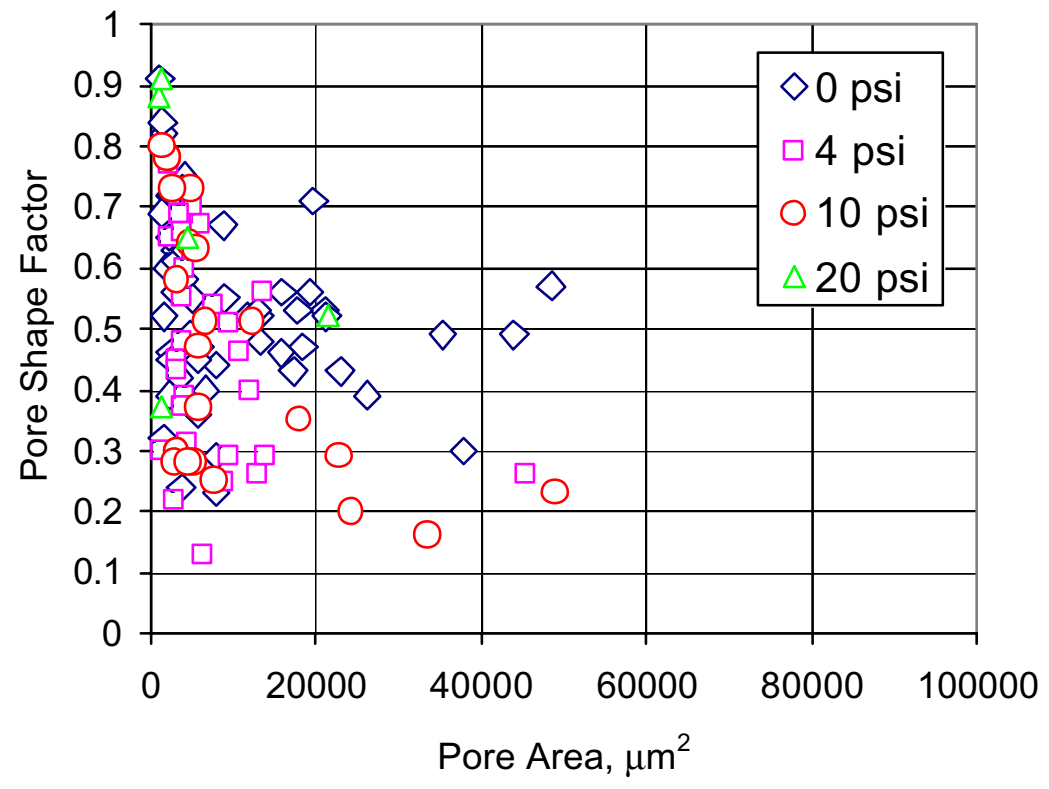

(a)

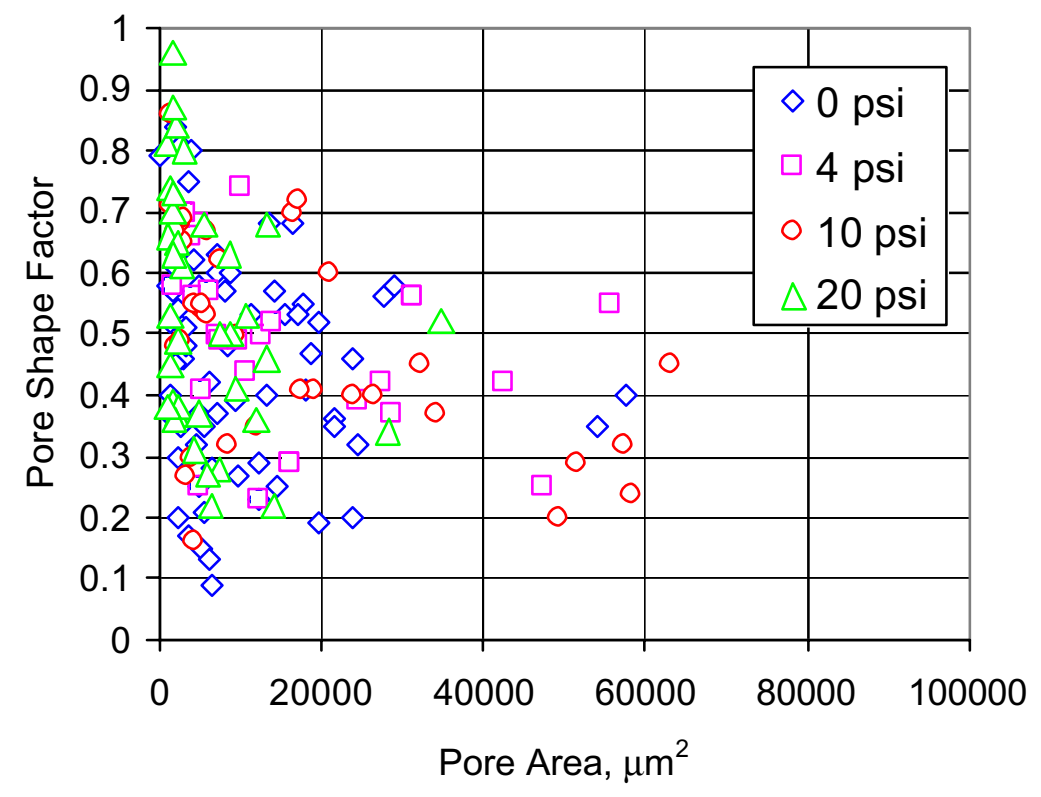

(b)

Figure 5-15. Shape factor of pores in castings obtained at different pressures: (a) from castings further from the pouring cup to the right (\#12-3); (b) from castings closer to the pouring cup to the left (\#15-3). 


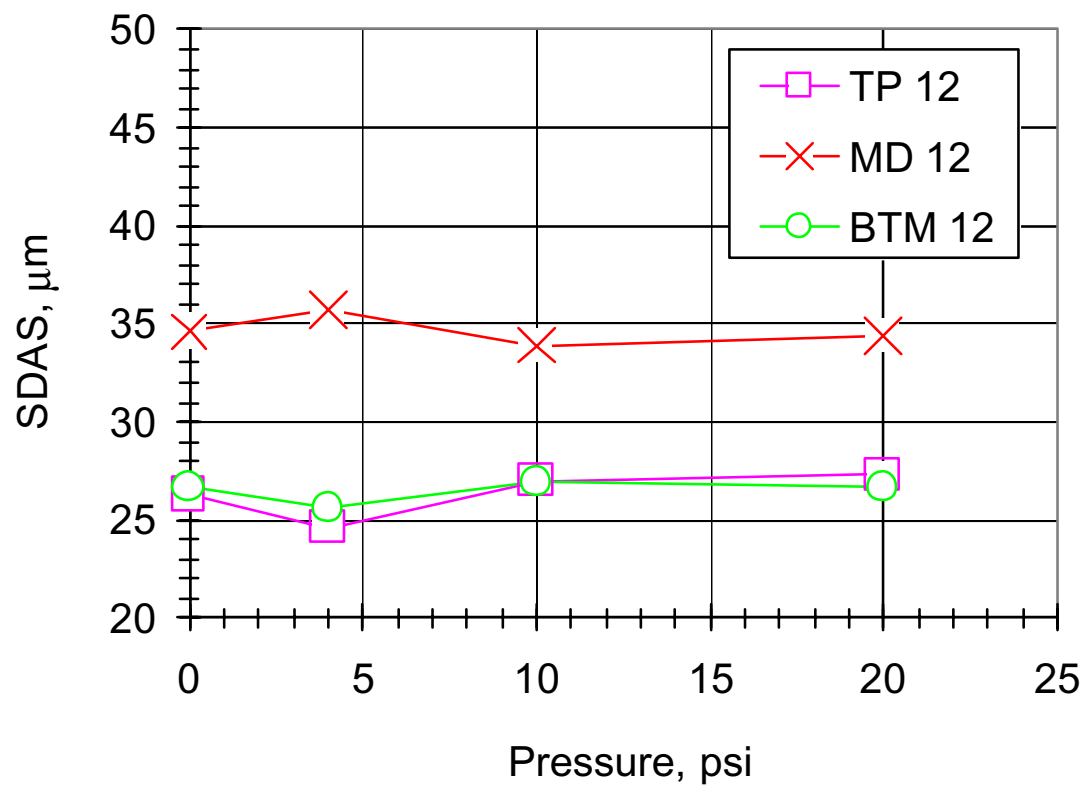

(a)

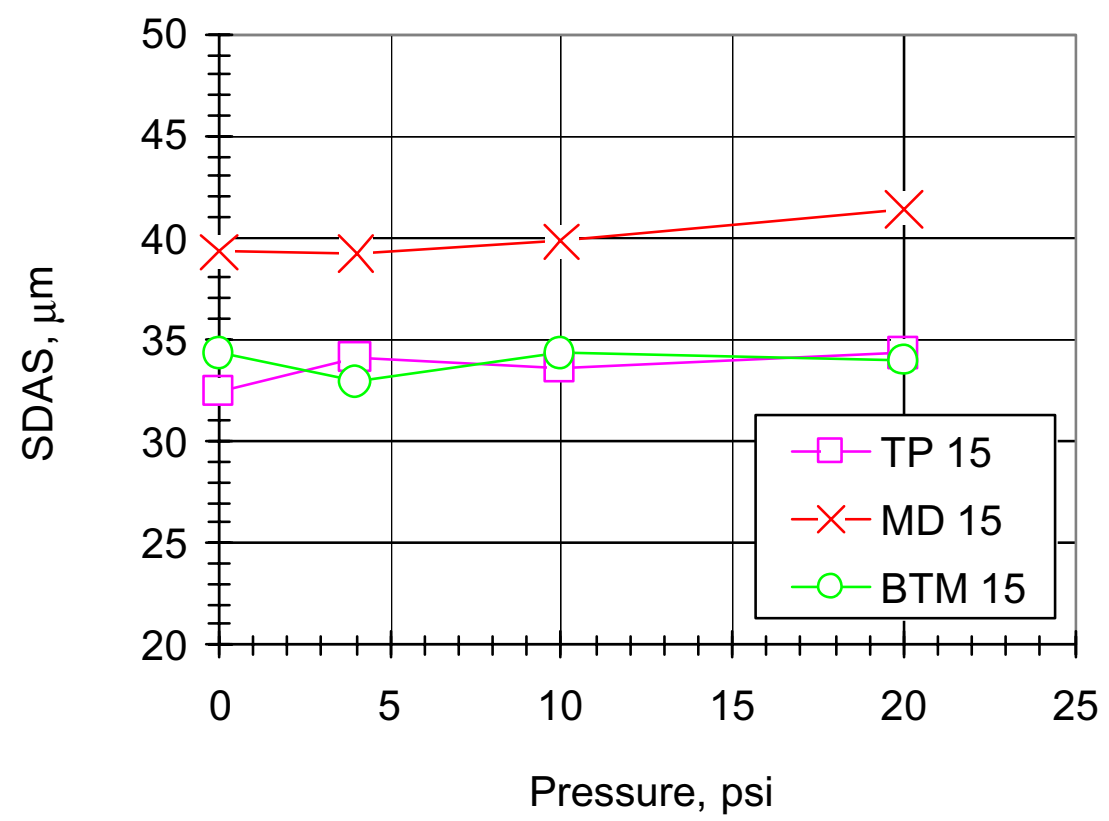

(b)

Figure 5-16. SDAS in castings with different pressures: (a) casting further from the pouring cup to the left (\#12); (b) casting closer to the pouring cup to the right (\#15). TP, MD, and BTM stand for positions at the top, middle and the bottom in the castings, respectively. 
It is also shown that castings closer to the pouring cup seem have larger SDAS than the ones further from the pouring cup. As is mentioned previously, this is possibly the result of more heat loss during the filling of the castings further from the pouring cup. Shorter local solidification time will result the smaller SDAS.

The effect of pressure on the surface roughness $\left(R_{t}\right.$, the maximum peak to valley height of the profile in the assessment length) of castings at different positions on the casting tree is shown in Figure 5-17 (a) to (d). Each casting was sectioned in two halves longitudinally, and the roughnesses of the left and right portions are shown respectively. Some halves were hipped before roughness was examined as shown in the figure caption. The surface roughness shown for each sample is the average of nine measurements in an area closer to where the cracks were initiated in the elbow area. In each measurement, the cut-off length is 0.1 inch and the assessment length is 0.5 inch.

Hipped castings tend to show greater roughness in Fig. 5-17 (c) for the casting closer to the pouring cup and on the right of the die; and hipped castings tend to show smaller roughness in Fig. 5-17 (b) for the casting further from the pouring cup and on the left of the die. But when all castings were examined, it is found that all right casting halves exhibit rougher surfaces. Thus it is concluded that hipping has no significant influence on the surface roughness. The differences between the roughnesses of the casting halves were possibly caused by either the original roughness in the dies or because of a sidewise tilting of the die sets. 


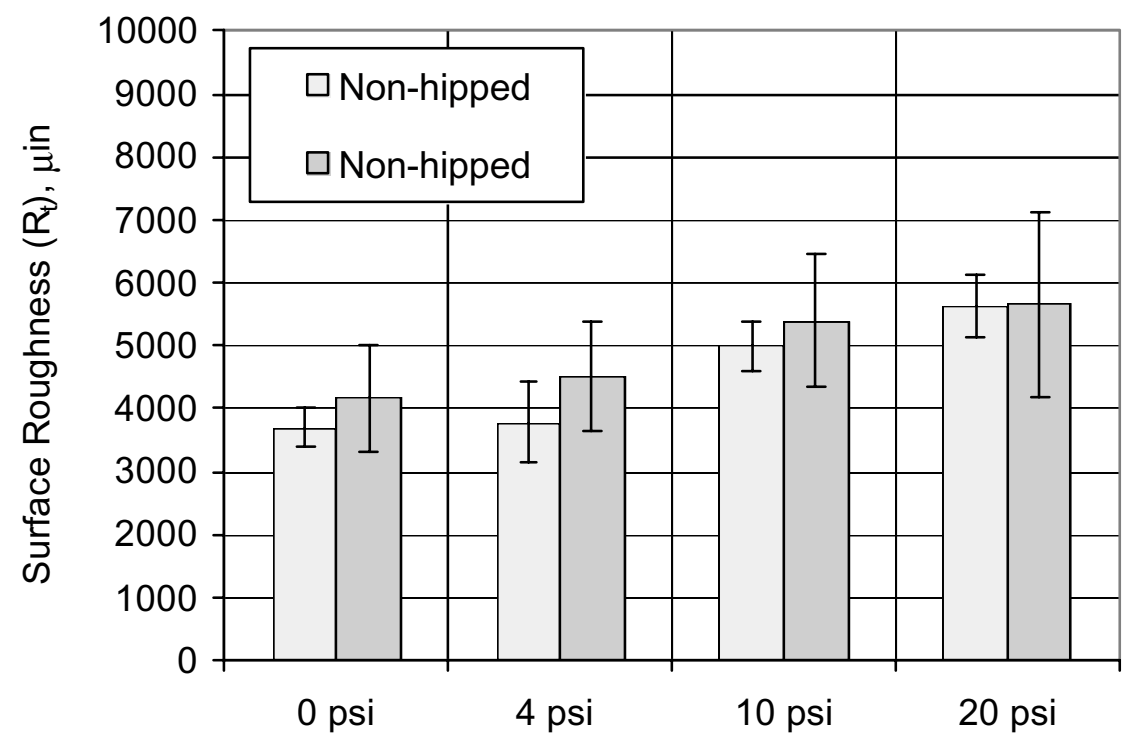

Pressure, psi

(a)

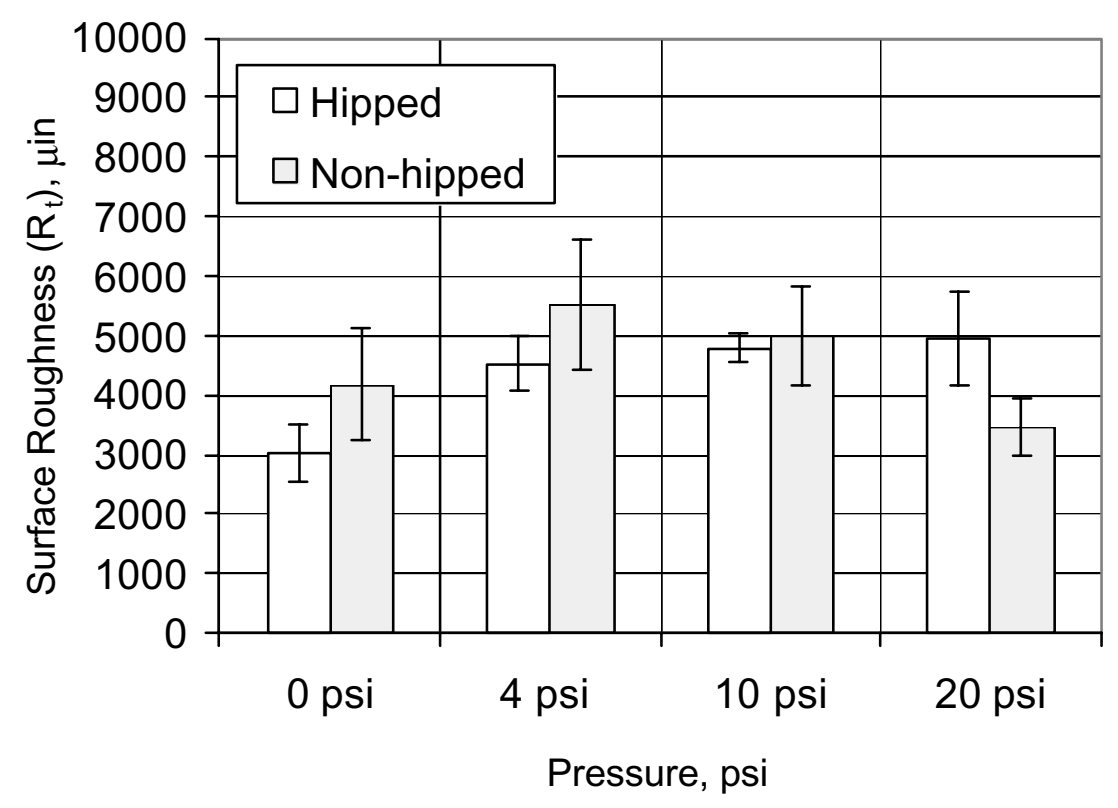

(b)

Figure 5-17. Effect of pressure on the surface roughness of castings at different positions in the casting tree: (a) Casting further from the pouring cup to the right of the gating system (\#11); (b) Casting further from the pouring cup to the left (\#12). (c) Casting closer to the pouring cup to the right (\#15); (d) Casting closer to the pouring cup to the left (\#16). $R_{t}$ is the maximum peak to valley height of the profile in the assessment length. 


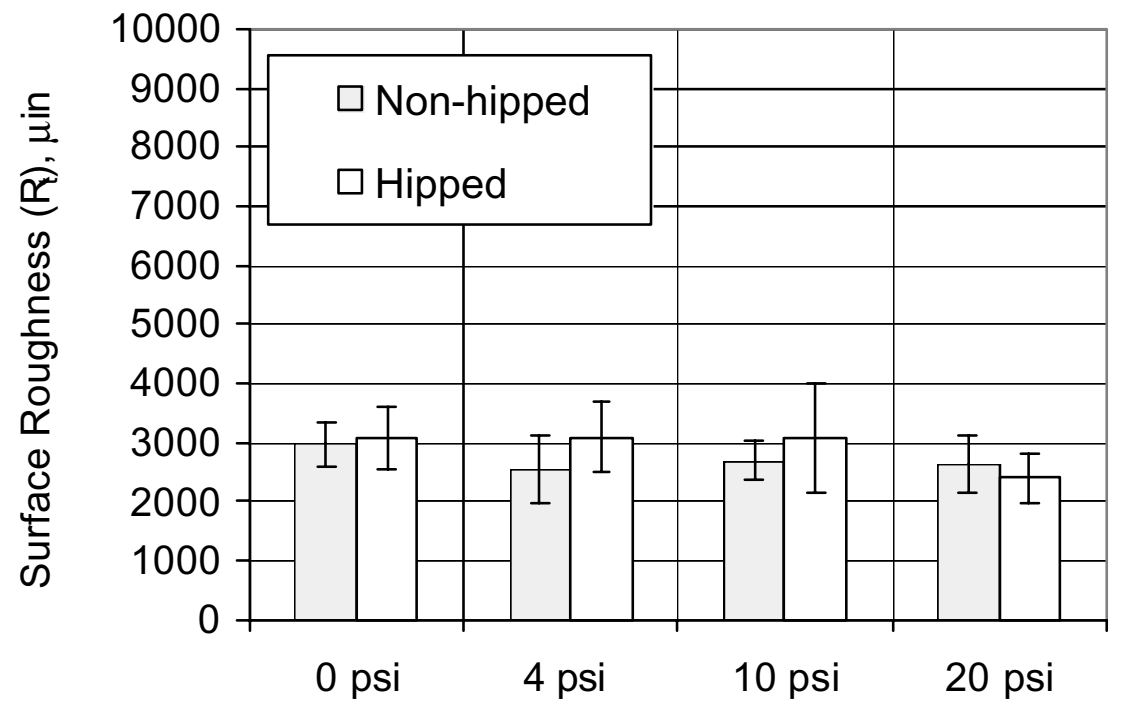

Pressure, psi

(c)

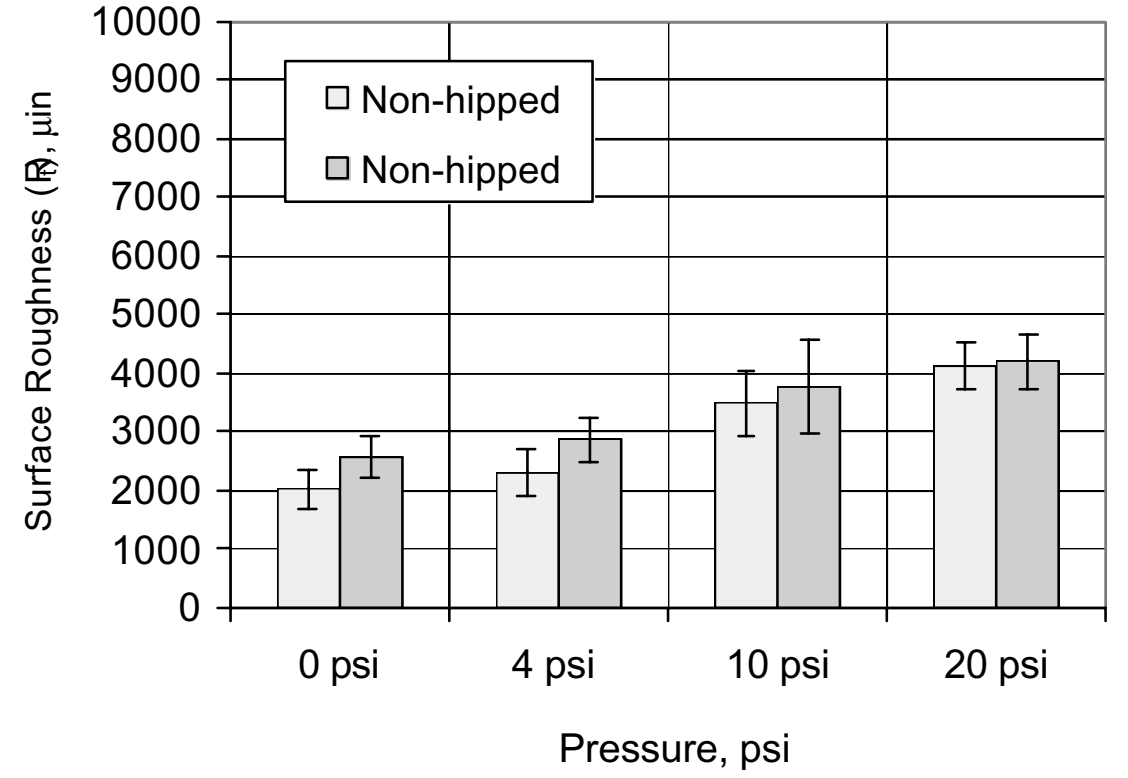

(d)

Figure 5-17. (Continued) 
When the pressure was increased from 0 psi to 20 psi, as is shown in Fig. 5-17 (a) and (d), the surface roughness increases from $\sim 4000 \mu$ in to $\sim 5500 \mu$ in $(101.6 \mu \mathrm{m}$ to 139.7 $\mu \mathrm{m})$ for castings further from the pouring cup and on the right of the die; and from $2300 \mu$ in to $4100 \mu$ in $(58.42 \mu \mathrm{m}$ to $104.1 \mu \mathrm{m})$ for the castings closer to the cup in the left. When the pressurization increase from 0 psi to 20 psi, as is shown in Fig. 5-17 (b) and (c), the roughness first increased from $\sim 3500 \mu$ in to $5000 \mu$ in and then decreased to $\sim$ $4000 \mu$ in for the castings further from the poring cup and on the left of die; and almost $3000 \mu$ in without change for the castings closer to the pouring cup and on the right of the die. The almost constant roughness of castings closer to the pouring cup and on the right of the die appear to be independent of the pressurization is intriguing and further work might be in order.

Regardless whether the castings were pressurized or not, it seems castings further from the pouring cup show rougher surface than those closer to the pouring cup. It appears likely that the nature of this localized roughness is related either to the particle size of the refractory within the coating, to the permanent mold cavity roughness itself, or both. The question of the effect of the distance from the pouring cup on roughness is baffling. It may be related to the time available in pouring for interaction between the molten metal and the coating.

It is noted that from Figures 5-17 (a)-(d) that hipping has no effect on the surface roughness of the castings. Image analysis result also showed no pores present in hipped microstructures, thus it is concluded that hipping is very effective in eliminating porosity. 


\section{REFERENCES}

1. S.T. McClain, A.S. McClain and J.T. Berry, Transactions of American Foundrymen's Society, 2000, (108), 183.

2. J. Campbell, Brit. Foundryman, 1969, (62), 147.

3. H. Jiang, P. Bowen, J.F. Knott, J. of Mat. Sci., 1999, (34), 719.

4. J. Campbell, Castings, $2^{\text {nd }}$ Edition, 2003, Butterworth-Heinemann. 


\subsection{CONCLUSIONS AND FUTURE WORK}

The following may be concluded from the investigation:

(i) Pressurization at the pouring cup during the tilt-pour permanent mold casting of a small pressure vessel like component leads to a modest overall improvement for alloy A356 (From a level of $\sim 0.546 \%$ to $\sim 0.460 \%$, that is roughly a $16 \%$ reduction overall). This figure relates to pressurization at $100 \%$ tilt.

(ii) Alloy 319 suffers from surface intrusions caused, it is believed, by the pressurization medium leaking into the air-gap between the casting surface and the die which then indents the casting surface in locations where the alloy is still partly molten. Although a small diminution of porosity was seen at $50 \%$ tilt (From $\sim 0.567 \%$ to $0.534 \%$ ), the result of the four-point bend test indicated serious surface damage for this case. The alloy is not recommended for pressurization where permanent molding is involved.

(iii) Sealing of the pouring cup prior to pressurization is difficult and needs further experimentation.

(iv) The use of 'squeeze pins' with the 319 alloy led to a modest level of porosity diminution $(\sim 10 \%)$. However, these results may be dependant on a copper segragation effect.

(v) Preliminary fatigue testing of non-pressurized A356-T6 tilt-poured structural castings in the form of a small bracket component showed an apparent sensitivity to surface roughness where fatigue resistance is required.

(vi) Whether the above sensitivity to surface roughness overpowers the effects of subsurface porosity in initiating fatigue cracks should be the subject of future work. 
(vii) The application of pressure up to $20 \mathrm{psi}$ at the blind riser feeding the small bracket casting in 356-T6 shows a distinct porosity diminution ( $40 \%$ from pyknometry, and over $50 \%$ from image analysis). These results are regarded as highly significant.

(viii) The above diminution was established by multiple porosity measurements using both pyknometry and image analysis based measurements.

(ix) Further reduction in porosity level appears possible by hot isostatic pressing. However, riser pressurization at levels of pressure greater than 20 psi may well lead to similar reductions. Thus further experiments at such pressure levels are recommended, using a graphitic mold coat. This choice is recommended because of two potential effects. Firstly, the replication of the particles within the mold coating and secondly because of the tendency of the pressurized solidifying metal to penetrate and lift-off the mold coating at pressures above $\sim 10$ psi.

(x) The surface roughness of the pressurized riser castings appears to vary with die impression location, especially with distance from the pouring cup. Also the inadvertent lateral tilt of the die set and its effects on filling may be involved. Here, roughness is seen varying from left to right in terms of impression location.

(xi) The secondary dendrite arm spacing appears to be affected more by location within the casting thickness than by the pressurization.

(xii) The sphere of action of the pressurized blind riser may be affected by the sequence of solidification within the casting. Consequently, locations remote from a riser may not benefit from the pressurization. 
(xiii) As a consequence of this, accurate solidification modeling and the concomitant judicious placement of pressurized risers are both essential.

(xiv) In order to ensure the above accuracy of modeling, realistic values of the moldmetal interfacial heat transfer coefficient as a function of time, temperature and pressure will be required. Further work on this aspect is thus recommended. 


\section{ACKNOWLEDGEMENTS}

The MSU team would like to acknowledge the indispensable help of Stahl Speciallity Co. (Mr. Rich Andriano), the Metalloy Division of General Aluminum (Mr. Greg Bowen), CMH Manufacturing Company (Mr. John Hall), Kittyhawk Products (Mr. D. Barre), the member of the AFS $2 \mathrm{H}$ and $2 \mathrm{E}$ Committees for their guidance and the numerous undergraduates and graduate students who worked on this project (See below). Finally, the financial support of the US DoE (through the Cast Metal Coalition) and the Department of Mechanical Engineering of Mississippi State University (Dr. W. Glenn Steele, head) is much appreciated. 


\section{CONTRIBUTORS TO THIS INVESTIGATION AT MSU}

The following individuals contributed to the present investigations:

- MSU Faculty and Staff

Dr. J.T. Berry, Dr. R. Luck, Dr. S. Daniewicz, Dr. R.P. Taylor, Dr. B. Zhang, Dr.

J. Shenefelt.

- Former MSU graduate and undergraduate students

Dr. S. McClain, Dr. G. Potirniche, Ms. A. McClain, Ms. S. Gales, Mr. C. Ferrell, Mr. R. Thavarajah, Mr. B. Boggess, and Mr. R. Williams. 


\section{LIST OF ASSOCIATED PUBLICATIONS}

1. J.T. Berry and R.P. Taylor, "Improving Casting Performance by Extending Feeding Action in Long-Freezing Range Cast Aluminum Alloys," Transactions of American Foundrymen's Society, 1999, (107), 203-206.

2. J.T. Berry, G.S. Jalewalia, and R.G. Kumble, "Anisotropy in Aluminum Castings 25 Years On," Transactions of American Foundrymen's Society, 2000, (108), 733740.

3. S.T. McClain, A.S. McClain, and J.T. Berry, "Theoretical Density Determination for Secondary Aluminum Alloys," Transactions of American Foundrymen's Society, 2000, (108), 183-187.

4. J. Shenefelt, S. Gales, R. Luck, J.T. Berry, and R. Andriano, "The Effects of Applied Pressure During Feeding on the Fatigue Properties of Critical Cast Aluminum Alloy Components - An AFS/CMS Research Progress Report,' Transactions of American Foundrymen's Society, 2001, (109), 593-604.

5. S.T. McClain, A.S. McClain, and J.T. Berry, "A Comparison of Image-Analysis and Pyknometry Results for the Percentage Porosity Evaluation of Two A356 Castings,' Transactions of American Foundrymen's Society, 2001, (109), 321-332.

6. R.P. Taylor, J. Shenefelt, J.T. Berry, and R. Luck, "Comparison and Criticism of Casting Criteria Functions," Transactions of American Foundrymen's Society, 2002, (110), 315-330.

7. J. Shenefelt, SR. Daniewicz, J.T. Berry, W.C. Ferrell and G. Bowen, "Effects of Applied Pressure During Feeding on the Fatigue Properties of Critical Cast Aluminum Alloy Components - An AFS/CMC Research Progress Report, No 2," Transactions of American Foundrymen's Society, 2002, (110), 339-345.

8. S.T. McClain, J.T. Berry, and B. Dawsey, "A Study of Porosity and Pore Morphology in Aluminum A356.2 Step Castings,' Transactions of American Foundrymen's Society, 2003, (111), in print (paper 03-045).

9. J.R. Shenefelt, R. Luck, J.T. Berry, and R. Andriano, "The Case for Riser Pressurization", in Proceedings $1^{\text {st }}$ AFS International Conference on Gating, Filling, and Feeding of Aluminum Castings, Nashville, TN, Oct. 1999, 227-237.

10. J.T. Berry, J. Shenefelt, and R. Luck," Pressurized Feeding Systems," International Jnl. Cast Metals Research, 2002, (14), 365-370. 


\section{APPENDIX 1. SELECTED POROSITY DISTRIBUTION \\ DATA FOR A356 PRESSURIZED AT POURING CUP}

\section{Porosity Results H Samples}

\begin{tabular}{|c|c|c|c|c|c|c|c|c|c|}
\hline & 1 & 2 & 3 & 4 & 5 & 6 & 7 & 8 & Average \\
\hline H5 & 0.469 & 0.462 & 0.483 & 0.475 & 0.932 & 0.489 & 0.491 & 0.505 & 0.5383 \\
\hline H6 & 0.413 & 0.708 & 0.505 & 0.585 & 0.910 & 0.483 & 0.441 & 0.546 & 0.5739 \\
\hline H8 & 0.379 & 0.462 & 0.411 & 0.531 & 0.867 & 0.456 & 0.429 & 0.522 & 0.5071 \\
\hline H11 & 0.372 & 0.865 & 0.497 & 0.441 & 0.962 & 0.447 & 0.417 & 0.507 & 0.5635 \\
\hline
\end{tabular}

Average of H5, H6, H8, and H11 groups: $0.546 \%$

H1-H16: No pressure applied to the pouring cup or squeeze pins.

\section{Porosity Results N Samples}

\begin{tabular}{|c|c|c|c|c|c|c|c|c|c|}
\hline & 1 & 2 & 3 & 4 & 5 & 6 & 7 & 8 & Average \\
\hline N5 & 0.485 & 0.370 & 0.476 & 0.488 & 0.502 & 0.468 & 0.494 & 0.495 & 0.4723 \\
\hline N6 & 0.439 & 0.676 & 0.487 & 0.405 & 0.574 & 0.482 & 0.497 & 0.492 & 0.5065 \\
\hline N7 & 0.400 & 0.370 & 0.472 & 0.526 & 0.557 & 0.477 & 0.480 & 0.454 & 0.467 \\
\hline N8 & 0.508 & 0.725 & 0.495 & 0.507 & 0.599 & 0.481 & 0.458 & 0.436 & 0.5261 \\
\hline
\end{tabular}

Average of N5, N6, N7, and N8 groups: $0.493 \%$

N1-N16: Full pressure applied to pouring cup without pins once the mold was 45 degrees from vertical. 


\section{Porosity Results J Samples}

\begin{tabular}{|c|c|c|c|c|c|c|c|c|c|}
\hline J6 & 1 & 2 & 3 & 4 & 5 & 6 & 7 & 8 & Average \\
\hline 1 & 0.67547 & 0.60924 & 0.4474 & 0.53681 & 0.53057 & 0.50335 & 0.51774 & 0.54878 & \\
\hline 2 & 0.66982 & 0.62608 & 0.4474 & 0.53509 & 0.5584 & 0.50591 & 0.51864 & 0.55066 & \multirow{2}{*}{0.54868} \\
\hline 3 & 0.67296 & 0.6222 & 0.44873 & 0.54127 & 0.52718 & 0.50521 & 0.51774 & 0.55178 & \\
\hline Average & 0.67275 & 0.61917 & 0.44784 & 0.53772 & 0.53872 & 0.50482 & 0.51804 & 0.55041 & \\
\hline
\end{tabular}

\begin{tabular}{|c|c|c|c|c|c|c|c|c|c|}
\hline J7 & 1 & 2 & 3 & 4 & 5 & 6 & 7 & 8 & Average \\
\hline 1 & 0.55303 & 0.75991 & 0.53331 & 0.5326 & 0.4805 & 0.48208 & 0.53159 & 0.48089 & \\
\hline 2 & 0.55719 & 0.75991 & 0.53413 & 0.52836 & 0.46457 & 0.48208 & 0.52915 & 0.47889 & \multirow{2}{*}{0.54413} \\
\hline 3 & 0.55464 & 0.76769 & 0.53331 & 0.53357 & 0.49036 & 0.48275 & 0.53098 & 0.4777 & \\
\hline Average & 0.55495 & 0.76251 & 0.53358 & 0.53151 & 0.47848 & 0.48231 & 0.53057 & 0.47916 & \\
\hline
\end{tabular}

\begin{tabular}{|c|c|c|c|c|c|c|c|c|c|}
\hline J8 & 1 & 2 & 3 & 4 & 5 & 6 & 7 & 8 & Average \\
\hline 1 & 0.8284 & 0.49254 & 0.51461 & 0.46827 & 0.52442 & 0.3624 & 0.38308 & 0.37587 & \\
\cline { 1 - 8 } 2 & 0.82987 & 0.50746 & 0.51374 & 0.46985 & 0.53464 & 0.36126 & 0.38038 & 0.3804 & \multirow{2}{*}{0.49574} \\
\hline 3 & 0.83075 & 0.49254 & 0.51606 & 0.47079 & 0.53464 & 0.3624 & 0.38308 & 0.3804 & \\
\hline Average & 0.82967 & 0.49752 & 0.5148 & 0.46963 & 0.53124 & 0.36202 & 0.38218 & 0.37889 & \\
\hline
\end{tabular}

Average of J6, J7, and J8 groups: $0.530 \%$

J1-I16: No pressure applied to the pouring cup and full pressure applied to pins once the mold was vertical. 


\section{Porosity Results K Samples}

\begin{tabular}{|c|c|c|c|c|c|c|c|c|c|}
\hline K5 & 1 & 2 & 3 & 4 & 5 & 6 & 7 & 8 & Average \\
\hline 1 & & 0.66211 & 0.66732 & 0.16831 & & 0.54092 & 0.42275 & 0.42952 & \\
\cline { 1 - 8 } 2 & & 0.68455 & 0.66153 & 0.16572 & & 0.54452 & 0.42627 & 0.43255 & \multirow{2}{*}{0.48220} \\
\hline 3 & & 0.64606 & 0.6665 & 0.17349 & & 0.538 & 0.42114 & 0.42838 & \\
\hline Average & & 0.66424 & 0.66512 & 0.16917 & & 0.54115 & 0.42339 & 0.43015 & \\
\hline
\end{tabular}

\begin{tabular}{|c|c|c|c|c|c|c|c|c|c|}
\hline K6 & 1 & 2 & 3 & 4 & 5 & 6 & 7 & 8 & Average \\
\hline 1 & 0.44778 & 0.42197 & 0.41246 & 0.52581 & 0.4715 & 0.3614 & 0.39258 & 0.45717 & \\
\cline { 1 - 9 } 2 & 0.45085 & 0.44548 & 0.41327 & 0.5174 & 0.46014 & 0.35784 & 0.39073 & 0.4622 & \multirow{2}{*}{0.435676} \\
\hline 3 & 0.44554 & 0.43103 & 0.41109 & 0.52685 & 0.46226 & 0.35561 & 0.38856 & 0.44674 & \\
\hline Average & 0.44806 & 0.43283 & 0.41227 & 0.52335 & 0.46463 & 0.35828 & 0.39062 & 0.45537 & \\
\hline
\end{tabular}

\begin{tabular}{|c|c|c|c|c|c|c|c|c|c|}
\hline K7 & 1 & 2 & 3 & 4 & 5 & 6 & 7 & 8 & Average \\
\hline 1 & & 0.39437 & 0.39972 & 0.40101 & 0.49193 & 0.44764 & 0.42997 & 0.19507 & \\
\cline { 1 - 8 } 2 & & 0.36725 & 0.3974 & 0.40677 & 0.48262 & 0.44281 & 0.42236 & 0.18688 & \multirow{2}{*}{0.393344} \\
\hline 3 & & 0.40652 & 0.40291 & 0.40517 & 0.50973 & 0.44948 & 0.42997 & 0.19063 & \\
\cline { 1 - 7 } Average & & 0.38938 & 0.40001 & 0.40431 & 0.49476 & 0.44665 & 0.42744 & 0.19086 & \\
\hline
\end{tabular}

\begin{tabular}{|c|c|c|c|c|c|c|c|c|c|}
\hline K8 & 1 & 2 & 3 & 4 & 5 & 6 & 7 & 8 & Average \\
\hline 1 & 0.44614 & 0.46081 & 0.41205 & 0.40817 & 0.53721 & 0.38414 & 0.44034 & 0.41548 & \\
\cline { 1 - 8 } 2 & 0.44286 & 0.46298 & 0.40597 & 0.41319 & 0.52131 & 0.37889 & 0.43698 & 0.42696 & \multirow{2}{*}{0.435578} \\
\cline { 1 - 8 } 3 & 0.43896 & 0.44364 & 0.41205 & 0.40157 & 0.53051 & 0.38589 & 0.43545 & 0.41231 & \\
\hline Average & 0.44265 & 0.45581 & 0.41003 & 0.40764 & 0.52968 & 0.38297 & 0.43759 & 0.41825 & \\
\hline
\end{tabular}

Average of K5, K6, K7, and K8 groups: $0.436 \%$

K1-K16: Full pressure applied to the pins and pouring cup once the mold was vertical. 


\section{Porosity Result I Samples}

\begin{tabular}{|c|c|c|c|c|c|c|c|c|c|}
\hline I5 & 1 & 2 & 3 & 4 & 5 & 6 & 7 & 8 & Average \\
\hline 1 & 0.461 & 0.603 & 0.433 & 0.431 & 0.366 & 0.456 & 0.492 & 0.412 & \\
\hline 2 & 0.454 & 0.603 & 0.419 & 0.424 & 0.329 & 0.465 & 0.482 & 0.422 & \multirow{2}{*}{0.452} \\
\hline 3 & 0.463 & 0.633 & 0.406 & 0.409 & 0.338 & 0.447 & 0.491 & 0.419 & \\
\hline Average & 0.459 & 0.613 & 0.419 & 0.421 & 0.344 & 0.456 & 0.488 & 0.418 & \\
\hline
\end{tabular}

\begin{tabular}{|c|c|c|c|c|c|c|c|c|c|}
\hline I6 & 1 & 2 & 3 & 4 & 5 & 6 & 7 & 8 & Average \\
\hline 1 & 0.458 & 0.653 & 0.438 & 0.3000 & 0.470 & 0.352 & 0.390 & 0.480 & \\
\hline 2 & 0.454 & 0.687 & 0.434 & 0.3000 & 0.446 & 0.343 & 0.375 & 0.468 & \multirow{2}{*}{0.438} \\
\hline 3 & 0.456 & 0.687 & 0.430 & 0.285 & 0.441 & 0.339 & 0.374 & 0.447 & \\
\hline Average & 0.456 & 0.676 & 0.434 & 0.295 & 0.452 & 0.345 & 0.380 & 0.465 & \\
\hline
\end{tabular}

\begin{tabular}{|c|c|c|c|c|c|c|c|c|c|}
\hline I7 & 1 & 2 & 3 & 4 & 5 & 6 & 7 & 8 & Average \\
\hline 1 & 0.469 & 0.697 & 0.602 & 0.510 & 0.519 & 0.475 & 0.474 & 0.545 & \\
\cline { 1 - 8 } 2 & 0.460 & 0.552 & 0.597 & 0.495 & 0.528 & 0.478 & 0.466 & 0.551 & \multirow{2}{*}{0.528} \\
\hline 3 & 0.467 & 0.667 & 0.596 & 0.485 & 0.519 & 0.469 & 0.494 & 0.551 & \\
\hline Average & 0.465 & 0.613 & 0.598 & 0.497 & 0.522 & 0.474 & 0.478 & 0.549 & \\
\hline
\end{tabular}

\begin{tabular}{|c|c|c|c|c|c|c|c|c|c|}
\hline I8 & 1 & 2 & 3 & 4 & 5 & 6 & 7 & 8 & Average \\
\hline 1 & 0.357 & 0.313 & 0.449 & 0.432 & 0.493 & 0.414 & 0.453 & 0.500 & \\
\hline 2 & 0.350 & 0.321 & 0.457 & 0.440 & 0.493 & 0.409 & 0.456 & 0.471 & \multirow{2}{*}{0.423} \\
\hline 3 & 0.343 & 0.367 & 0.451 & 0.416 & 0.446 & 0.416 & 0.430 & 0.480 & \\
\hline Average & 0.350 & 0.334 & 0.452 & 0.429 & 0.477 & 0.413 & 0.446 & 0.484 & \\
\hline
\end{tabular}

Average of 4 groups (I5, I6, I7, I8): $0.460 \%$

I1-I16: Full pressure applied to the pouring cup without pins once the mold was vertical. 


\section{Porosity Result M Samples}

\begin{tabular}{|c|c|c|c|c|c|c|c|c|c|}
\hline M5 & 1 & 2 & 3 & 4 & 5 & 6 & 7 & 8 & Average \\
\hline 1 & 0.333 & 0.529 & 0.506 & 0.455 & 0.544 & 0.441 & 0.445 & 0.429 & \\
\hline 2 & 0.338 & 0.417 & 0.495 & 0.470 & 0.521 & 0.432 & 0.454 & 0.424 & \multirow{2}{*}{0.452} \\
\hline 3 & 0.312 & 0.462 & 0.506 & 0.457 & 0.552 & 0.430 & 0.450 & 0.439 & \\
\hline Average & 0.328 & 0.469 & 0.502 & 0.461 & 0.539 & 0.434 & 0.450 & 0.431 & \\
\hline
\end{tabular}

\begin{tabular}{|c|c|c|c|c|c|c|c|c|c|}
\hline M6 & 1 & 2 & 3 & 4 & 5 & 6 & 7 & 8 & Average \\
\hline 1 & 0.344 & 0.216 & 0.490 & 0.553 & 0.644 & 0.452 & 0.453 & 0.580 & \\
\cline { 1 - 9 } 2 & 0.420 & 0.208 & 0.484 & 0.538 & 0.700 & 0.443 & 0.448 & 0.561 & \multirow{2}{*}{0.464} \\
\hline 3 & 0.341 & 0.177 & 0.537 & 0.536 & 0.585 & 0.443 & 0.443 & 0.543 & \\
\hline Average & 0.368 & 0.200 & 0.504 & 0.542 & 0.643 & 0.446 & 0.448 & 0.561 & \\
\hline
\end{tabular}

\begin{tabular}{|c|c|c|c|c|c|c|c|c|c|}
\hline M 8 & 1 & 2 & 3 & 4 & 5 & 6 & 7 & 8 & Average \\
\hline 1 & 0.665 & 0.727 & 0.546 & 0.520 & 0.784 & 0.525 & 0.430 & 0.523 & \\
\cline { 1 - 9 } 2 & 0.603 & 0.683 & 0.505 & 0.498 & 0.671 & 0.478 & 0.376 & 0.494 & \multirow{2}{*}{0.549} \\
\hline 3 & 0.581 & 0.596 & 0.532 & 0.492 & 0.619 & 0.465 & 0.393 & 0.465 & \\
\hline Average & 0.616 & 0.669 & 0.528 & 0.503 & 0.691 & 0.489 & 0.400 & 0.494 & \\
\hline
\end{tabular}

\begin{tabular}{|c|c|c|c|c|c|c|c|c|c|}
\hline M 11 & 1 & 2 & 3 & 4 & 5 & 6 & 7 & 8 & Average \\
\hline 1 & 0.504 & 0.598 & 0.545 & 0.594 & 0.776 & 0.460 & 0.488 & 0.682 & \\
\hline 2 & 0.493 & 0.618 & 0.505 & 0.537 & 0.778 & 0.402 & 0.455 & 0.634 & \multirow{2}{*}{0.555} \\
\hline 3 & 0.433 & 0.559 & 0.488 & 0.507 & 0.799 & 0.374 & 0.465 & 0.633 & \\
\hline Average & 0.477 & 0.592 & 0.513 & 0.546 & 0.784 & 0.412 & 0.469 & 0.650 & \\
\hline
\end{tabular}

Average of 4 groups (M5, M6, M8, M11): $0.505 \%$

M1-M16: Full pressure applied to the pouring cup when the mold was rotated 70 degrees from horizontal (mold 20 degrees from vertical). 


\section{APPENDIX 2. SOLIDIFICATION SIMULATION EXPERIMENTS - BRACKET CASTING}

At the commencement of the second phase of the program, which involved the pouring of the bracket castings, a number of simulations were performed in order to determine the order of freezing of various locations within the casting and its adjacent rigging.

The simulation utilized the AFSolid system (now SolidCast). At the time of the experiments the tilt pour filling option was not available. The heat transfer coefficient between the casting and the mold which was utilized in the simulation was that recommended from the database for the mold material selected (low carbon steel with typical coating). Consequently the total freezing times given are approximate.

Pressurization took place at the end of the test cycle (Approx. 25 seconds).

Three simulations were performed, only two of which are illustrated.

a. Casting with blind riser and portion of gating system attached.

b. As (a.) above but with a choke at 1 inch from the riser.

c. As (a.) above but with a choke at 3 inches from the riser.

The purpose of the choke, essentially a constriction, was to accelerate local solidification time at its location to insure that the metal was not expelled back through the gating system on pressurization. 


\section{Model Properties}

\section{$\underline{\text { Aluminum Casting of A356.0 }}$}

Thermal Conductivity

$91.998(\mathrm{Btu} / \mathrm{Hr}-\mathrm{ft}-\mathrm{F})$

Specific Heat $0.230(\mathrm{Btu} / \mathrm{Hr}-\mathrm{ft}-\mathrm{F})$

Density $167.60\left(\mathrm{lbm} / \mathrm{ft}^{3}\right)$

Pouring Temperature $.1350^{\circ} \mathrm{F}$

Solidification Temperature $1007.6^{\circ} \mathrm{F}$

Freezing Range $127.8^{\circ} \mathrm{F}$

Latent Heat of Fusion $167.00(\mathrm{Btu} / \mathrm{lbm})$

Fill Time. 6 seconds

\section{Mold Properties}

Material Steel

Shape Rectangular

(NOTE: For the purposes of this model AFSolid 2000 was allowed to create a rectangular mold around the geometry of the Casting, Riser, and 6 inches of Gate. The minimum thickness of this mold was chosen to be 6 inches.)

Thermal Conductivity $31(\mathrm{Btu} / \mathrm{Hr}-\mathrm{ft}-\mathrm{F})$

Specific Heat $0.111(\mathrm{Btu} / \mathrm{Hr}-\mathrm{ft}-\mathrm{F})$

Density $489.6\left(\mathrm{lbm} / \mathrm{ft}^{3}\right)$

Preheat Temperature $800^{\circ} \mathrm{F}$

Ambient Temperature $85^{\circ} \mathrm{F}$

\section{Weights}

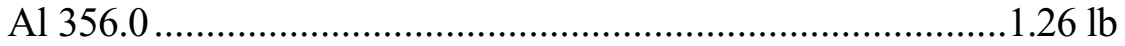

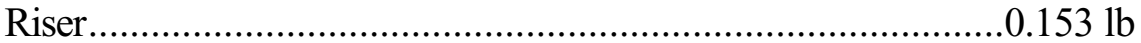

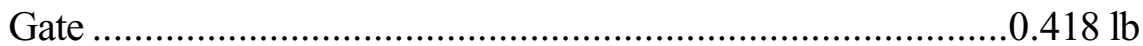

Steel Mold ......................................................................... 1490 lb 


\section{Simulation Data}

\section{Model with No Choke in the Gate:}

Simulated Solidification Time ..... 0.662 minutes

Maximum Casting Temperature $1006^{\circ} \mathrm{F}$

Minimum Casting Temperature $830.6^{\circ} \mathrm{F}$

Maximum Mold Temperature $1006^{\circ} \mathrm{F}$

Minimum Mold Temperature. $.791 .4^{\circ} \mathrm{F}$

(NOTE: These temperatures are after the casting and the riser are fully solidified.)

Number of Nodes $1,499,600$

Node Size 0.152 inches

Model with 0.5 inch Semicircular Choke Centered 1 inch from the Riser in Gate:

Simulated Solidification Time 0.716 minutes

Maximum Casting Temperature $1006.3^{\circ} \mathrm{F}$

Minimum Casting Temperature $829.2^{\circ} \mathrm{F}$

Maximum Mold Temperature $1006.1^{\circ} \mathrm{F}$

Minimum Mold Temperature $.791 .1^{\circ} \mathrm{F}$

Number of Nodes $1,499,600$

Node Size .0 .152 inches

Model with 0.5 inch Semicirclar Choke Centered 3 inch from the Riser in the Gate:

Simulated Solidification Time .0 .705 minutes Maximum Casting Temperature $1007.1^{\circ} \mathrm{F}$

Minimum Casting Temperature $829.2^{\circ} \mathrm{F}$

Maximum Mold Temperature $1007.1^{\circ} \mathrm{F}$

Minimum Mold Temperature $.791 .1^{\circ} \mathrm{F}$

Number of Nodes $1,499,600$

Node Size 0.152 inches 


\section{Isometric View of the Model.}

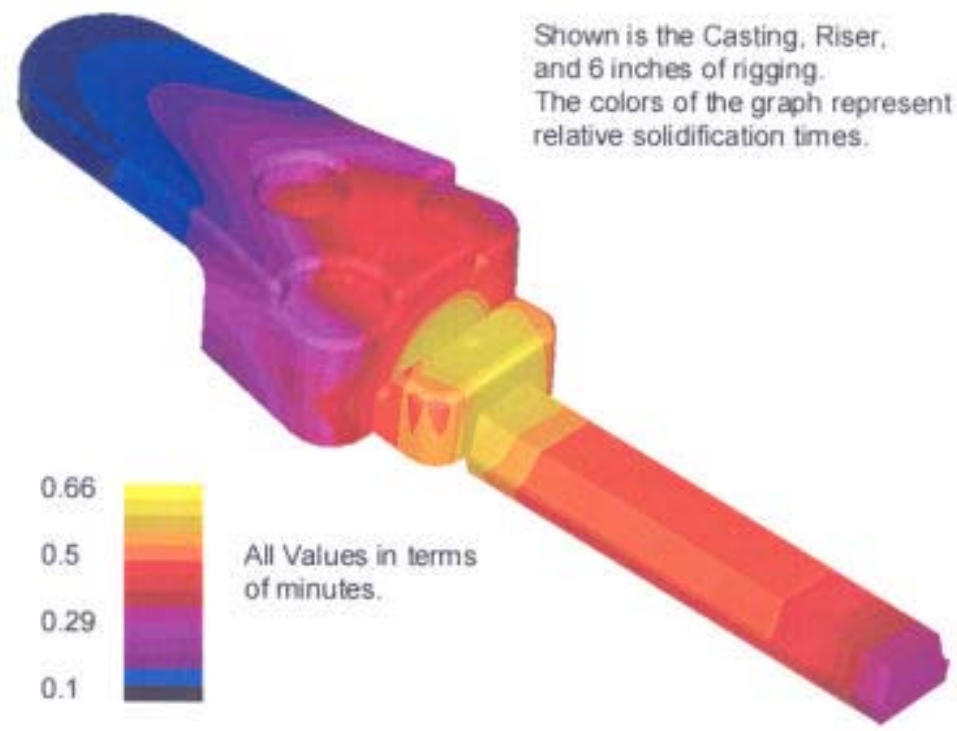

Side View of the Plane of Symmetry.

Relative Solidification times are shown by the colors of the graph.

Deep Blue froze first. Yellow froze last.

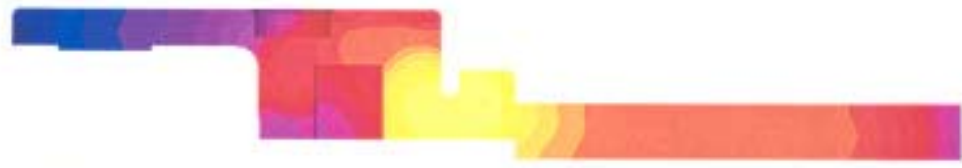

0.66

0.5 All Values in terms of minutes.

0.29

0.1

Figure A2-1. Result of simulation with no choke in the gate. 


\section{Isometric View of the Model}

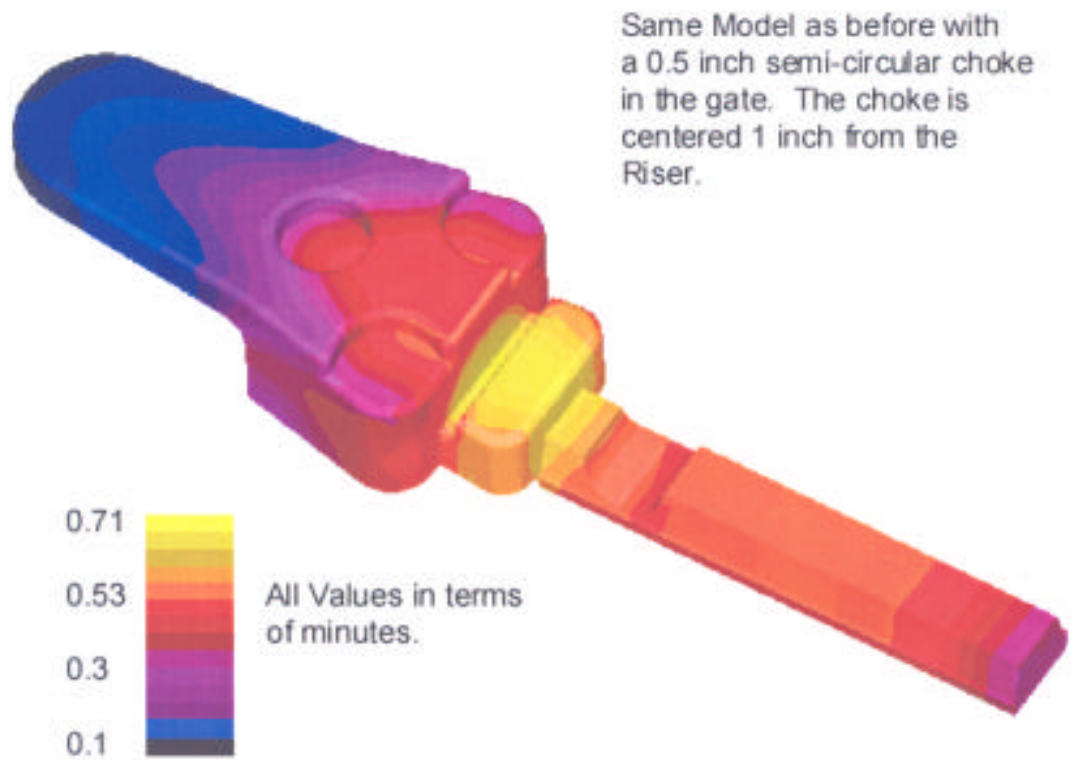

Side View of the Plane of Symmetry.

Colors represent relative solidification times.
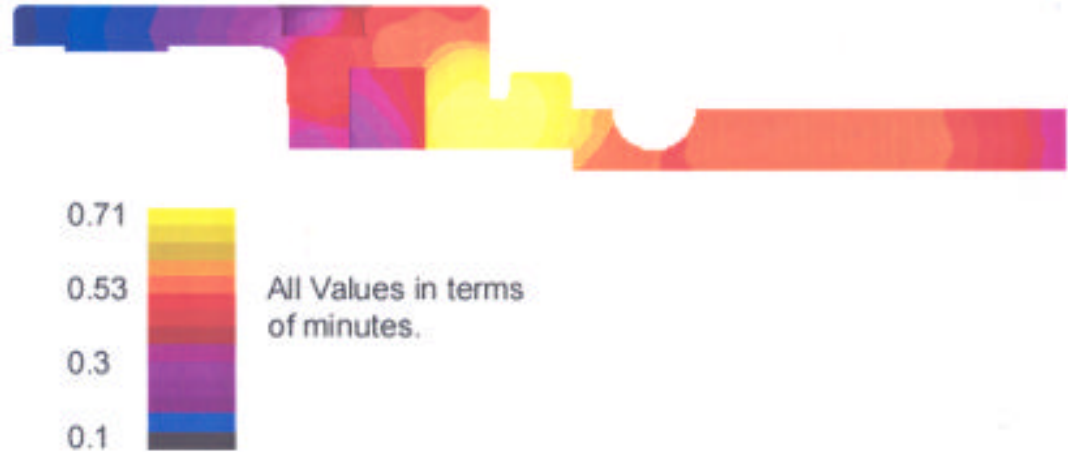

Figure A2-2. Result of simulation with 0.5 inch semicircular choke centered 1 inch from the riser in gate. 


\section{Isometric View of the Model}

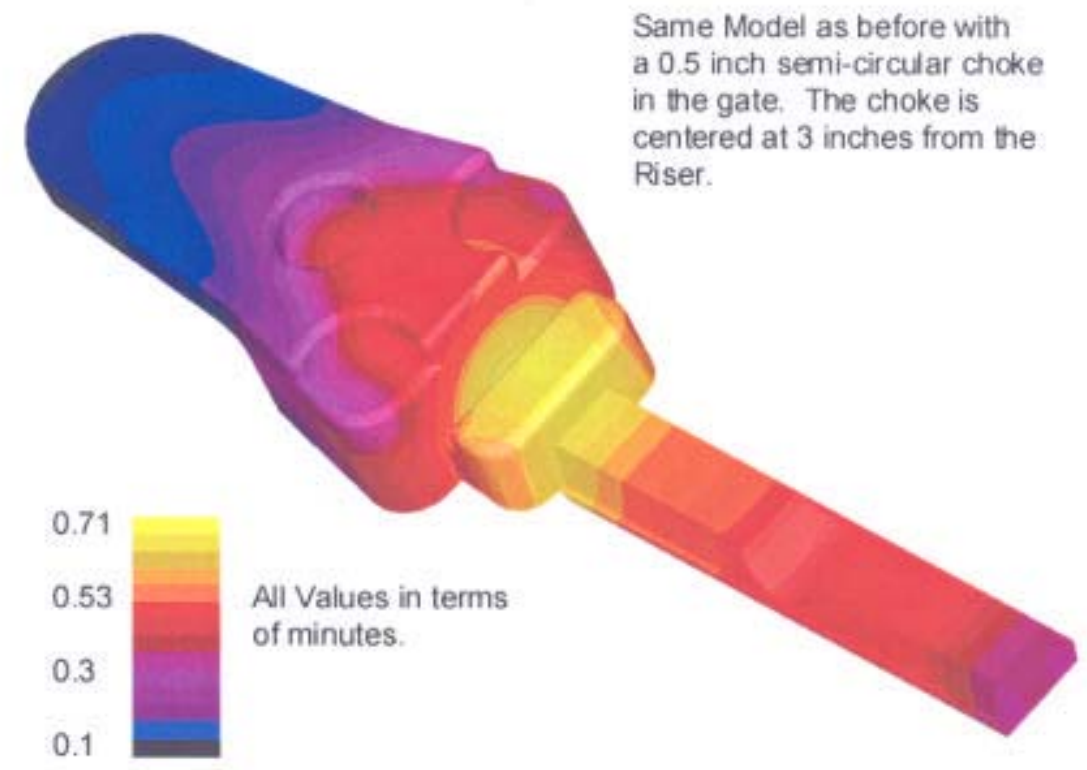

Side View of the Plane of Symmetry.

Colors represent relative solidification times.
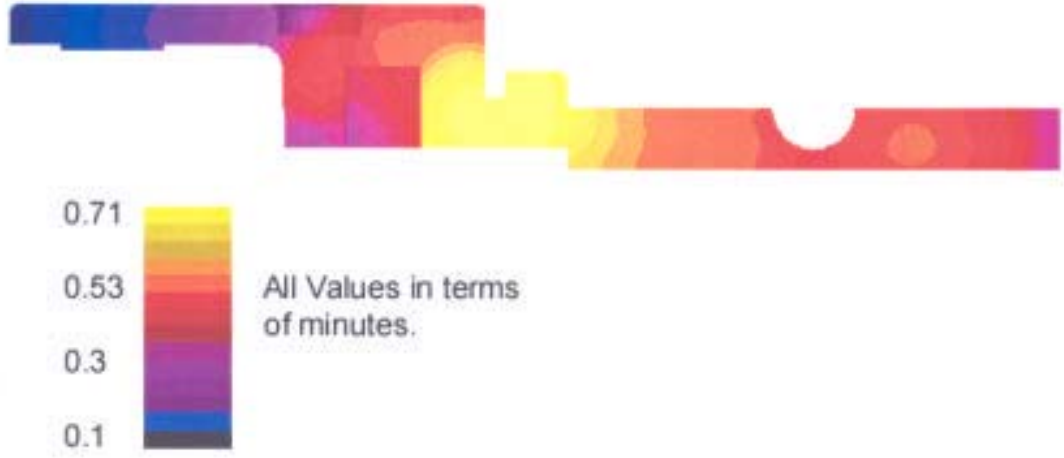

Figure A2-3. Result of simulation with 0.5 inch semicirclar choke centered 3 inch from the riser in the gate. 


\title{
APPENDIX 3. THEORETICAL DENSITY DETERMINATION FOR SECONDARY ALUMINUM ALLOYS
}

\author{
S.T. McClain, A.S. McClain, J.T. Berry
}

\begin{abstract}
The deleterious effects of dispersed or micro-porosity in cast aluminum alloys are widely recognized. Ductility and fatigue resistance, in particular, are strongly affected. In the course of investigating improvements in casting techniques it is often necessary to determine the levels and distribution of porosity, as well as its shape and size, within a particular casting. While the porosity level can be evaluated using pyknometry or image analysis techniques, pyknometry techniques are much less time consuming and less expensive than image analysis techniques and are much less affected by the randomness of the porosity location in the sample. In evaluating the porosity using pyknometry, a theoretical density of the alloy must be used. This theoretical density is usually obtained from reference materials, but because of the multiple casting processes experienced by secondary aluminum alloys, their chemical compositions and theoretical densities vary greatly. This paper presents a method for determining the theoretical density of an engineering alloy using the combination of pyknometry and image analysis techniques.

This method can be used to decrease casting evaluation time by analyzing the porosity of one specimen from a casting extensively using image analysis, then using the results to evaluate the rest of the casting specimens using pyknometry. The new method is currently being employed in an investigation of pressurized riser based feeding supported by the USDOE through CMC and guided by the AFS 2-H committee.
\end{abstract}




\section{Introduction}

The formation and diminution of micro-porosity in hypo-eutectic aluminum alloy castings has been the subject of much ongoing research. Not only have mold design techniques been explored, but also many new casting methods, such as counter-gravity and autoclave based methods and the like, have been developed in an attempt to eliminate porosity formation. None of the techniques have completely eliminated the problem. At best, mold design techniques and new casting methods have reduced the amount of porosity formation or controlled the location of the formation of porosity.

Some researchers have suggested that with a perfectly clean and gas free melt, a properly designed mold, together with quiescent pouring and filling, it may be possible to completely eliminate the formation of micro-porosity in aluminum alloy castings. ${ }^{1}$ Unfortunately, these possible porosity-eliminating conditions are often costly or difficult to obtain. Focusing on the quality of the melt, it is much cheaper to cast with secondary alloys than with primary alloys or virgin melts. ${ }^{2}$ Because of their relative costs, many foundries choose to cast with secondary alloys, thus it is necessary to look at ways to control micro-porosity formation in secondary alloys.

A number of researchers have looked at techniques to control porosity formation in secondary alloys. Several of the techniques have proved moderately successful in controlling the amount of porosity formed in the casting, but the question begs itself, "which casting technique best controls the formation of micro-porosity?" This is a difficult question to answer for many reasons. In order to satisfactorily answer this question and also bearing in mind the extremely low levels of porosity sought by the primary customers of today's metal casting industry, a robust but expeditious method of 
determining porosity is necessary which is capable of providing accurate repeatable results.

The two most common techniques used to determine the local level of porosity in a casting, or percentage porosity, are image analysis and pyknometry. Using image analysis, samples from the casting are polished and viewed using a microscope. Images are then taken using image acquisition equipment, or the images are taken using photography, the products of which are then digitized using a scanner. After the images are digitized, the images are analyzed using image analysis software. There are several drawbacks to performing porosity evaluations using image analysis. Complete image analysis systems including microscope, acquisition computer and software are expensive. Furthermore, when attempting to evaluate the porosity of a sample, the researcher may slice though a considerably porous sample and not hit a pore. Related to this fact, the number of fields required for the evaluation of an entire casting has not yet been adequately answered.

Pyknometry is the technique based on comparing the density of a sample to the density of a known liquid using Archimedes' principle of buoyancy. The sample is weighed in air then weighed while submerged in the liquid. If the sample is held in the water using a basket, then the weight of the basket in water must also be considered. Using pyknometry with a basket to hold the sample in water, the following expression is used to determine the density of a sample.

$$
\rho_{s}=\frac{\rho_{w} W_{s}}{W_{s}-\left(W_{s b}-W_{b}\right)}\left(1+\frac{N_{w} D_{b}^{2}}{D_{c}^{2}-N_{w} D_{b}^{2}}\right)
$$

where $\rho_{s}$ is the density of the sample, $\rho_{w}$ is the density of the water, $W_{s}$ is the weight of the sample in air, $W_{s b}$ is the weight of the sample and basket submerged in the liquid, $W_{b}$ 
is the weight of the basket submerged in water, $D_{b}$ is the diameter of the wire used to construct the basket, $D_{c}$ is the diameter of the container used to hold the liquid, and $N_{w}$ is the number of wires used to hold the basket to the balance. More information on the method used for pyknometry can be found in Taylor et al. ${ }^{3}$ The percentage porosity is then found using the following expression.

$$
\% P=\frac{\rho_{t h}-\rho_{s}}{\rho_{t h}} \times 100 \%
$$

where $\% P$ is the percentage porosity of the sample and $\rho_{t h}$ is the theoretical or defect free density of the sample. Pyknometry is simple and inexpensive. Only about one-tenth of the money required to purchase a complete image analysis system is needed to purchase a balance with the accuracy required for weight measurements used in pyknometry.

The principal problem with using pyknometry and in particular with respect to equation (2) is the question of what theoretical density to use. In most references, significant ranges in chemical composition may be reported for a given alloy. For example in the ASM Handbook, Vol. 15, reports that the Cu content of Al 319 can vary from $3 \%$ to $4 \% .{ }^{4}$ The wide range of compositions, especially of heavy elements such as $\mathrm{Cu}, \mathrm{Fe}$, and $\mathrm{Mn}$, cause large variations in theoretical densities. In fact, Sigworth et al. noted that Sr-modified Al 356 castings had significantly higher densities than nonmodified Al 356 castings, ${ }^{5}$ while McClain noted that a particular melt of 356 with a high Fe content had a density greater than the theoretical densities listed in either the ASM Handbook, Vol. 15 or Aluminum: Properties and Physical Metallurgy. ${ }^{6,4,7}$ This leads to problems when trying to evaluate the percentage porosity using equation (1). It may also lead to the erroneous conclusion that negative porosity exists! To circumvent this problem, some researchers have only presented their results in terms of sample density 
rather than porosity. ${ }^{5,8}$ This causes problems when trying to compare two casting methods. If the results of one experiment are presented in terms of densities, they cannot be compared to the results of another experiment performed by another group of researchers even if the two experiments were performed using the same alloy. Because of these problems, a method must be found that can be used to determine the theoretical density of the alloy used in each experiment.

\section{The Proposed Method}

In the course of investigating new casting techniques, test castings are frequently sectioned and samples located at critical locations examined for porosity. Assuming that time were available, the test samples would then be carefully polished and image analysis conducted on a representative number of fields.

More expeditiously, densities of the individual samples would be determined using a pyknometry based technique, following, for example, the method recommended by Taylor et al. and using equation (1). The percentage porosity of one of the samples should then be determined using image analysis. The theoretical density of sample is then determined using the following expression.

$$
\rho_{t h}=\frac{\rho_{s}}{\left(1-\frac{\% P_{i a}}{100}\right)}
$$

where $\% P_{i a}$ is the percentage porosity of the sample as found using image analysis. The percentage porosities of the rest of the samples can then be evaluated employing equation (2) and the calculated theoretical density which was found using equation (3). 
Using this method, casting evaluation time can be greatly reduced. Instead of measuring the percentage porosity of every casting sample using image analysis, only one sample has to be analyzed. For organizations that do not possess an image analysis system, a single sample might be sent to a laboratory that does.

The one question that remains to be answered is "on which sample should the theoretical density determination be performed?" Using uncertainty analysis, it can be shown that the theoretical density calculation should be performed on the sample with the highest density as determined using pyknometry. This is demonstrated in the next section.

\section{Uncertainty Analysis}

Since the actual density of the sample is determined using equation (1), equation (4) expresses the theoretical density completely in terms of measured variables.

$$
\rho_{t h}=\frac{\rho_{w, r e f} W_{s, r e f}}{W_{s, \text { ref }}-\left(W_{s b, r e f}-W_{b, r e f}\right)}\left(1+\frac{N_{w} D_{b}^{2}}{D_{c}^{2}-N_{w} D_{b}^{2}}\right)\left(1-\frac{\% P_{i a}}{100}\right)^{-1}
$$

where the ref subscript indicates that the measurements were made of the reference sample and the $i a$ subscript indicates that the measurement of $\% P$ was made using image analysis. The method of uncertainty analysis follows the method prescribed by Coleman and Steele. ${ }^{9}$ Coleman and Steele suggest determining the total uncertainty in an experimental result by first considering the random uncertainties and systematic uncertainties separately. Random uncertainties of a measurement are statistical estimates of the errors in a measurement that are, as the name implies, random. Systematic uncertainties of a measurement are statistical estimates of errors in a measurement that occur with the same value in repeated readings. Systematic 
uncertainties are also known as "bias" uncertainties. The random uncertainty of the theoretical density is determined using equation (5).

$$
\begin{aligned}
\left(\frac{P_{\rho_{t h}}}{\rho_{t h}}\right)^{2} & =\tilde{\theta}_{\% P_{i a}}^{2}\left(\frac{P_{\% P_{i a}}}{\% P_{i a}}\right)^{2}+\tilde{\theta}_{\rho_{w}}^{2}\left(\frac{P_{\rho_{w, r e f}}}{\rho_{w, r e f}}\right)^{2}+\tilde{\theta}_{W_{s, \text { ref }}}^{2}\left(\frac{P_{W_{s, r e f}}}{W_{s, r e f}}\right)^{2}+\tilde{\theta}_{W_{s b, r e f}}^{2}\left(\frac{P_{W_{s b, r e f}}}{W_{s b, r e f}}\right)^{2} \\
& +\tilde{\theta}_{W_{b, r e f}}^{2}\left(\frac{P_{W_{b, r e f}}}{W_{b, r e f}}\right)^{2}+\tilde{\theta}_{D_{b}}^{2}\left(\frac{P_{D_{b}}}{D_{b}}\right)^{2}+\tilde{\theta}_{D_{c}}^{2}\left(\frac{P_{D_{c}}}{D_{c}}\right)^{2}
\end{aligned}
$$

where $P_{X}$ is the random uncertainty of the measurement of $X$, and $\tilde{\theta}_{X}$ is the percentage uncertainty magnification factor (PUMF) of the measurement of X. The systematic uncertainty of the theoretical density is determined using equation (6).

$$
\begin{aligned}
\left(\frac{B_{\rho_{t h}}}{\rho_{t h}}\right)^{2} & =\tilde{\theta}_{\% P_{i a}}^{2}\left(\frac{B_{\% P_{i a}}}{\% P_{i a}}\right)^{2}+\tilde{\theta}_{\rho_{w}}^{2}\left(\frac{B_{\rho_{w, r e f}}}{\rho_{w, r e f}}\right)^{2}+\tilde{\theta}_{W_{s, r e f}}^{2}\left(\frac{B_{W_{s, r e f}}}{W_{s, r e f}}\right)^{2}+\tilde{\theta}_{W_{s b, r e f}}^{2}\left(\frac{B_{W_{s b, r e f}}}{W_{s b, r e f}}\right)^{2} \\
& +\tilde{\theta}_{W_{b, r e f}}^{2}\left(\frac{B_{W_{b, r e f}}}{W_{b, r e f}}\right)^{2}+\tilde{\theta}_{D_{b}}^{2}\left(\frac{B_{D_{b}}}{D_{b}}\right)^{2}+\tilde{\theta}_{D_{c}}^{2}\left(\frac{B_{D_{c}}}{D_{c}}\right)^{2}+2 \tilde{\theta}_{W_{s, r e f}} \tilde{\theta}_{W_{s b, r e f}}\left(\frac{B_{W_{s, r e f}}}{W_{s, r e f}}\right)\left(\frac{B_{W_{s b, r e f}}}{W_{s b, r e f}}\right) \\
& +2 \tilde{\theta}_{W_{s, \text { ref }}} \tilde{\theta}_{W_{b, r e f}}\left(\frac{B_{W_{s, r e f}}}{W_{s, r e f}}\right)\left(\frac{B_{W_{b, r e f}}}{W_{b, r e f}}\right)+2 \tilde{\theta}_{W_{s b, r e f}} \tilde{\theta}_{W_{b, r e f}}\left(\frac{B_{W_{s b}, r e f}}{W_{s b, r e f}}\right)\left(\frac{B_{W_{b, r e f}}}{W_{b, r e f}}\right)
\end{aligned}
$$

where $B_{X}$ is the systematic uncertainty of the measurement of $X$. The last three terms of equation (6) take into account the fact that the systematic uncertainties of the weight measurements are correlated, or dependent, on one another when all of the weight measurements are made using the same balance. The total uncertainty of the theoretical density, $U_{\rho_{t h}}$, is then determined using equation (7)

$$
\left(\frac{U_{\rho_{t h}}}{\rho_{t h}}\right)^{2}=\left(\frac{P_{\rho_{t h}}}{\rho_{t h}}\right)^{2}+\left(\frac{B_{\rho_{t h}}}{\rho_{t h}}\right)^{2}
$$

The PUMF is also called the normalized sensitivity coefficient. The formula for the PUMF of any measurement $\mathrm{X}$ is presented in equation (8). 


$$
\tilde{\theta}_{X}=\frac{X}{\rho_{t h}} \frac{\partial \rho_{t h}}{\partial X}
$$

The PUMF possesses its name because it describes how the percentage uncertainty of the measurement of $\mathrm{X}$ propagates into a percentage uncertainty in the experimental result. Observing equation (5), if the percentage random uncertainty in $\rho_{w}$ is $3.5 \%$ and the PUMF of $\rho_{w}$ is 1 , then the percentage random uncertainty in $\rho_{t h}$ is at least $3.5 \%$. The same cannot be said for the systematic uncertainty since the correlation terms can actually decrease the systematic uncertainty of $\rho_{t h}$ if the PUMF's of correlated terms are opposite in sign. In any case, the PUMF's indicate how sensitive the theoretical density is to uncertainties in any of the measured variables.

To show that the sample from a casting that has the lowest porosity should be used in the theoretical density determination, the PUMF of the percentage porosity, $\% \mathrm{P}$, can be calculated for a given range of percentage porosities. To perform the analysis, values for the all of the measured variables must be assumed. Typical values determined in the Mechanics and Materials Laboratory at Mississippi State University are used for the example. If water at about $70^{\circ} \mathrm{F}$ is used for the pyknometry, then using the ASTM standard B311-93, the density of water is $0.9980 \mathrm{~g} / \mathrm{cm}^{3}$. Based on the physical dimensions of the pyknometry setup, the optimum sample weight in dry air is about $15 \mathrm{~g}$. The weight of the basket in water is usually about $2.29 \mathrm{~g}$. The diameters of the container, a $200 \mathrm{ml}$ beaker, and basket wire used at MSU are $6.433 \mathrm{~cm}$ and $0.150 \mathrm{~cm}$, respectively. For the calculations, the weight of the sample and basket while submerged in water is then allowed to vary from $11.7803 \mathrm{~g}$ to $11.6679 \mathrm{~g}$; this allows the percentage porosity to vary from $0 \%$ to $2 \%$. The value of the theoretical density of a representative alloy must 
also be chosen to complete the calculations. The value of $2.7200 \mathrm{~g} / \mathrm{cm}^{3}$ was chosen as a representative density for a secondary Al-Si alloy such as 319. The PUMF of the percentage porosity was then calculated using equation (9) and plotted in Figure 1.

$$
\tilde{\theta}_{\% P_{i a}}=\frac{1}{100} \frac{\% P_{i a}}{\rho_{t h}} \frac{\rho_{w} W_{s, r e f}}{W_{s, r e f}-\left(W_{s b, r e f}-W_{b, r e f}\right)}\left(1+\frac{N_{w} D_{b}^{2}}{D_{c}^{2}-N_{w} D_{b}^{2}}\right)\left(1-\frac{\% P_{i a}}{100}\right)^{-2}
$$

From Figure 1, it will be seen that $\tilde{\theta}_{\% P_{i a}}$ is about 0.02 for a percentage porosity of $2 \%$. This means that if the percentage uncertainty in the measured percentage porosity, $P_{\% P_{i a}} / \% P_{i a}$, is $5 \%$, then that will produce only a $0.1 \%$ uncertainty in the theoretical density (not considering the rest of the experimental uncertainties). As the percentage porosity is lowered, the PUMF also decreases. If the percentage porosity of the sample used for theoretical density determination is $0.5 \%$, then $\tilde{\theta}_{\% P_{i a}}$ is about 0.005 . Now, if $P_{\% P_{i a}} / \% P_{i a}$ is $5 \%$, this will produce only a $0.025 \%$ uncertainty in the theoretical density. To look at this another way, if the researcher requires that the percentage uncertainty in the theoretical density be limited to $0.1 \%$, then for a sample that has $2 \%$ porosity, the percentage uncertainty of the measurement of that percentage porosity must be limited to $P_{\% P_{i a}} / \% P_{i a}=5 \%$. For a sample that has $0.5 \%$ porosity, the percentage uncertainty of the measurement of that percentage porosity must be limited to $P_{\% P_{i a}} / \% P_{i a}=20 \%$.

At the same time, it is the experience of the MSU team that higher levels of porosity are often associated with clustering of pores. This clustering can lead to poor repeatability using image analysis (high uncertainty). The MSU team has found that, in general, the lower the level of porosity in the sample, the more evenly distributed the pores are. Thus, samples with lower levels of porosity should have better image analysis 
repeatability, and therefore, lower percentage uncertainty. Considering the problems that the authors have experienced with clustering and considering the trend in the PUMF of $\% P_{i a}$, the authors find that the theoretical density determination should be performed using the sample from a casting that has the highest density.

To demonstrate what magnitude of uncertainties in the theoretical density should be obtained using this method, a complete uncertainty analysis is carried out again using typical uncertainty values determined in the Mechanics and Materials Laboratory at Mississippi State University. At MSU a Mettler H748AR mechanical balance is used for all weight measurements. The manufacturer's specified systematic uncertainty for the balance is $0.0001 \mathrm{~g}$. The random uncertainty of the weight measurements was found by making repeated measurements of each of the weight measurements using a given standard sample. The standard deviation of the repeated measurements multiplied by the Student's t value, based $95 \%$ coverage and the number of repeated measurements. The standard used is an $18 \mathrm{~g}$ cylinder of wrought aluminum 6061-T6. The measurements of the standard are repeated on a regular basis. Using all of the measurements of the standard over time, the random uncertainty of a single weight measurement in dry air is $0.0001 \mathrm{~g}$. The random uncertainty of any single weight measurement in water $\left(W_{s b}\right.$ or $\left.W_{b}\right)$ is $0.0050 \mathrm{~g}$. The high random uncertainty of the weight measurements in water as compared to the dry air measurements is caused by many factors such as water currents and bubble attachment to the sample. These factors are discussed more thoroughly by Taylor et al. ${ }^{3}$ To reduce the high random uncertainties in the measurements of $W_{s b, r e f}$ and $W_{b, r e f}$, each measurement is repeated multiple times. For $N$ repeated readings of a weight 
measurement in water, $W_{W}$, the random uncertainty of the mean of the readings is related to the random uncertainty of any one measurement using equation (10).

$$
P_{\bar{W}_{W}}=\frac{P_{W_{W}}}{\sqrt{N}}
$$

where the over bar represents the mean reading of $W_{W}$. The average of the three measurements is thus used for any measurement taken in water. This lowers the random uncertainty of any mean value of three readings of $W_{s b}$ or $W_{b}$ to $0.0029 \mathrm{~g}$.

The diameter of the container and the diameter of the wire were measured with a digital caliper. The systematic uncertainty of each of the caliper measurements is taken to be the resolution of the caliper, $0.001 \mathrm{~cm}$. The random uncertainties of the diameter measurements were found by making fifteen repeated readings of each measurement. The random uncertainty was then found using equation (11).

$$
P_{X}=\frac{t_{v, 95 \%} S_{X}}{\sqrt{N}}
$$

where $t_{v, 95 \%}$ is the Student's t value based on the degrees of freedom, $v=N-1$, and $95 \%$ level of confidence, $S_{X}$ is the sample standard deviation of the measurement of $X$, and $N$ is the number of samples taken. For the diameter of the basket and the diameter of the wire the random uncertainties were determined to be $0.106 \mathrm{~cm}$ and $0.004 \mathrm{~cm}$, respectively.

The density of the water used in the pyknometry analysis comes from a table in ASTM standard B311-93. The table lists the density of the water versus temperature. The uncertainty in the density value thus comes from the thermometer used to measure the temperature of the water. The thermometer used at MSU has a systematic uncertainty $0.5^{\circ} \mathrm{C}$ and a random uncertainty of $0.5^{\circ} \mathrm{C}$. These temperature uncertainties correspond 
to a systematic uncertainty in the density of $0.0001 \mathrm{~g} / \mathrm{ml}$ and a random uncertainty in the density of $0.0001 \mathrm{~g} / \mathrm{ml}$.

The method used to determine the uncertainty associated with the measurement of the percentage porosity has had little discussion in previous research. The authors assume that any systematic uncertainties are on the order of a few pixels of the digitized image and are thus negligible compared to the random uncertainty. The random uncertainty is determined using equation (11), where $N$ is the number of fields taken from the sample and $S_{X}$ is the sample standard deviation of the percentage porosity of each field. Because of the method used for calculating the random uncertainty in $\% P_{i a}$, the percentage uncertainty of $\% P_{i a}$ can have a wide range of values. Figure 2 shows the expected uncertainties in the calculated theoretical density for percentage uncertainty of $\% P_{i a}$ values of $5 \%, 7.5 \%$, and $10 \%$.

Figure 2 shows that the expected uncertainties in the theoretical density are unaffected by the percentage porosity in $\% P_{i a}$ when the value of $\% P_{i a}$ is less than approximately $0.5 \%$. This reinforces the observation above that; the sample with the highest density should be used for the theoretical density determination using equation (3). When the sample with the highest density has $\% P_{i a}$ of $0.5 \%$ or less, the expected uncertainty in the theoretical density is approximately $0.0020 \mathrm{~g} / \mathrm{ml}$. For reference porosities above $0.5 \%$, the expected uncertainty in the theoretical density is highly dependent on the percentage uncertainty in $\% P_{i a}$.

Table 1 summarizes the nominal values and uncertainties used for the uncertainty analysis. More information on uncertainty analysis and estimating random and systematic uncertainties can be found in references 10 and 11. 


\section{Expected Porosity Results}

This paper would be incomplete without providing some discussion of what type of percentage porosity results should be expected using the proposed method. To express the measurement of the percentage porosity of a sample in terms of measured variables, equations (1) and (4) are substituted into equation (2) to yield equation (12).

$$
\% P_{j}=100-100 \frac{W_{s, r e f}-\left(W_{s b, r e f}-W_{b, r e f}\right)}{W_{s, j}-\left(W_{s b, j}-W_{b, j}\right)} \frac{W_{s, j}}{W_{s, r e f}} \frac{\rho_{w, j}}{\rho_{w, r e f}}\left(1-\frac{\% P_{i a}}{100}\right)
$$

where the subscript $j$ refers to made for any sample from a given casting other than the reference sample. It should be noted that equation (12) does not depend on the measurements of $D_{c}$ and $D_{b}$, while the densities do not cancel out in equation (12). Since the diameter measurements do not change for the given apparatus, these terms cancel in equation (12). The density measurements, on the other hand, do not cancel because they are two distinct measurements. The values of $\rho_{w, j}$ and $\rho_{w, r e f}$ may not always be equal.

An uncertainty analysis was also performed on equation (12) for the situation when the $j^{\text {th }}$ sample has a weight of $15 \mathrm{~g}$. The value of $\% P_{i a}$ was selected as $0.2 \%$. The weight of the $j^{\text {th }}$ sample in water, $W_{s b, j}$, was varied from $11.4904 \mathrm{~g}$ to $11.7693 \mathrm{~g}$ to produce values of $\% P_{j}$ from $0.2 \%$ to $5 \%$. The remaining values and uncertainties are presented in Table 2. Just as with the analysis of equation (4), the uncertainty analysis of equation (12) follows the method prescribed by Coleman and Steele. ${ }^{9}$ The results of the uncertainty analysis are plotted in Figure 3 for values of the percentage porosity in $\% P_{i a}$ of $5 \%, 7.5 \%$, and $10 \%$.

Figure 3 shows that method used for determining the theoretical density should be able to produce percentage porosity measurements with uncertainties, $U_{\% P j}$, around $\pm 0.1 \%$. This reinforces the conclusions of Taylor et al. that the method of percentage 
porosity determination using pyknometry is useful when the required resolution is not less than $\pm 0.1 \%$ (again, this value is of $U_{\% P j}$ and not of $U_{\% P_{j}} / \% P_{j}$ ). ${ }^{3}$

\section{Conclusions}

A method for determining the theoretical or defect free density of a casting for use in percentage porosity evaluation was presented. The proposed theoretical density determination technique involves the following steps:

1. Section a given casting into many small samples.

2. Using pyknometry and equation (1), determine the density of each of the samples.

3. Take the sample with the highest density and perform an image analysis evaluation of the percentage porosity of that sample.

4. Using equation (3), calculate the theoretical density of the sample.

The measurements made in determining the theoretical density can then used to determine the percentage porosity of the rest of the samples using equation (12). The theoretical density can also be used to explore concepts like macro-segregation within the casting, since segregation of heavier alloying elements will clearly affect local theoretical density. When the method is used solely for theoretical density determination, the expected uncertainties are around $0.002 \mathrm{~g} / \mathrm{ml}$ when the uncertainty in the percentage uncertainty in the percentage porosity, as evaluated in step 3, is less than $10 \%$. When the method is used to determine the percentage porosities of the remaining samples from the casting, the expected uncertainties in the percentage porosity values should be around $\pm 0.1 \%$ using the equipment located in the Mechanics and Materials Laboratory at Mississippi State University. 
Acknowledgements

The authors thank the United States Department of Energy, the CMC, the American Foundrymen's Society, and the Department of Mechanical Engineering at Mississippi State University for partial financial support of this work. 


\section{References}

[1] J. Campbell, "The 10 Casting Rules: Guidelines for the Reliable Production of Reliable Castings; A Draft Process Specification," $1^{\text {st }}$ International Conference on Gating, Filling and Feeding of Aluminum Castings, American Foundrymen's Society, Nashville, TN, Oct. 11-13, 1999.

[2] J. A. Taylor, "Metal-Related Castability Effects in Aluminum Foundry Alloys." Cast Metals, 1995, Vol. 8, No. 4, 225-252.

[3] R. P. Taylor, S. T. McClain, and J. T. Berry, "Uncertainty Analysis of MetalCasting Porosity Measurements Using Archimedes' Principle,” International Journal of Cast Metals Research, 1999, Vol. 11, 247-257.

[4] Metals Handbook, Volume 15, "Casting," ASM International, Metals Park, OH, 1988.

[5] G. K. Sigworth, C. Wang, H. Huang, and J. T. Berry, "Porosity Formation in Modified and Unmodified Al-Si Alloy Castings," AFS Transactions, 1994, Vol. $102,245-261$.

[6] S. T. McClain, A Study of Porosity Quantification Techniques and Pore Morphology in Aluminum Alloy Castings, MS Thesis, 1997, Department of Mechanical Engineering, Mississippi State University, Mississippi State, MS, 39762.

[7] J. E. Hatch, Aluminum: Properties and Physical Metallurgy, American Society for Metals, Metals Park, OH, 1984.

[8] A. K. Dahle, L. Arnberg, and D. Apelian, "Burst Feeding and its Role in Porosity Formation During Solidification of Aluminum Foundry Alloys," $101^{\text {st }}$ Casting Congress, American Foundrymen's Society, Seattle WA, April 20-23, 1997.

[9] H. W. Coleman and W. G. Steele, Experimentation and Uncertainty Analysis for Engineers, J. Wiley and Sons, New York, $2^{\text {nd }}$ edition, 1999.

[10] H. W. Coleman and W. G. Steele, "Engineering Application of Experimental Uncertainty Analysis,” AIAA Journal, 1995, Vol. 33, No. 10, 1888-1896.

[11] K. K. Brown, H. W. Coleman, W. G. Steele, and R. P. Taylor, "Evaluation of Correlated Bias Approximations in Experimental Uncertainty Analysis" AIAA Journal, 1996, Vol. 34, No. 5, 1013-1018. 


\section{Table and Figure Captions}

Table 1. Nominal Values and Uncertainties Used in the Theoretical Density Determination Uncertainty Analysis

Table 2. Nominal Values and Uncertainties Used in the Percentage Porosity Uncertainty Analysis

Figure 1. The Percentage Uncertainty Magnification Factor of $\% P_{i a}$ as $\% P_{i a}$ Varies from 0 to $2 \%$

Figure 2. The Expected Uncertainty in the Calculated Theoretical Density as $\% P_{i a}$ Varies from $0 \%$ to $2 \%$ for $U_{\% \text { Pia }} / \% P_{i a}$ of $5 \%, 7.5 \%$, and $10 \%$

Figure 3. The Expected Uncertainty in Percentage Porosity Values Found Using the New Method as a function of the Percentage Porosity of the $j^{\text {th }}$ sample for $U_{\% \text { Pial }}$ $\% P_{i a}$ of $5 \%, 7.5 \%$, and $10 \%$ 
Table 1. Nominal Values and Uncertainties Used in the Theoretical Density Determination Uncertainty Analysis

\begin{tabular}{|l|l|l|l|}
\hline Measurement & Nominal Value & $\begin{array}{l}\text { Systematic } \\
\text { Uncertainty }\end{array}$ & Random Uncertainty \\
\hline$W_{s, \text { ref }}$ & $15 \mathrm{~g}$ & $0.0001 \mathrm{~g}$ & $0.0001 \mathrm{~g}$ \\
\hline$W_{\text {sb,ref }}$ & $\begin{array}{l}11.7803 \mathrm{~g} \text { to } \\
11.6679 \mathrm{~g}\end{array}$ & $0.0001 \mathrm{~g}$ & $0.0029 \mathrm{~g}$ \\
\hline$W_{b, r e f}$ & $2.29 \mathrm{~g}$ & $0.0001 \mathrm{~g}$ & $0.0029 \mathrm{~g}$ \\
\hline$\% P_{i a}$ & 0 to $2 \%$ & Negligible & $\frac{U_{\% P_{i a}}}{\%}=5 \%, 7.5 \%, 10 \%$ \\
\hline$D_{c}$ & & & $0.106 \mathrm{~cm}$ \\
\hline$D_{b}$ & $6.433 \mathrm{~cm}$ & $0.001 \mathrm{~cm}$ & $0.004 \mathrm{~cm}$ \\
\hline$N_{w}$ & $0.150 \mathrm{~cm}$ & $0.001 \mathrm{~cm}$ & - \\
\hline$\rho_{w, \text { ref }}$ & 2 & - & $0.0001 \mathrm{~g} / \mathrm{ml}$ \\
\hline
\end{tabular}


Table 2. Nominal Values and Uncertainties Used in the Percentage Porosity Uncertainty Analysis

\begin{tabular}{|c|c|c|c|}
\hline Measurement & Nominal Value & $\begin{array}{l}\text { Systematic } \\
\text { Uncertainty }\end{array}$ & Random Uncertainty \\
\hline$W_{s, r e f}$ & $15 \mathrm{~g}$ & $0.0001 \mathrm{~g}$ & $0.0001 \mathrm{~g}$ \\
\hline$W_{s b, r e f}$ & $11.7693 \mathrm{~g}$ & $0.0001 \mathrm{~g}$ & $0.0029 \mathrm{~g}$ \\
\hline$W_{b, r e f}$ & $2.29 \mathrm{~g}$ & $0.0001 \mathrm{~g}$ & $0.0029 \mathrm{~g}$ \\
\hline$W_{s, j}$ & $15 \mathrm{~g}$ & $0.0001 \mathrm{~g}$ & $0.0001 \mathrm{~g}$ \\
\hline$W_{s b, j}$ & $\begin{array}{l}11.4904 \mathrm{~g} \text { to } \\
11.7693 \mathrm{~g}\end{array}$ & $0.0001 \mathrm{~g}$ & $0.0029 \mathrm{~g}$ \\
\hline$W_{b, j}$ & $2.29 \mathrm{~g}$ & $0.0001 \mathrm{~g}$ & $0.0029 \mathrm{~g}$ \\
\hline$\% P_{i a}$ & $0.2 \%$ & Negligible & $\frac{U_{\% P_{i a}}}{\% P_{i a}}=5 \%, 7.5 \%, 10 \%$ \\
\hline$\% P_{j}$ & 0.2 to $5 \%$ & see Fig. 3 & see Fig. 3 \\
\hline$\rho_{w, r e f}$ & $0.9980 \mathrm{~g} / \mathrm{ml}$ & $0.0001 \mathrm{~g} / \mathrm{ml}$ & $0.0001 \mathrm{~g} / \mathrm{ml}$ \\
\hline$\rho_{w, j}$ & $0.9980 \mathrm{~g} / \mathrm{ml}$ & $0.0001 \mathrm{~g} / \mathrm{ml}$ & $0.0001 \mathrm{~g} / \mathrm{ml}$ \\
\hline
\end{tabular}




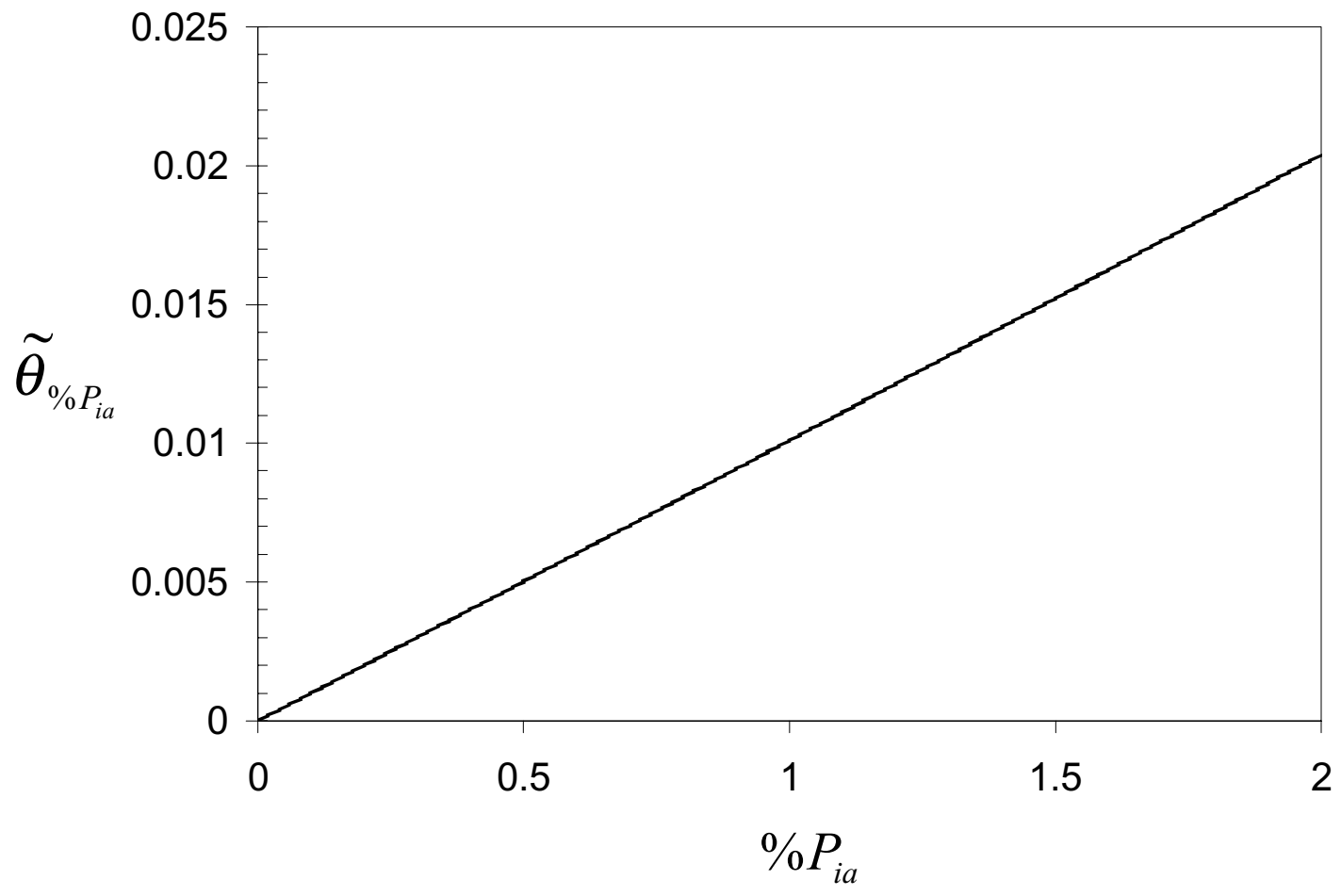

Figure 1. The Percentage Uncertainty Magnification Factor of $\% P_{i a}$ as $\% P_{i a}$ Varies from 0 to $2 \%$ 


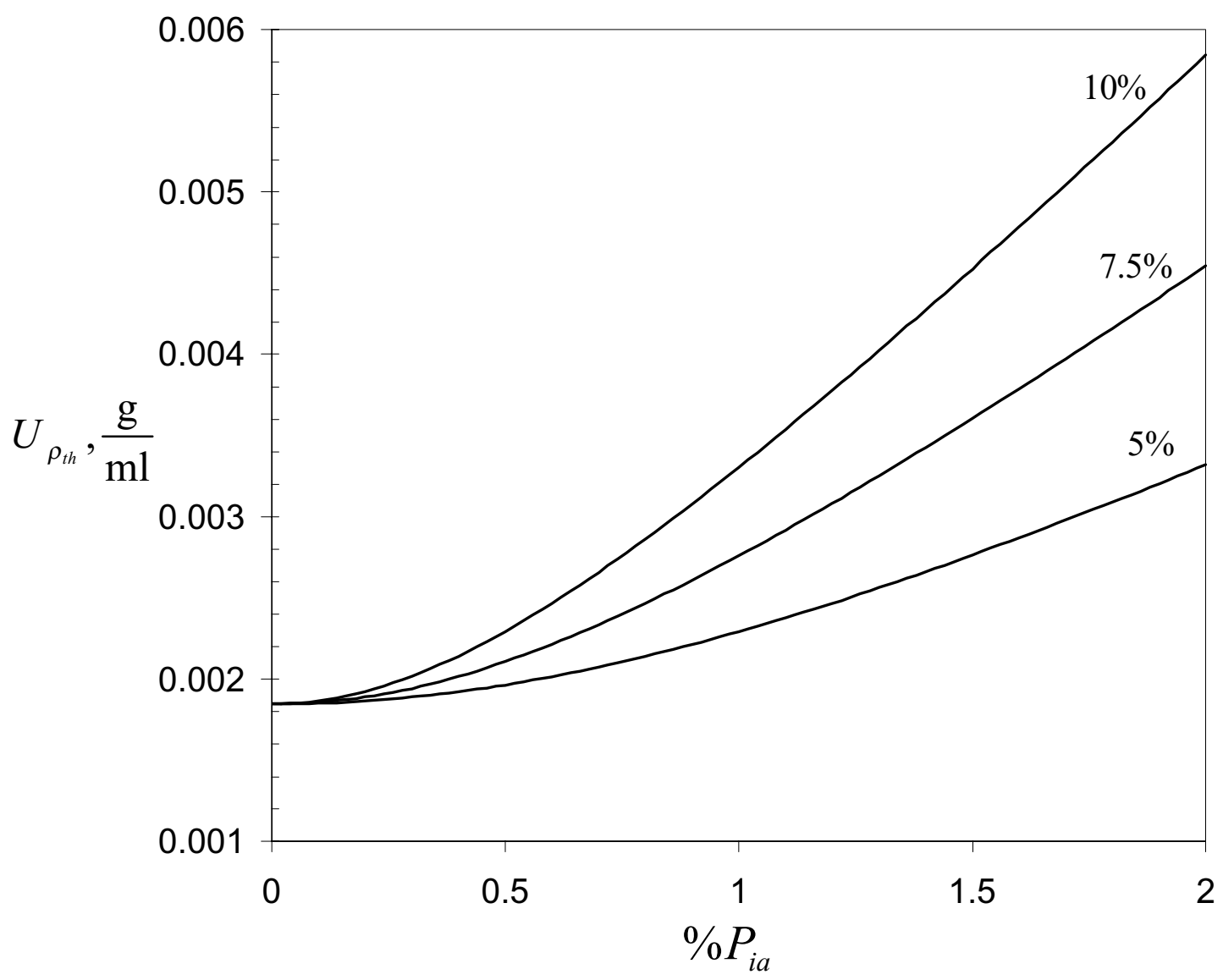

Figure 2. The Expected Uncertainty in the Calculated Theoretical Density as $\% P_{i a}$ Varies from $0 \%$ to $2 \%$ for $U_{\% P i a} / \% P_{i a}$ of $5 \%, 7.5 \%$, and $10 \%$ 


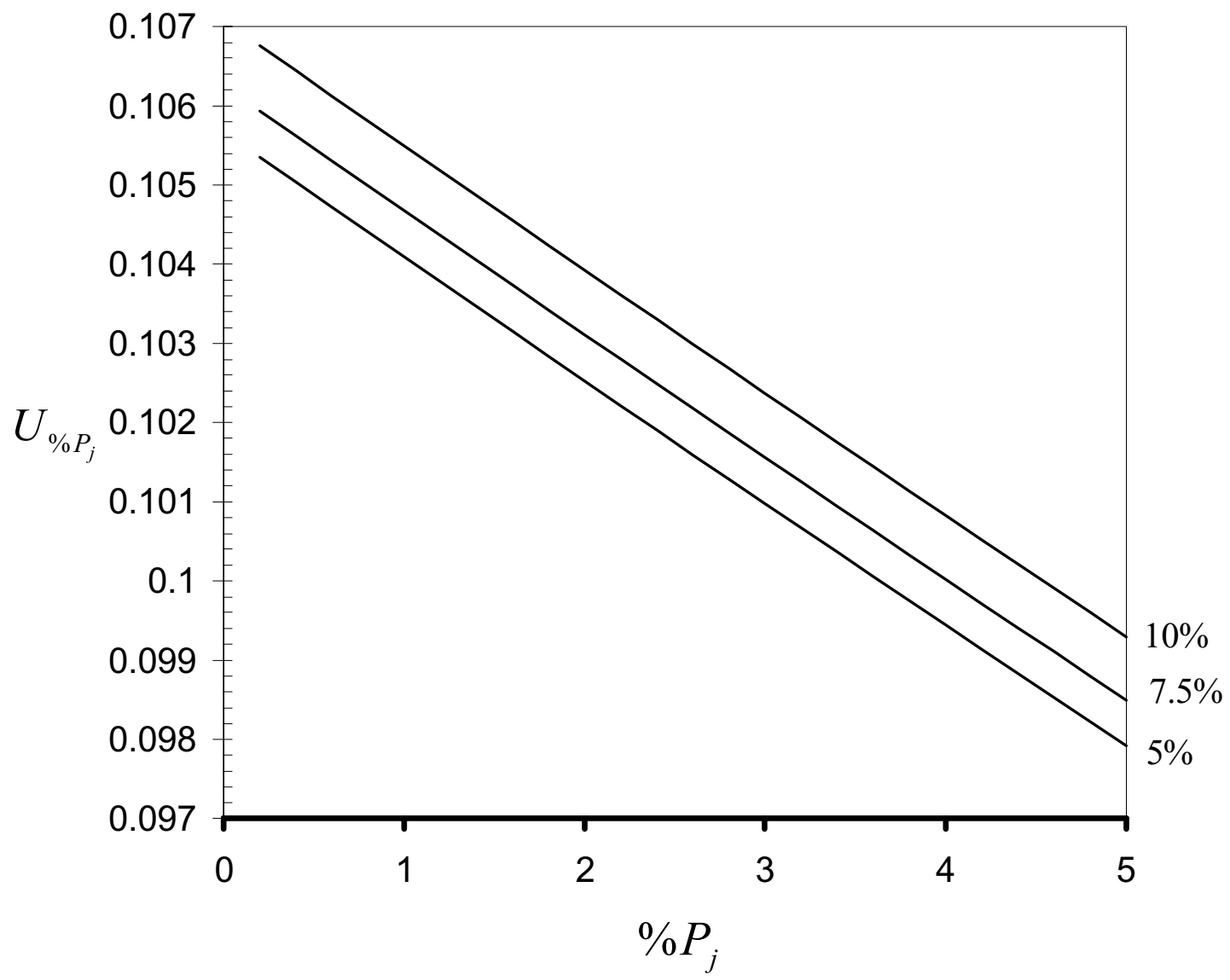

Figure 3. The Expected Uncertainty in Percentage Porosity Values Found Using the New Method as a function of the Percentage Porosity of the $j^{\text {th }}$ sample for $U_{\% \text { Pial }}$ $\% P_{i a}$ of $5 \%, 7.5 \%$, and $10 \%$ 


\title{
APPENDIX 4. COMPARISON AND CRITICISM OF CASTING CRITERIA FUNCTIONS
}

\author{
R.P. Taylor, J. Shenefelt, J.T. Berry, R. Luck
}

\begin{abstract}
Commercial software packages enable the thermal environment within shaped castings to be determined provided the boundary conditions are well understood. Criteria functions (CFs) based on the thermal environment provide a means for estimating shrinkage porosity within a casting. However, current CFs do not account for gas driven porosity forming within the casting. This paper reviews the CFs and discusses their inherent shortcomings concerning hydrogen evolution in aluminum-copper and aluminum-silicon alloys. Recommendations for future work are made.
\end{abstract}

\section{NOMENCLATURE}

A correlation parameter in equation (41)

a correlation parameter in equation (41)

b correlation parameter in equation (41)

$\mathrm{CF}$ criteria function value

$\mathrm{D}_{\mathrm{o}} \quad$ dendrite length scale, equiaxed

$\mathrm{D}_{\mathrm{p}}$ dendrite primary arm spacing, columnar

$\mathrm{f}_{\text {drag }} \quad$ friction drag term

$\mathrm{f}_{\mathrm{L}} \quad$ local liquid fraction

$\mathrm{f}_{\mathrm{g}} \quad$ local solid fraction

G temperature gradient $=\frac{\mathrm{dT}}{\mathrm{dx}}$

K permeability

L thickness of mushy zone

$\mathrm{M}_{(,)} \quad$ material parameter

$\mathrm{P}$ pressure

p porosity

$\mathrm{R} \quad$ cooling rate $=\frac{\mathrm{dT}}{\mathrm{dt}}$

$\mathrm{R}_{2} \quad$ statistical correlation coefficient

$\mathrm{t}$ time from start of solidification

$\mathrm{x} \quad$ distance from chill

$\mathrm{V}$ local liquid superficial velocity relative to the solidification front

$\mathrm{V}_{\mathrm{s}} \quad$ velocity of the solidification front 


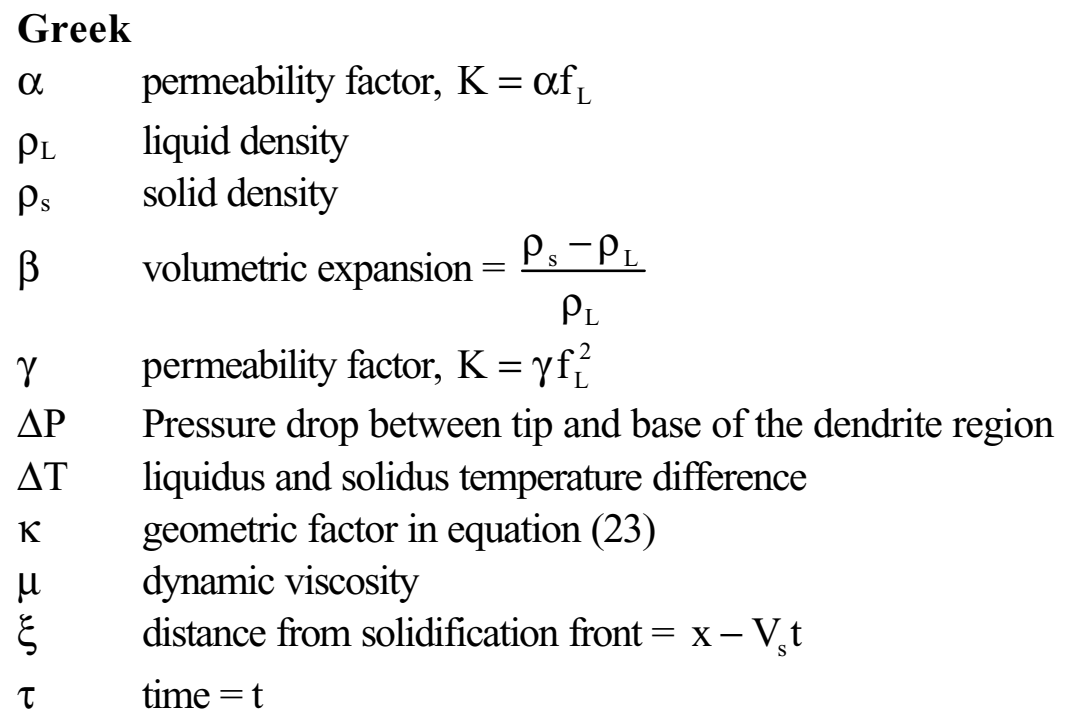

\section{INTRODUCTION}

A common problem with many aluminum alloys that possess a measurable freezing range is dispersed void formation or microporosity, whereas eutectic compositions or pure metals are likely to form macroporosity, manifest as centerline or under riser shrinkage. The shrinkage porosity phenomenon is thus freezing range dependent for many sand-cast alloys. Solidification related thermal conditions are employed to predict the distribution of macroporosity in eutectic or short-freezing alloys, such as low carbon steel. The distribution of microporosity in long-freezing range $\mathrm{Al}-\mathrm{Si}$ and $\mathrm{Al}-\mathrm{Cu}$ alloys has been more difficult to predict because here the formation of microporosity involves incorporating dissolved hydrogen in the modeling procedure.

A number of models based on conservation of mass and momentum for flow through porous media have been developed over the last 35 years. In 1966, Piwonka and Flemings employed a Darcy flow model to pore formation and solidification [1]. In 1980 the term Criteria Function (CF) appeared at the Modeling of Casting and Welding Processes Conference in Rindge, NH. Shortly thereafter (1982) Niyama et al. derived a criteria function to aid in determining whether or not porosity may develop in steel alloys [2]. Following Niyama's analysis, Lee et al. (1990) and Suri $(1993,1995)$ developed two different criteria functions [3, 4, 5]. More recently, other authors, including Poirier, Kuznetsov et al., Huang et al. have developed more complete models of microporosity based on fluid, thermal and thermodynamic relationships $[6,7,8]$. These models include complete phenomenological mechanism and yield a great deal of insight into the formation of porosity. However, the models contain empirical information that may or may not be available for an alloy of interest.

At the time of introduction of $\mathrm{CFs}$, the evolution of microstructure of a casting had already been established as a function of several thermal parameters, and controlling these parameters has been found to improve casting quality. However, criteria for avoiding microporosity are less well established. The authors envisioned that combining experimental thermal parameter data and data determined from computer simulation would lead to more sound castings. The subsequent evolution of the Niyama criterion in 1982 redoubled efforts in this area. Such CFs are currently employed to reduce the level of microporosity in long freezing range alloys. This is especially relevant to the automotive and aerospace industries that are currently replacing components 
with light alloy castings, where the performance of these products is adversely affected by porosity. Subsequent investigation by Mississippi State University's casting group indicates the thermal parameters alone do not provide enough information to properly predict microporosity in aluminum alloys, although they provide general guidance $[9,10]$.

In order to reduce the propensity of a casting process to produce unacceptable levels of porosity, a number of criteria functions have been proposed. These CFs are combinations of casting thermal and material parameters that are related to the porous (interdendritic) feeding capabilities of the mushy zone. There should exist a critical value for a CF that predicts a lack of interdendritic feeding, and thus the onset of feedingresistance porosity. Once this value is determined, the extent of the feeding-resistance porosity should correlate with the CF. Three criteria functions are considered herein:

1) Niyama et al. (1982)

$$
\frac{\mathrm{G}}{\mathrm{R}} \text { or } \quad \frac{\mathrm{G}^{2}}{\mathrm{R}} \sim \frac{\mathrm{G}}{\mathrm{V}_{\mathrm{s}}}
$$

2) Lee et al. (1990)

$$
\frac{V_{s}}{G t^{\frac{2}{3}}} \sim\left(\frac{V_{s}^{5}}{G}\right)^{\frac{1}{3}}
$$

3) Suri (1993) and Suri et al. (1995)

$$
\frac{1}{\mathrm{G}^{\mathrm{n}} \mathrm{V}_{\mathrm{s}}^{\mathrm{m}}} \sim\left\{\begin{array}{cl}
\frac{\mathrm{V}_{\mathrm{s}}^{1.63}}{\mathrm{G}^{0.052}}, & \text { dimensiona } 1 \\
\frac{1}{\mathrm{~V}_{\mathrm{s}}^{0.37} \mathrm{G}^{0.052}}, & \text { nondimensi onal }
\end{array}\right.
$$

All three CFs were derived from understandable fundamental reasoning based on the one-dimensional continuity and momentum flow equations. These derivations are reproduced below to show the three CFs mainly differ on the assumption of the permeability parameter.

The CFs are then assessed for their ability to predict porosity by correlating data from Lee et al. (1990), Suri (1993) and Kao et al. (1995) using each criteria function and comparing the results. After the comparison, a discussion of more recent microporosity models is discussed in relation to the CFs.

\section{ANALYSIS}

The derivations are taken in the order Niyama, Lee and Suri. Figure 1 shows a schematic diagram of the assumed columnar dendritic system. In the models, solid cones approximate the dendrites; secondary arms are ignored.

\section{Niyama et al. :}

The starting point for both derivations in the one-dimensional continuity equation for a liquid 


$$
\frac{\partial \rho_{\mathrm{L}} \mathrm{f}_{\mathrm{L}}}{\partial \mathrm{t}}+\frac{\partial \rho_{\mathrm{L}} \mathrm{V}}{\partial \mathrm{x}}=-\frac{\partial \rho_{\mathrm{s}} \mathrm{f}_{\mathrm{s}}}{\partial \mathrm{t}}
$$

The coordinates are transformed into the front-fixed coordinates $(\xi, \tau)$ using the chain rule

$$
\begin{gathered}
\frac{\partial}{\partial \mathrm{t}}=\frac{\partial \tau}{\partial \mathrm{t}} \frac{\partial}{\partial \tau}+\frac{\partial \xi}{\partial \mathrm{t}} \frac{\partial}{\partial \xi}=1 \frac{\partial}{\partial \tau}-\mathrm{V}_{\mathrm{s}} \frac{\partial}{\partial \xi} \\
\frac{\partial}{\partial x}=\frac{\partial \tau}{\partial x} \frac{\partial}{\partial \tau}+\frac{\partial \xi}{\partial x} \frac{\partial}{\partial \xi}=0 \frac{\partial}{\partial \tau}+1 \frac{\partial}{\partial \xi}
\end{gathered}
$$

Under steady state conditions to an observer traveling with the front $\mathrm{B}-\mathrm{B}$, all $\partial / \partial \tau=0$, and equation (4) becomes

$$
-\rho_{\mathrm{L}} \mathrm{V}_{\mathrm{s}} \frac{\partial \mathrm{f}_{\mathrm{L}}}{\partial \xi}+\rho_{\mathrm{L}} \frac{\partial \mathrm{V}}{\partial \xi}=\rho_{\mathrm{s}} \mathrm{V}_{\mathrm{s}} \frac{\partial \mathrm{f}_{\mathrm{s}}}{\partial \xi}=-\rho_{\mathrm{s}} \mathrm{V}_{\mathrm{s}} \frac{\partial \mathrm{f}_{\mathrm{L}}}{\partial \xi}
$$

where the densities are assumed constant. Collecting terms and simplifying

$$
\frac{\partial \mathrm{V}}{\partial \xi}=-\frac{\rho_{\mathrm{s}}-\rho_{\mathrm{L}}}{\rho_{\mathrm{L}}} \mathrm{V}_{\mathrm{s}} \frac{\partial \mathrm{f}_{\mathrm{L}}}{\partial \xi}=-\beta \mathrm{V}_{\mathrm{s}} \frac{\partial \mathrm{f}_{\mathrm{L}}}{\partial \xi}
$$

Integration yields

$$
\mathrm{V}=-\beta \mathrm{V}_{\mathrm{s}} \mathrm{f}_{\mathrm{L}}(\xi)+\mathrm{C}
$$

Applying the initial condition $\mathrm{V}=-\beta \mathrm{V}_{\mathrm{s}}$ and $\mathrm{f}_{\mathrm{L}}=1$ at $\xi=\mathrm{L}$ results in $\mathrm{C}=0$

$$
\mathrm{V}=-\beta \mathrm{V}_{\mathrm{s}} \mathrm{f}_{\mathrm{L}}(\xi)
$$

When Darcy's law is employed to account for the flow in the dendritic region, the momentum equation reduces to

$$
\frac{\mathrm{dP}}{\mathrm{d} \xi}=\left\{\begin{array}{cc}
-\frac{\mu}{\mathrm{K}} \mathrm{V}, & \text { Darcy's Law } \\
\frac{\mu}{\mathrm{K}} \beta \mathrm{V}_{\mathrm{s}} \mathrm{f}_{\mathrm{L}}
\end{array}\right.
$$

Niyama et al. assumed the permeability parameter $K$ is linearly related to $f_{L}, K=\alpha f_{L}$. Applying this assumption yields 


$$
\frac{\mathrm{dP}}{\mathrm{d} \xi}=\frac{\mu \beta}{\alpha} \mathrm{V}_{\mathrm{s}}(\mathrm{L}-\xi)
$$

Integrating and applying the initial condition $\mathrm{P}=\mathrm{P}_{\mathrm{o}}$ at $\xi=\mathrm{L}$ yields

$$
\mathrm{P}_{\mathrm{o}}-\mathrm{P}=\frac{\mu \beta}{\alpha} \mathrm{V}_{\mathrm{s}}(\mathrm{L}-\xi)
$$

This allows the pressure drop from the tip to the base $(\xi=0)$ of the dendrite region to be determined

$$
\Delta \mathrm{P}=\frac{\mu \beta}{\alpha} \mathrm{V}_{\mathrm{s}} \mathrm{L}
$$

The freezing front velocity and dendrite length are related to the local temperature gradient and cooling rate, by scale analysis, as

$$
\begin{aligned}
& \mathrm{L} \sim \frac{\Delta \mathrm{T}}{\mathrm{G}} \\
& \mathrm{V}_{\mathrm{s}} \sim \frac{\mathrm{R}}{\mathrm{G}}
\end{aligned}
$$

Substitution yields

$$
\Delta \mathrm{P} \sim\left(\frac{\mu \beta \Delta \mathrm{T}}{\alpha}\right) \frac{\mathrm{V}_{\mathrm{s}}}{\mathrm{G}} \sim\left(\frac{\mu \beta \Delta \mathrm{T}}{\alpha}\right) \frac{\mathrm{R}}{\mathrm{G}^{2}}
$$

Where $\mu, \beta$ and $\Delta \mathrm{T}$ are material properties that only weakly depend on the thermal environment. Additionally, Niyama et al., assume that $\alpha$ is a material property, without comment. Replacing the first term with $\mathrm{M}_{1}$

$$
\Delta \mathrm{P} \sim \mathrm{M}_{1}\left(\frac{\mathrm{R}}{\mathrm{G}^{2}}\right)
$$

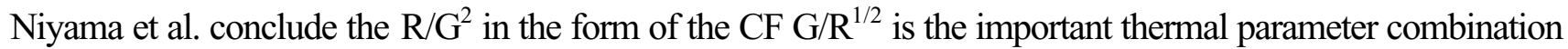
that controls flow in the dendrite region and the formulation of feeding-resistance porosity. Note the term $R / G^{2}$ is the same as the ratio of the front velocity to gradient, that is $R / G^{2} \sim V_{s} / G$.

\section{Lee et al. :}


Lee's analysis is similar to Niyama's using continuity (10) and Darcy's law (11). However, Lee et al. employ a permeability relationship in the form $\mathrm{K} \sim \gamma \mathrm{f}_{\mathrm{L}}^{2}$ instead of the linear relationship employed by Niyama. Substituting this relationship into Darcy's law yields

$$
\frac{\mathrm{dP}}{\mathrm{d} \xi}=\frac{\mu \beta \mathrm{V}_{\mathrm{s}}}{\gamma} \frac{1}{\mathrm{f}_{\mathrm{L}}}
$$

Integrating and applying the initial condition $\mathrm{P}=\mathrm{P}_{\mathrm{o}}$ at $\xi=\mathrm{L}$ yields

$$
\mathrm{P}_{\mathrm{o}}-\mathrm{P}=\frac{\mu \beta \mathrm{V}_{\mathrm{s}} \mathrm{L}}{\gamma} \int_{\xi / \mathrm{L}}^{1} \frac{\mathrm{d} \xi / \mathrm{L}}{\mathrm{f}_{\mathrm{L}}}
$$

Assuming the liquid fraction varies linearly in the mushy zone, $\mathrm{f}_{\mathrm{L}}=\xi / \mathrm{L}$, the equation reduces to

$$
\mathrm{P}_{\mathrm{o}}-\mathrm{P}=\frac{\mu \beta \mathrm{V}_{\mathrm{s}} \mathrm{L}}{\gamma} \ln \left(\frac{\mathrm{L}}{\xi}\right)
$$

Following Apelian et al. (1974) [14], Lee relates $\gamma$ to the dendritic structure

$$
\gamma=\frac{1}{24 \pi \mathrm{n} \tau}
$$

where

$\tau=$ tortuosity factor, taken as a constant, and

$\mathrm{n}=$ number of flow channels per unit area.

Lee states the number of flow channels are proportional to the inverse of the square of the secondary dendrite arm spacing, $1 / \mathrm{D}^{2}$, that is proportional to the cube root of the solidification time, and $n=C / t^{2 / 3}$. Substitution into equations (15) and (21) gives

$$
\mathrm{P}-\mathrm{P}_{\mathrm{o}}=24 \pi \tau^{3} \mathrm{C} \mu \beta \Delta \mathrm{T} \ln \left(\frac{\mathrm{L}}{\xi}\right) \frac{\mathrm{V}_{\mathrm{s}}}{\mathrm{Gt}^{2 / 3}}
$$

If the solidification is directional, the solidification time $\mathrm{t}$ is related to the gradient and velocity

$$
\mathrm{t}=\frac{\Delta \mathrm{T}}{\mathrm{GV}}
$$

and equation (23) reduces to 


$$
\mathrm{P}-\mathrm{P}_{\mathrm{o}}=24 \pi \tau^{3} \mathrm{C} \mu \beta \Delta \mathrm{T} \ln \left(\frac{\mathrm{L}}{\xi}\right)\left(\frac{\mathrm{V}_{\mathrm{s}}^{5}}{\mathrm{G}}\right)^{\frac{1}{3}}
$$

As $\xi \rightarrow 0$, a singularity exists in equation (25). Lee et al. redefines the length scale by letting $L \sim L^{*}$ which is the critical radius of porosity. They go on to argue that $\mathrm{L} /\left(\mathrm{L}-\mathrm{L}^{*}\right)$ is a characteristic constant of the material and dissolved gas. Thus, equation (29) reduces to

$$
\mathrm{P}_{\mathrm{o}}-\mathrm{P} \sim \mathrm{M}_{2}\left(\frac{\mathrm{V}_{\mathrm{s}}^{5}}{\mathrm{G}}\right)^{\frac{1}{2}}
$$

and Lee's CF is proportional to $\mathrm{V}_{\mathrm{s}}^{5} / \mathrm{G}$.

\section{Suri et al. :}

Suri's analysis begins with the continuity equation and resembles Niyama's analysis to lead to the solution for the superficial velocity in equation (10)

$$
\mathrm{V}=-\beta \mathrm{V}_{\mathrm{s}} \mathrm{f}_{\mathrm{L}}
$$

Suri derived the one-dimensional continuity equation from fundamental principles applying Newton's second law of motion to a control volume traveling with the solidification front to provide

$$
\frac{d P}{d \xi}=\frac{1}{\beta} \frac{d V}{d \xi}-2 V \frac{d V}{d \xi}+\frac{\rho_{s}}{\rho_{L} \beta} \frac{d f_{L}}{d \xi} V-f_{d r a g}
$$

where $\mathrm{f}_{\text {drag }}$ is the momentum flux per unit volume as a result of surface shear stress. Suri postulated expressions for $\mathrm{f}_{\text {drag }}$ for columnar and equiaxed dendrites have the form

$$
f_{\text {drag }}= \begin{cases}\frac{\kappa \mu V}{D_{p}^{2}}, & \text { columnar } \\ \frac{\kappa \mu V}{D_{o}^{2} f_{L}}, & \text { equiaxed }\end{cases}
$$

where $\kappa$ is a geometric parameter that is constant for a given geometry.

A scale analysis reveals that in all cases where incomplete feeding is possible, $\mathrm{f}_{\text {drag }}$ is more influential than the first three terms in equation (28). Thus, without serious loss, equation (28) reduces to 


$$
\frac{d P}{d \xi}=-f_{\text {drag }}= \begin{cases}-\frac{\kappa \mu V}{D_{p}^{2}}, & \text { columnar } \\ -\frac{\kappa \mu V}{D_{o}^{2} f_{L}}, & \text { equiaxed }\end{cases}
$$

Equation (30) is identical to Darcy's law, with permeability $\mathrm{K}=\mathrm{D}_{\mathrm{p}}{ }^{2} / \kappa$ or $\mathrm{D}_{\mathrm{o}}{ }^{2} \mathrm{f} / \kappa$. Thus, the only fundamental difference between Suri, Lee or Niyama is the treatment of the permeability.

\section{Columnar Dendrites:}

Substitution of the velocity distribution into the columnar form of equation (30 yields

$$
\frac{\mathrm{dP}}{\mathrm{d} \xi}=\frac{\kappa \mu \beta \mathrm{V}_{\mathrm{s}}}{\mathrm{D}_{\mathrm{p}}^{2}} \mathrm{f}_{\mathrm{L}}
$$

Like Lee, Suri assumes $\mathrm{f}_{\mathrm{L}}=\xi / \mathrm{L}$. Integrating and applying the boundary condition $\mathrm{P}=\mathrm{P}_{\mathrm{o}} @ \xi=\mathrm{L}$ yields

$$
\mathrm{P}_{\mathrm{o}}-\mathrm{P}=\frac{1}{2} \frac{\kappa \mu \beta \mathrm{V}_{\mathrm{s}} \mathrm{L}}{\mathrm{D}_{\mathrm{p}}^{2}}\left[1-\left(\frac{\xi}{\mathrm{L}}\right)^{2}\right]
$$

Substituting $\mathrm{L} \sim \Delta \mathrm{T} / \mathrm{G}$

$$
\mathrm{P}_{\mathrm{o}}-\mathrm{P}=\frac{1}{2} \frac{\kappa \mu \beta \Delta \mathrm{TV}_{\mathrm{s}}}{\mathrm{D}_{\mathrm{p}}^{2} \mathrm{G}}\left[1-\left(\frac{\xi}{\mathrm{L}}\right)^{2}\right]
$$

\section{Equiaxed Dendrites:}

Substitution of the velocity distribution for equiaxed dendrites in equation (30) yields

$$
\frac{\mathrm{dP}}{\mathrm{d} \xi}=\frac{\kappa \mu \beta \mathrm{V}_{\mathrm{s}}}{\mathrm{D}_{\mathrm{o}}^{2}}
$$

Integrating and applying the initial conditions

$$
\mathrm{P}_{\mathrm{o}}-\mathrm{P}=\frac{\kappa \mu \beta \mathrm{V}_{\mathrm{s}} \mathrm{L}}{\mathrm{D}_{\mathrm{o}}^{2}}\left[1-\left(\frac{\xi}{\mathrm{L}}\right)\right]
$$

Substitution of $\mathrm{L} \sim \Delta \mathrm{T} / \mathrm{G}$ yields 


$$
\mathrm{P}_{\mathrm{o}}-\mathrm{P}=\frac{\kappa \mu \beta \Delta \mathrm{TV} \mathrm{V}_{\mathrm{s}}}{\mathrm{D}_{\mathrm{o}}^{2} \mathrm{G}}\left[1-\left(\frac{\xi}{\mathrm{L}}\right)\right]
$$

\section{Nondimensional Criteria Function:}

Suri normalizes the pressure by dividing by $\rho_{\mathrm{L}} \beta \mathrm{V}_{\mathrm{s}}{ }^{2}$. Therefore, equations (33) and (36) become

$$
\mathrm{P}_{\mathrm{o}}^{\prime}-\mathrm{P}^{\prime}=\frac{1}{2} \frac{\kappa \mu \Delta \mathrm{T}}{\rho_{\mathrm{L}} \beta} \frac{1}{\mathrm{D}_{\mathrm{p}}^{2} \mathrm{~V}_{\mathrm{s}} \mathrm{G}}\left[1-\left(\frac{\xi}{\mathrm{L}}\right)^{2}\right]
$$

and

$$
\mathrm{P}_{\mathrm{o}}^{\prime}-\mathrm{P}^{\prime}=\frac{\kappa \mu \beta \Delta \mathrm{T}}{\rho_{\mathrm{L}} \beta} \frac{1}{\mathrm{D}_{\mathrm{o}}^{2} \mathrm{~V}_{\mathrm{s}} \mathrm{G}}\left[1-\left(\frac{\xi}{\mathrm{L}}\right)\right]
$$

The coefficients in (37) and (38) are similar and are defined as a feeding resistance number, FRN, by Suri

$$
F R N=\frac{\kappa \mu \beta \Delta T}{\rho_{L} \beta D^{2} V_{s} G}
$$

where $\mathrm{D}=\mathrm{D}_{\mathrm{p}}$ for columnar and $\mathrm{D}=\mathrm{D}_{\mathrm{o}}$ for equiaxed.

Suri postulates drag mechanisms and expresses the constant values of $\kappa$ as

$$
\kappa= \begin{cases}16 \pi, & \text { columnar } \\ 216, & \text { equiaxed }\end{cases}
$$

\section{Dendritic Structure Correlations:}

Suri employs a correlation of the form

$$
\mathrm{D}_{\mathrm{p}}=\mathrm{AG}^{\mathrm{a}} \mathrm{V}_{\mathrm{s}}^{\mathrm{b}}
$$

For aluminum alloys, Suri employs a correlation obtained for an $\mathrm{Al}-\mathrm{Cu}(6 \% \mathrm{Cu}$ by weight $)$ alloy with columnar dendrites presented by Poirier (1987) with $\mathrm{A}=359, \mathrm{a}=-0.474$ and $\mathrm{b}=-0.317$ [14]. He further assumes that this correlation can be used to fin $\mathrm{D}_{\mathrm{o}}$ in an aluminum alloy with an equiaxed structure. Substituting these values results in the following dimensional criteria function

$$
\kappa \mu \beta \Delta T \frac{V_{s}}{D^{2} G} \sim M_{3} \frac{V_{s}^{1.63}}{G^{0.052}}
$$


and in nondimensional form

$$
\frac{\kappa \mu \Delta T}{\rho_{L} \beta D^{2} V_{s} G} \sim \frac{M_{4}}{V_{s}^{0.037} G^{0.052}}
$$

If a theoretically derived relationship from Kurz and Fisher (1992) is employed for primary dendrite arm spacing [11]

$$
\mathrm{D}=\mathrm{BV}_{\mathrm{s}}^{-0.25} \mathrm{G}^{-0.5}
$$

Suri's dimensional criteria reduces to

Suri's dimensional criteria reduces to

$$
\kappa \mu \beta \Delta \mathrm{T} \frac{\mathrm{V}_{\mathrm{s}}}{\mathrm{D}^{2} \mathrm{G}} \sim \mathrm{M}_{5} \mathrm{~V}_{\mathrm{s}}^{1.5}
$$

and the nondimensional criteria reduces to

$$
\frac{\kappa \mu \Delta \mathrm{T}}{\rho_{\mathrm{L}} \mathrm{D}^{2} \mathrm{~V}_{\mathrm{s}} \mathrm{G}} \sim \frac{\mathrm{M}_{6}}{\mathrm{~V}_{\mathrm{s}}^{0.5}}
$$

In this case, Suri's criteria functions are reduced to constants and solidification front velocity.

\section{CRITERIA FUNCTION COMPARISON}

The criteria functions are evaluated by how well porosity is determined. This is accomplished by correlating porosity data from Suri (1993), Lee et al. (1990) and Kao et al. (1995) for A356 using each criteria function and comparing the results. Seven criteria functions are considered for each data set

$\begin{array}{llc}\text { 1. } & \text { Niyama, } & \mathrm{V}_{\mathrm{s}} / \mathrm{G} \\ \text { 2. } & \text { Lee, } & \mathrm{V}_{\mathrm{s}}^{5} / \mathrm{G} \\ \text { 3. } & \text { Suri dimensional, } & \mathrm{V}_{\mathrm{s}}^{1.63} / \mathrm{G}^{0.052} \\ \text { 4. } & \text { Suri nondimensional, } & 1 / \mathrm{V}_{\mathrm{s}}^{0.37} \mathrm{G}^{0.052} \\ \text { 5. } & \text { Gradient, } & \mathrm{G} \\ \text { 6. } & \text { Solidus Velocity } & \mathrm{V}_{\mathrm{s}} \\ \text { 7. } & \text { Least-squares power law, } & \mathrm{V}_{\mathrm{s}}^{\mathrm{a}} \mathrm{G}^{\mathrm{b}}\end{array}$

The first six correlations were observed to fit the following power-law and log-quadratic formulas using a least-square approach 


$$
\begin{gathered}
\mathrm{p}=\mathrm{C}(\mathrm{CF})^{\mathrm{a}} \\
\mathrm{p}=\mathrm{A}+\mathrm{B} \log (\mathrm{CF})+\mathrm{C}[\log (\mathrm{CF})]^{2}
\end{gathered}
$$

by determining the correlation coefficient

$$
R^{2}=\frac{\sum_{t=1}^{N}\left(p_{t}-\bar{p}\right)^{2}-\sum_{t=1}^{N}\left(p_{t}-p\left(C F_{t}\right)\right)^{2}}{\sum_{t=1}^{N}\left(p_{t}-\bar{p}\right)^{2}}
$$

This is the standard statistical value that measures how much of the porosity variation is due to the model compared with random variation. A value of $\mathrm{R}^{2}=1$ indicates the formula can account for all variation. A value of $\mathrm{R}^{2}=0$ indicates the formula cannot account for variation. A value of $0.80(80 \%)$ indicates 80 percent of the variation is accounted for by the formula. Therefore, the larger the value of $\mathrm{R}^{2}$, the better the correlation.

Using the best-fit power law

$$
\mathrm{p}=\mathrm{CV}_{\mathrm{s}}^{\mathrm{a}} \mathrm{G}^{\mathrm{b}}
$$

the coefficients are determined by a multi-linear regression of the form

$$
\log (\mathrm{p})=\log (\mathrm{c})+\mathrm{a} \log \left(\mathrm{V}_{\mathrm{s}}\right)+\mathrm{b} \log (\mathrm{G})
$$

The correlation coefficient for $\mathrm{R}^{2}$ was determined using the same principle as above.

Suri (1993) reports porosity data for a 5.1 by 10.2 by 30.1 A356 cast plates with and without end chills. The density was calculated using pyknometry. Different techniques, by different authors, were employed to obtain thermal parameters:

1. $\mathrm{V}_{\mathrm{s}}$ and $\mathrm{G}$ were determined from experimental thermocouple data.

2. Local $\mathrm{G}$ and $\mathrm{R}$ were determined instantaneously using finite-element calculations, and $\mathrm{V}_{\mathrm{s}}$ was calculated as $\mathrm{R} / \mathrm{G}$.

3. Local $\mathrm{G}$ values were determined instantaneously using finite-element calculations. Average $\mathrm{R}$ values were determined from the calculations, and $\mathrm{V}_{\mathrm{s}}$ was calculated as $\mathrm{R} / \mathrm{G}$.

4. Local $\mathrm{G}$ values were determined instantaneously using finite-element calculations. An average $\mathrm{V}_{\mathrm{s}}$ values were calculated from total solidification time and plate length. 
For this paper, case 1-data were obtained from plots and case-2, -3 and -4 data were kindly provided in tabular form from Dr. Suri. Reduced pressure tests on the metal indicated a hydrogen level of $0.2 \mathrm{cc} / 100 \mathrm{~g}$.

Lee et al. (1990) measured porosity distribution in Al-7Si-0.3Mg rectangular plates. The plate dimensions were $2-\mathrm{cm}$ thick, $14-\mathrm{cm}$ wide and $15-$ or $25-\mathrm{cm}$ long. The hydrogen level was controlled to a maximum of $0.01 \mathrm{cc} / 100 \mathrm{~g}$. In a series of experiments the $15-$ and $25-\mathrm{cm}$ long plates were cast using different riser diameters. Six thermocouples were utilized to record temperature. Like Suri, the porosity was determined through pyknometry. For this paper, porosity $(\mathrm{p})$ data, $\mathrm{G}$ data and $\mathrm{V}_{\mathrm{s}}$ data were taken from graphs presented by Lee et al. It is important to note the hydrogen content of the metal is very low for the castings Lee evaluated.

Kao et al. (1195) presents porosity data for A356 plate castings. The experiments were similar to Lee's work except the hydrogen content was varied at values of $0.073 \mathrm{cc} / 100 \mathrm{~g}, 0.12 \mathrm{cc} / 100 \mathrm{~g}$ and 0.18 $\mathrm{cc} / 100 \mathrm{~g}$. Values for $\mathrm{p}, \mathrm{G}$ and Vs were table from graphs in Kao's paper.

Table 1 shows the $\mathrm{R}^{2}$ correlation coefficient for seven criteria functions utilizing the power-law formula. The right two columns the average $\mathrm{R}^{2}$ value and average rank per case. The rank is determined by evaluating how well each criteria function correlates the data. The criteria function that has the highest $\mathrm{R}^{2}$ value is given a rank of 1 . If two or more criteria functions provide identical $\mathrm{R}^{2}$ values, the criteria functions are given the same rank. The underlined numbers indicate the largest value among the first four criteria functions. The $\mathrm{R}^{2}$ data shows none of the criteria functions correlate the data very well. In case, except Lee et al., the correlation coefficient is 0.5 or less. This indicates the data is scattered or the proposed law does not indicate data trends.

Table 1. $\mathrm{R}^{2}$ Correlation Coefficient Summary for the Power Law

\begin{tabular}{|c|c|c|c|c|c|c|c|c|c|c|}
\hline $\begin{array}{c}\text { Criteria Function } \\
\text { Name Formula }\end{array}$ & $\begin{array}{c}\text { Suri } \\
\text { Exp. }\end{array}$ & $\begin{array}{c}\text { Suri } \\
\text { Sim }\end{array}$ & $\begin{array}{c}\text { Suri } \\
\text { Sim R }\end{array}$ & $\begin{array}{c}\text { Suri } \\
\text { Sim } \mathrm{V}_{\mathrm{s}}\end{array}$ & Lee & $\begin{array}{c}\text { Kao } \\
0.07 \mathrm{H}_{2}\end{array}$ & $\begin{array}{c}\text { Kao } \\
0.12 \mathrm{H}_{2}\end{array}$ & $\begin{array}{c}\text { Kao } \\
0.18 \mathrm{H}_{2}\end{array}$ & $\begin{array}{c}\text { Avg. } \\
\mathrm{R}^{2}\end{array}$ & $\begin{array}{c}\text { Avg. } \\
\text { Rank }\end{array}$ \\
\hline Niyama $\mathrm{V}_{\mathrm{s}} / \mathrm{G}$ & $\underline{0.41}$ & $\underline{0.30}$ & $\underline{0.34}$ & 0.33 & 0.83 & 0.29 & 0.23 & 0.33 & $\underline{0.38}$ & $\underline{3}$ \\
\hline Lee et al. $\mathrm{V}_{\mathrm{s}}^{5} / \mathrm{G}$ & 0.25 & 0.24 & $\underline{0.34}$ & 0.23 & $\underline{0.86}$ & $\underline{0.30}$ & 0.21 & 0.35 & 0.35 & $\underline{3}$ \\
\hline Suri-dim $\mathrm{V}_{\mathrm{s}}^{1.63} / \mathrm{G}^{0.052}$ & 0.23 & 0.22 & 0.33 & 0 & 0.84 & $\underline{0.30}$ & 0.24 & 0.35 & 0.31 & 3.4 \\
\hline Suri-nond $1 / \mathrm{V}_{\mathrm{s}}^{0.37} \mathrm{G}^{0.052}$ & 0.08 & 0.15 & 0.33 & $\underline{0.41}$ & 0.76 & $\underline{0.30}$ & $\underline{0.25}$ & $\underline{0.36}$ & 0.33 & 3.5 \\
\hline Gradient $\mathrm{G}$ & 0.51 & 0.35 & 0.35 & 0.35 & 0.71 & 0.25 & 0.14 & 0.26 & 0.37 & 3.4 \\
\hline Velocity $\mathrm{V}_{\mathrm{s}}$ & 0.22 & 0.21 & 0.33 & 0 & 0.82 & 0.30 & 0.24 & 0.36 & 0.31 & 3.8 \\
\hline Least-Squares $\mathrm{V}_{\mathrm{s}}^{\mathrm{a}} \mathrm{G}^{\mathrm{b}}$ & 0.51 & 0.36 & 0.55 & 0.55 & 0.86 & 0.30 & 0.27 & 0.36 & 0.47 & 1 \\
\hline
\end{tabular}

Of the first four criteria functions, Niyama's seems to best correlate Suri's data except for Suri's simulated data based on $\mathrm{V}^{\mathrm{s}}$ where Suri's nondimensional criteria function performs the best. The thermal gradient $(\mathrm{G})$ alone provides the best correlation for Suri's data. The power-law correlation using Lee's criteria function provides a correlation as good as the best least-squares case. Furthermore, the data shows the difference between Lee's, Niyama's and Suri's dimensional criteria functions are small. Kao's data is best correlated using Suri's nondimensional criteria function. However, the correlation coefficients are very small. The summary data shows Niyama's criteria function and the thermal gradient provide the highest correlation coefficients, and Niyama's and Lee's criteria functions have the highest rank. 
The last row in Table 1 shows the best least-squares power law for the porosity data. The table indicates that none of the first six criteria functions correspond to a best case for Suri's data. Lee's criteria function provides a correlation as good as the best least-squares case to his own data. Suri's nondimensional function and Vs alone come closest to the best possible power-law correlation for Kao's data.

Table 2 shows similar data for the log-quadratic data. The trends are essentially the same as the trends indicated by the power-law. As expected, the average correlation coefficient value is slightly grater because there is one more degree of freedom. The value of $\mathrm{R}^{2}$ for Suri's data is greater in each case indicating the power-law does not represent Suri's data as well as the log-quadratic formula. The $\mathrm{R}^{2}$ values for Lee's and Kao's data are not substantially greater when compared with the power-law data.

Table 2. $\mathrm{R}^{2}$ Correlation Coefficient Summary for the Log-Quadratic

\begin{tabular}{|c|c|c|c|c|c|c|c|c|c|c|}
\hline $\begin{array}{c}\text { Criteria Function } \\
\text { Name Formula }\end{array}$ & $\begin{array}{c}\text { Suri } \\
\text { Exp. }\end{array}$ & $\begin{array}{c}\text { Suri } \\
\text { Sim }\end{array}$ & $\begin{array}{c}\text { Suri } \\
\text { Sim } \mathrm{R}\end{array}$ & $\begin{array}{c}\text { Suri } \\
\text { Sim } \mathrm{V}_{\mathrm{s}}\end{array}$ & Lee & $\begin{array}{c}\text { Kao } \\
0.07 \mathrm{H}_{2}\end{array}$ & $\begin{array}{c}\text { Kao } \\
0.12 \mathrm{H}_{2}\end{array}$ & $\begin{array}{c}\text { Kao } \\
0.18 \mathrm{H}_{2}\end{array}$ & $\begin{array}{c}\text { Avg. } \\
\mathrm{R}^{2}\end{array}$ & $\begin{array}{c}\text { Avg. } \\
\text { Rank }\end{array}$ \\
\hline Niyama $\mathrm{V}_{\mathrm{s}} / \mathrm{G}$ & $\underline{0.75}$ & $\underline{0.51}$ & $\underline{0.43}$ & 0.40 & 0.86 & 0.30 & 0.27 & 0.35 & $\underline{0.48}$ & $\underline{2.9}$ \\
\hline Lee et al. $\mathrm{V}_{\mathrm{s}}^{5} / \mathrm{G}$ & 0.69 & 0.49 & 0.41 & 0.32 & $\underline{0.87}$ & 0.32 & 0.24 & 0.40 & 0.47 & 3.1 \\
\hline Suri-dim $\mathrm{V}_{\mathrm{s}}^{1.63} / \mathrm{G}^{0.052}$ & 0.46 & 0.39 & 0.40 & 0.58 & 0.85 & 0.33 & 0.28 & 0.41 & 0.46 & 3.1 \\
\hline Suri-nond $1 / \mathrm{V}_{\mathrm{s}}^{0.37} \mathrm{G}^{0.052}$ & 0.12 & 0.18 & 0.39 & $\underline{0.86}$ & 0.78 & $\underline{0.34}$ & $\underline{0.30}$ & $\underline{0.44}$ & 0.43 & 3.1 \\
\hline Gradient $\mathrm{G}$ & 0.68 & 0.47 & 0.47 & 0.47 & 0.78 & 0.26 & 0.20 & 0.27 & 0.45 & 3.9 \\
\hline Velocity $\mathrm{V}_{\mathrm{s}}$ & 0.39 & 0.35 & 0.40 & 0 & 0.84 & 0.33 & 0.29 & 0.42 & 0.38 & 3.9 \\
\hline
\end{tabular}

A major differnce between Table 1 and Table 2 is the data for Suri's nondimensional criteria unction and Suri's simulation data based on average Vs. The log-quadratic correlation shows an $\mathrm{R}^{2}$ value of 0.86 and the power-law data shows an $\mathrm{R}^{2}$ value of 0.41 .

Figures 2 and 3 are plots of the porosity data along with curve fits for Lee and Suri's data versus Niyama's criteria function. The figures indicate the power-law formula reasonably represents the trends in the observed data. The curve fits for Kao's data are very flat, and the data scatter is about the same magnitude as the predicted porosity change when $\mathrm{V}_{\mathrm{s}} / \mathrm{G}$ increases for 0.1 to 100 . Again is should be noted that the Lee data involves a very low hydrogen content, suggesting that the criteria work better in the absence of a higher incidence of gas driven porosity.

Figure 4 shows the same plot for Suri's experimental data. In this case, Vs and G were determined experimentally. All of the best follow the same trend, and the log-quadratic curve matches the data well. Unlike Lee's and Kao's data, Suri's data is not well represented by the power-law.

Figure 5 shows Suri's simulation data using average Vs plotted against Niyama's, Lee's, Suri's dimensional and Suri's nondimensional criteria functions. The figure shows Suri's nondimensional criteria function has collapsed the data onto one curve. Part of the curve in Figure 5 is equivalent to the relationship Suri et al. presented in 1995. 


\section{CONCLUSIONS}

The criteria functions derived by Niyama, Lee and Suri are based on the same physical equations. The main difference in the derivations is in the treatment of the mushy zone. Niyama assumes the permeability is linearly proportional to liquid fraction, Lee assumes the permeability is proportional to the square of the liquid fraction and Suri postulates drag models for columnar and equiaxed dendrites based on physical reasoning. In each case, the criteria function can be expressed in terms of solidus-front velocity, $\mathrm{V}_{\mathrm{s}}$, and thermal gradient, $\mathrm{G}$.

The data in Tables 1 and 2 indicates that if the hydrogen content is grater than $0.07 \mathrm{cc} / 100 \mathrm{~g}$, it is difficult to determine the differences between criteria functions proposed by Niyama, Lee and the two from Suri.

The stronger correlation of Lee's criteria function with experimental data with a hydrogen content of less than $0.01 \mathrm{cc} / 100 \mathrm{~g}$ indicates criteria functions only provide good correlation with melts that are thoroughly degassed. However, there is little difference between the four before mentioned criteria functions. Nonetheless, with the trend to more efficient degassing and improved pouring pratices CFs are likely to become more relevant to casting quality improvement.

One criticism of the experimental data examined here is that was obtained from horizontally poured castings with a fixed thickness (Suri $5.1-\mathrm{cm}$, Lee/Kao $2-\mathrm{cm}$ ). Clearly future work should embrace a wide range of section thicknesses and other poring methods.

It can be seen that the CF approaches ignore the hydrogen evolution and nucleation problems, in particular the role of double folded oxide films expressed by Campbell [12]. Furthermore, all CF approaches neglect the effect of porosity in the continuity equation. The latter effect may not be negligible because modeling a casting that exhibits $7 \%$ shrinkage and ignoring porosity of $1 \%$ in the modeling is questionable.

To overcome some of the limitations involving criteria functions, recently authors have proposed more detailed models of microporosity. These models incorporate more rigorous treatments of gas evolution/nucleation, fluids, heat transfer, permeability and solubility. A general model for an $\mathrm{Al}-\mathrm{Cu}$ alloy outlining newer microporosity modeling approaches is presented in Figure 6. Nomenclature for Figure 6 is presented in Table 3. Questions requiring answers and assumptions made in order to use the model in Figure 6 are presented in Table 4. It must be noted that in order to solve the model represented, inclusion of the descriptions of nucleation and growth of bubbles (oxide film entrapment), permeability, etc. must be empirically determined and thus the model will be alloy dependent. Hopefully, future work will consider these aspects in a more rigorous fashion. 
Table 3. Nomenclature for Figure 6

\begin{tabular}{|c|c|c|}
\hline Fluids & Materials & Thermal \\
\hline $\begin{array}{c}\mathbf{v}_{\mathbf{s}}, \mathbf{v}_{\mathbf{L}}=\begin{array}{l}\text { Solid, Liquid Front } \\
\text { Velocities }\end{array} \\
\end{array}$ & $\mathrm{m}_{\mathrm{H} 2}=$ Hydrogen Mass & $\mathrm{c}_{\mathrm{p}}=$ Specific Heat \\
\hline $\begin{array}{c}\mathrm{g}_{\mathrm{S}}, \mathrm{g}_{\mathrm{L}}=\text { Solid, Liquid Volume } \\
\text { Fractions }\end{array}$ & $\mathrm{C}_{\mathrm{H}}=$ Hydrogen Concentration & $\mathrm{T}_{\mathrm{E}}=$ Eutectic Temperature \\
\hline $\mathrm{P}_{\mathrm{g}}=$ Gas Pressure & $\begin{array}{c}\mathrm{C}_{\mathrm{H} 0}=\text { Melt Hydrogen } \\
\text { Concentration }\end{array}$ & $\mathrm{T}_{\mathrm{L}}=$ Liquidus Temperature \\
\hline $\mathrm{P}=$ Pressure & $\begin{array}{c}\mathrm{C}_{\mathrm{H}}^{\mathrm{L}}=\text { Hydrogen Concentration in } \\
\text { Liquid }\end{array}$ & $\mathrm{T}=$ Temperature \\
\hline $\begin{array}{c}\rho_{\mathrm{S}}, \rho_{\mathrm{L}}=\text { Solid and Liquid } \\
\text { Densities }\end{array}$ & $\begin{array}{c}\mathrm{C}_{\mathrm{Cu}}{ }^{\mathrm{L}}=\text { Copper Concentration in } \\
\text { Liquid }\end{array}$ & \\
\hline \multirow[t]{4}{*}{$\sigma=$ Surface Tension } & $\mathrm{f}_{\mathrm{s}}=$ Fraction Solid & \\
\hline & $\begin{array}{c}\mathrm{K}_{\mathrm{eq}}=\text { Equilibrium Reaction } \\
\text { Constant }\end{array}$ & \\
\hline & $\mathrm{K}=$ Permeability & \\
\hline & $\varepsilon=$ Porosity & \\
\hline
\end{tabular}

Table 4. Fluid Flow, Material and Thermal Parameters Assumptions and Required Correlations

\begin{tabular}{|c|c|c|}
\hline Fluids & Materials & Thermal \\
\hline $\begin{array}{l}\text { What is the Flow Regime? If } \\
\text { Slow and Steady (Darcy) }\end{array}$ & What Type of Dendritic Structure? & $\begin{array}{c}\text { Casting is Isothermal, } \\
\Delta \mathrm{T}_{\text {casting }}<\text { Interval of Solidification }\end{array}$ \\
\hline $\begin{array}{l}\text { What is the Model for } \\
\text { Permeability? }\end{array}$ & $\begin{array}{c}\text { Is Concentration of Dissolved } \\
\text { Hydrogen is given } \\
\text { By Equilibrium Equation? }\end{array}$ & $\begin{array}{l}\text { Constant Gap between } \\
\text { Casting and Mold }\end{array}$ \\
\hline Is the Density of Gas $<<1$ ? & Solubility Model? & $\begin{array}{c}\text { Constant Thermal } \\
\text { Conductivity }\end{array}$ \\
\hline $\begin{array}{c}\text { Are Density of Solid and Liquid = } \\
\text { f(time)? }\end{array}$ & $\begin{array}{c}\text { Is There Solute } \\
\text { Macrosegregation? }\end{array}$ & $\begin{aligned} \rho_{\text {avg }} & =\rho_{L}+\left(\rho_{E} / 2\right) \\
\left(c_{p}\right)_{\text {avg }} & =\left(c_{p}\right)_{L}+\left(c_{p}\right)_{E} / 2\end{aligned}$ \\
\hline $\begin{array}{l}\text { Is the Problem One-, Two- or } \\
\text { Three-Dimensional? }\end{array}$ & $\begin{array}{c}\text { Will all Hydrogen Nucleate if } \\
\text { Possible? }\end{array}$ & $\mathrm{T}_{\mathrm{E}}<\mathrm{T}_{\text {porosity }}<\mathrm{T}_{\mathrm{L}}$ \\
\hline $\begin{array}{l}\text { Is } g_{L}=f_{L}(1-\varepsilon) ? \\
\text { Is } g_{S}=f_{S}(1-\varepsilon) ?\end{array}$ & $\begin{array}{l}\text { What is the Model for Surface } \\
\text { Tension? }\end{array}$ & Porosity does not affect Heat Transfer \\
\hline Are $\varepsilon$ and $\beta<<1$ ? & Is Porosity only due to $\mathrm{H}_{2}$ ? & \\
\hline \multicolumn{3}{|l|}{ Are $\mathbf{v}_{\mathrm{S}}, \mathbf{v}_{\mathrm{L}}<<1 ?$} \\
\hline Is $\mathrm{P}(\mathrm{x})=\mathrm{f}($ porosity $)$ ? & & \\
\hline $\begin{array}{c}\text { Is there Interdendritic Flow at } \\
\text { Casting/Mold Interface? }\end{array}$ & & \\
\hline
\end{tabular}

\section{ACKNOWLEDGEMENTS}

The current work at Mississippi State University is supported by the Cast Metals Coalition through a USDOE grant with inkind industry support. The authors would also like to thank Dr. Glenn Steele, Head of the Mechanical Engineering Department ant Mississippi State University. 


\section{REFERENCES}

[1] Piwonka, T.S. and Flemmings, M.C., "Pore Formation in Solidification," Transactions of the Metallurgical Society of AIME, Vol. 236, August, 1966, pp. 1157-1165.

[2] Niyama, E., Uchida, T., Morikawa, M, Shigeki, S, “A method of Shrinkage Prediction and Its Application to Steel Castings Practice, " presented at the $49^{\text {th }}$ International Foundry Congress, Chicago, April 1982.

[3] Lee, Y.W., Change, E., Chieu, C.F., "Modeling of Feeding Behavior of Solidifying Al-7Si0.3Mg Alloy Plate Castings," Metallurgical Transactions, Vol. 21B, August, 1990, pp. 715722.

[4] Suri, V.K., "Theoretical and Experimental Studies on Pore Formation During Casting Solidification," Ph.D. Dissertation, University of Alabama, Tuscaloosa, 1993.

[5] Suri, V.K., Paul, A.J., El-Kaddah, N, Berry, J.T., "Determination of Correlation Factos for Prediction of Shrinkage in Castings-Part 1: Prediction of Microporosity in Castings; A general Criterion," AFS Transactions, Vol. 103, 1995, pp. 861-867.

[6] Poirier, D.R., "Phenomena Related to the Formation of Microporosity in Castings, Modeling of Casting," Welding and Advanced Solidification Processes VIII, The Minerals, Metals \& Materials Society, 1998, pp. 837-848.

[7] Kuznetsov, A.V., Vafai, K., "Development and Investigation of Three-Phase Model of the Mushy Zone for Analysis of Porosity Formation in Solidifying Castings," International Journal of Heat and Mass Transfer, vol. 38, no. 14, 1995, pp. 2557-2567.

[8] Huang, J, Mori, T., Conley, G., "Simulation of Microporosity Formation in Modified and Unmodified A356 Alloy Castings," Metallurgical and Materials Transactions B, vol. 29B, Dec. 1998, pp. 1249-1260.

[9] Taylor, R.P., Berry, J.T., Overfelt, R.A., "Parallel Derivation and Comparison of FeedingResistance Porosity Criteria Functions for Castings," Proc. ASME National Heat Transfer Conference, HTD-Vol. 323, 1996, pp. 69-77.

[10] Shenefelt, J.R., Luck, R., Berry, J.T., “The Case for Riser Pressurization,” Presented at $1^{\text {st }}$ Annual AFS Gating Conference, Nashville, October 1999, pp. 227-237.

[11] Kurz, W., Fisher, D.J., Fundamentals of Solidification, Trans Tech Publications, Aedermannsdorf, Switzerland, 1992. 
[12] Runyoro, J.J., Boutarabi, S.M.A., Campbell, J., AFS Transactions, Vol. 100, 1992, pp. 225234.

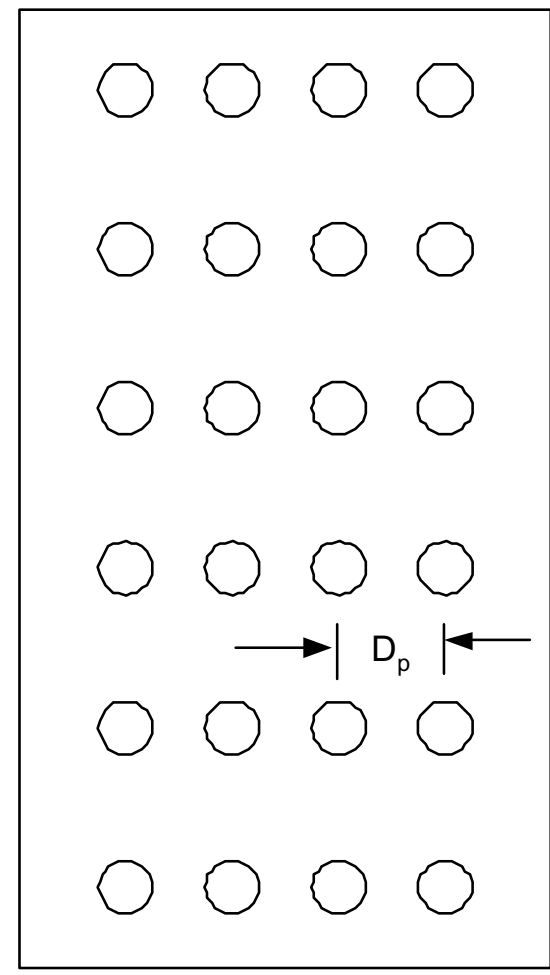

A

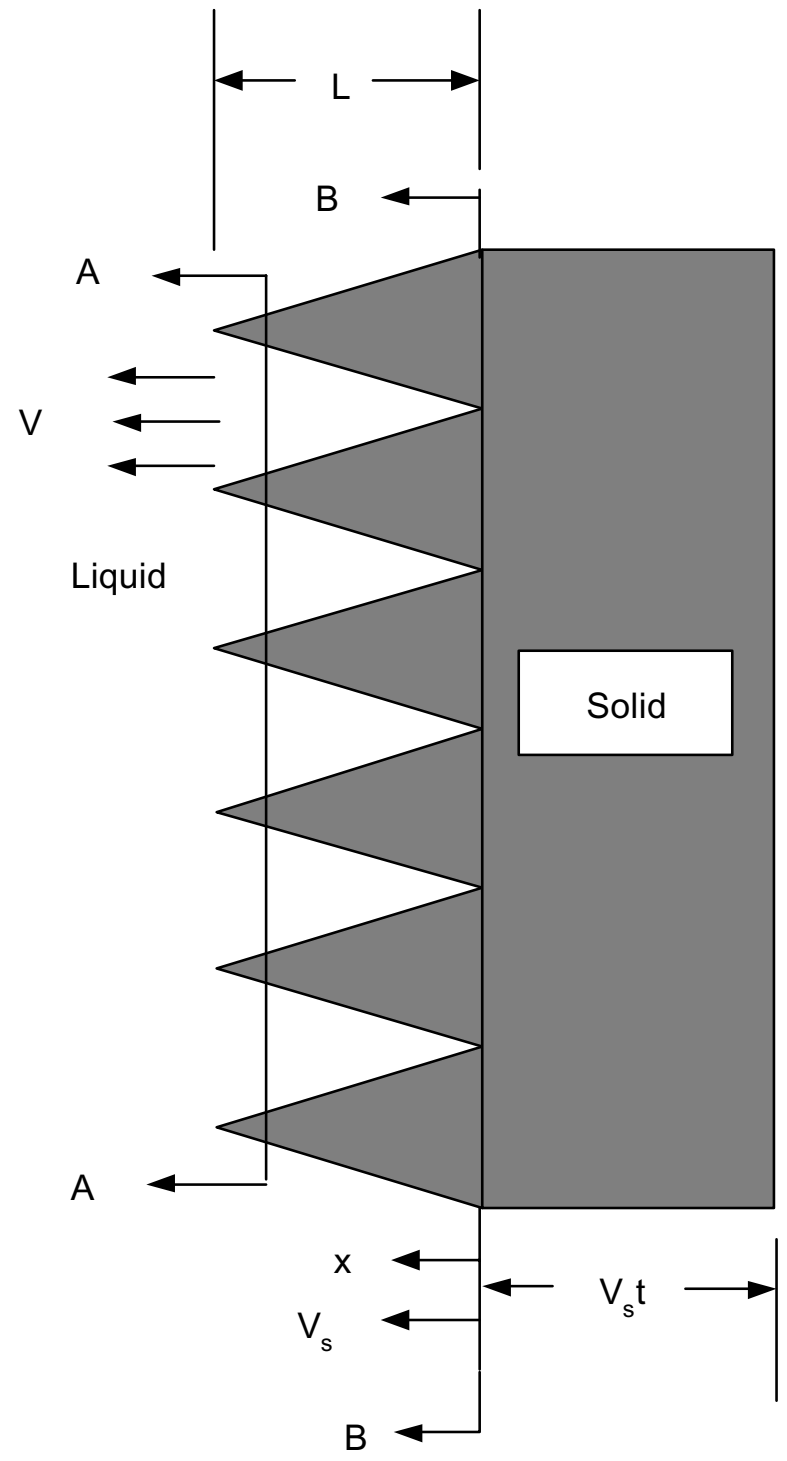

Figure 1: Schematic Diagram for Columnar Dendrites 


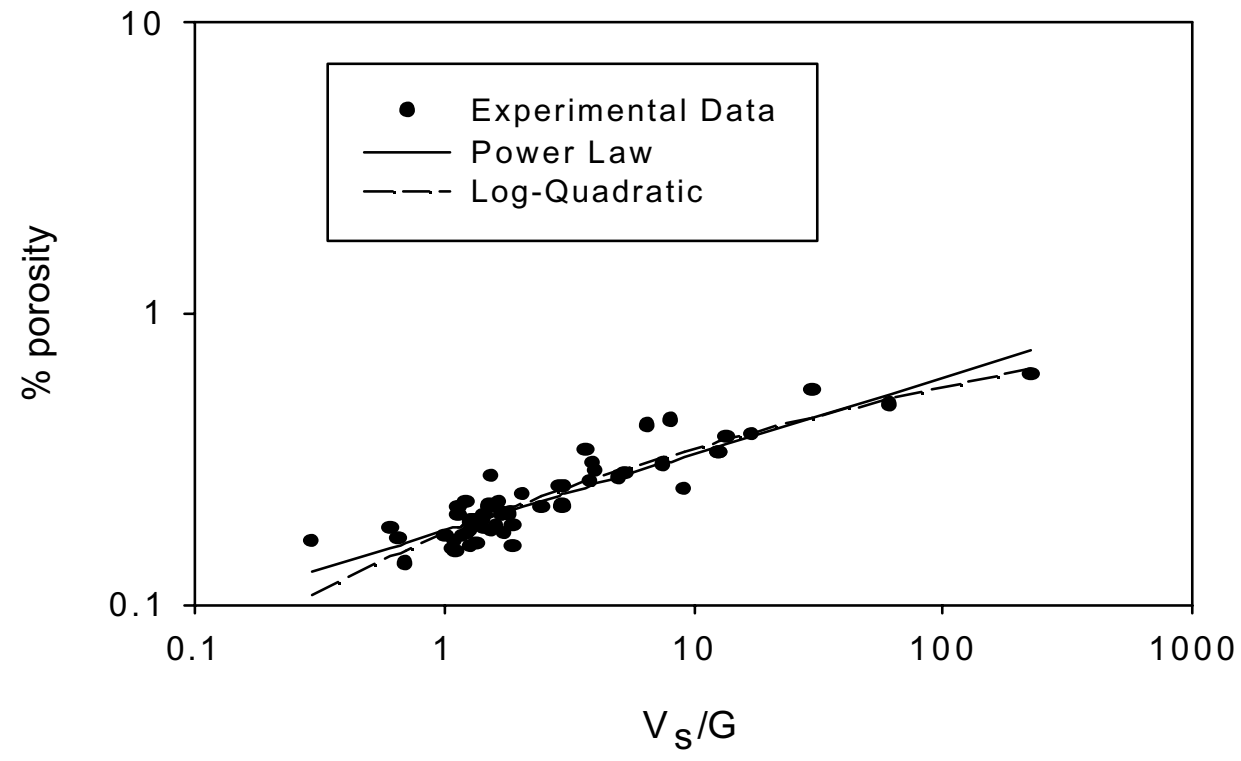

Figure 2: Lee's Experimental Values Plotted Versus Niyama's Criteria Function

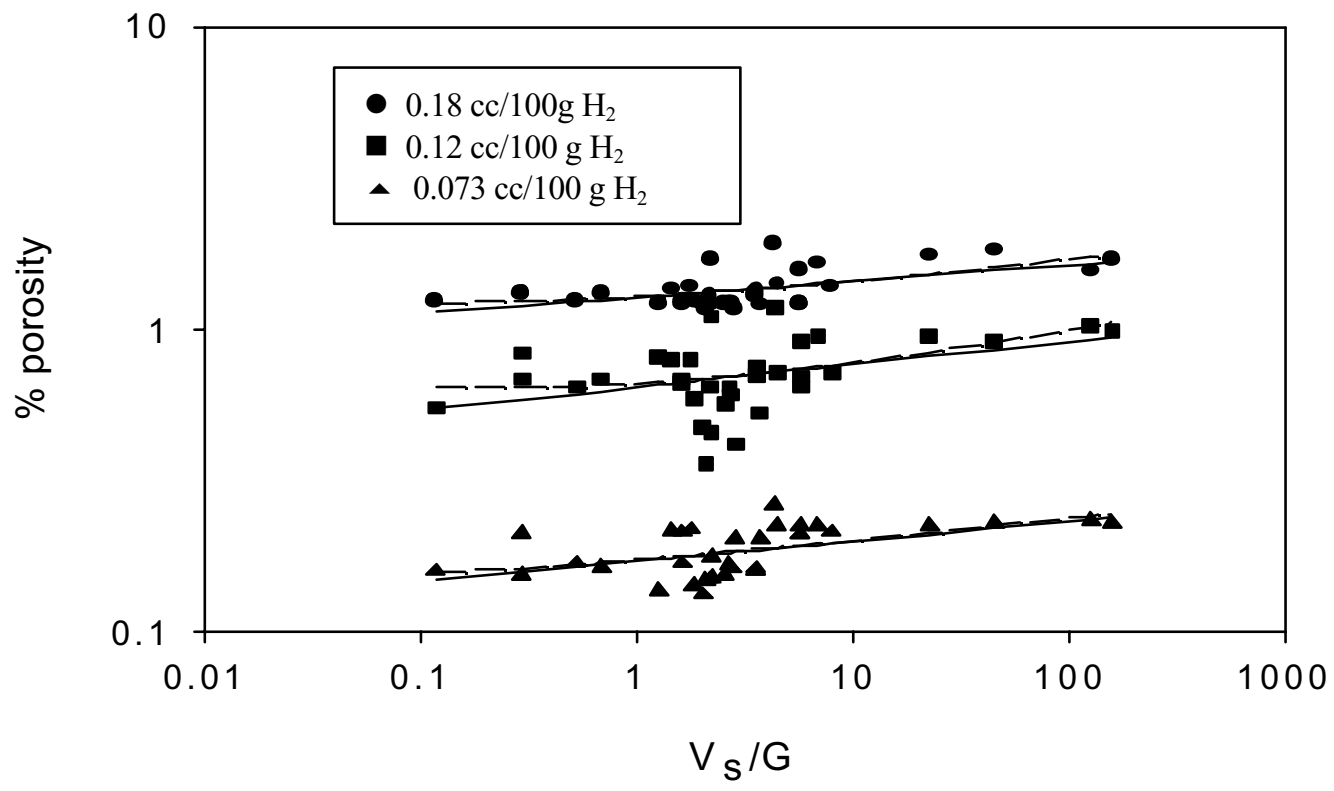

Figure 3: Kao's Experimental Values Plotted versus Niyama's Criteria Function 


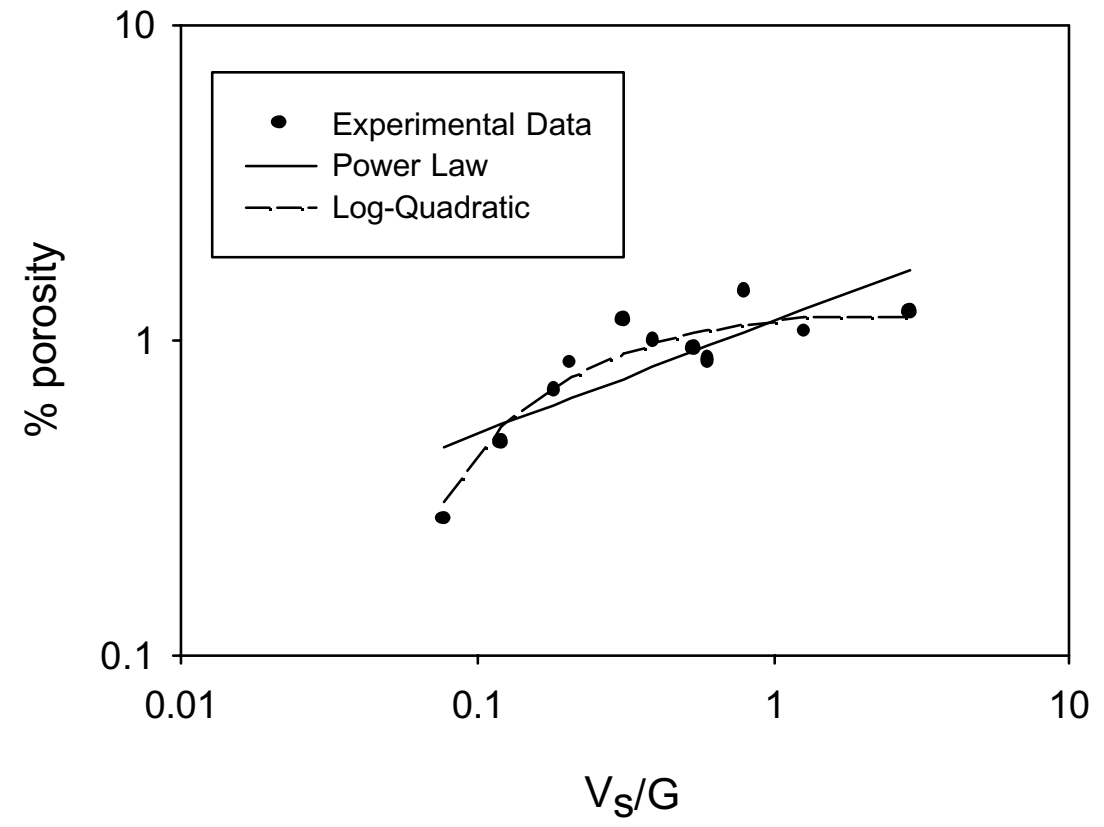

Figure 4: Suri's Experimental Values Plotted versus Niyama's Criteria Function 


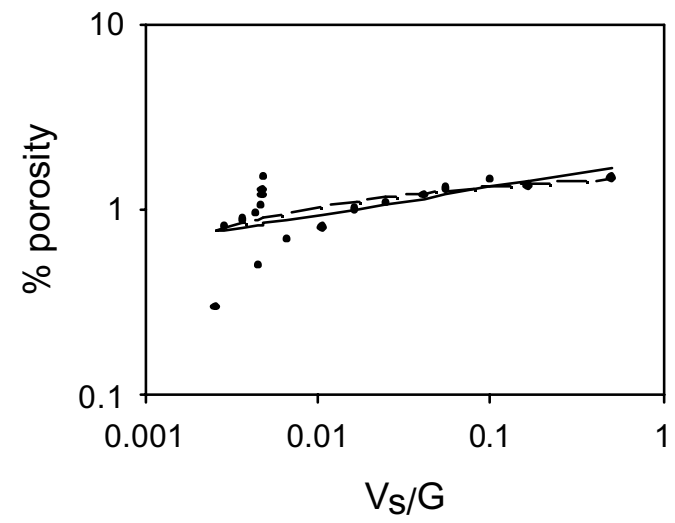

(a) Niyama's Criteria Function

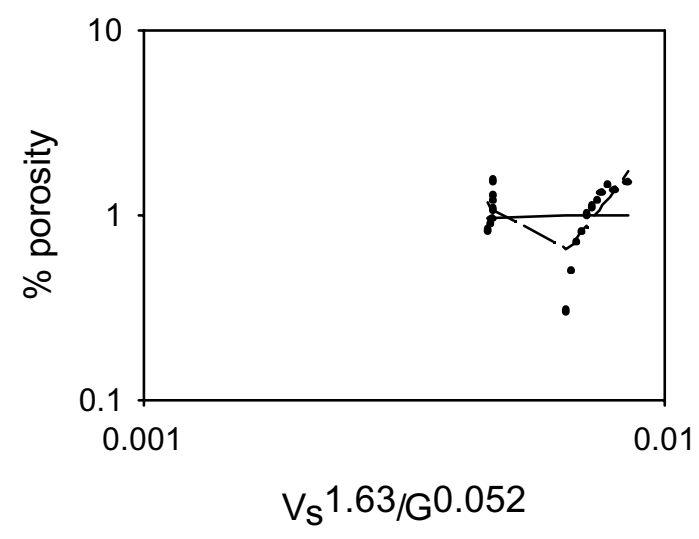

(c) Suri's Dim'l Criteria Function

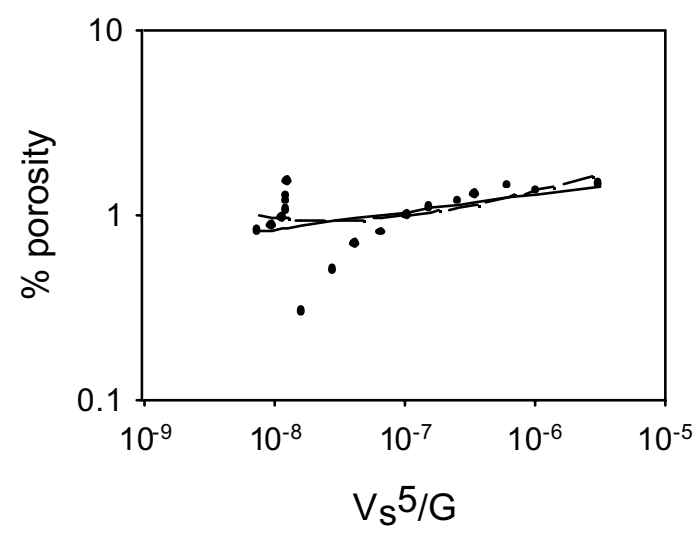

(b) Lee's Criteria Function

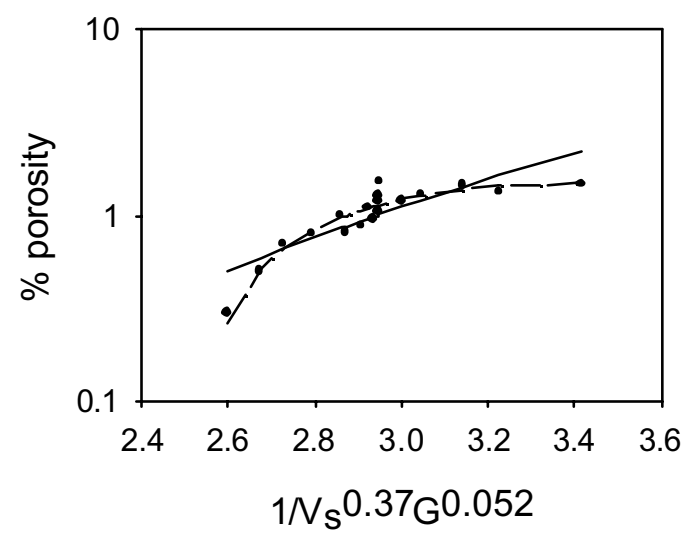

(d) Suri's Nondim'l Criteria Function

Figure 5: Comparison of Suri's Simulated Data Using Average $V_{s}$ with the four Criteria Functions 


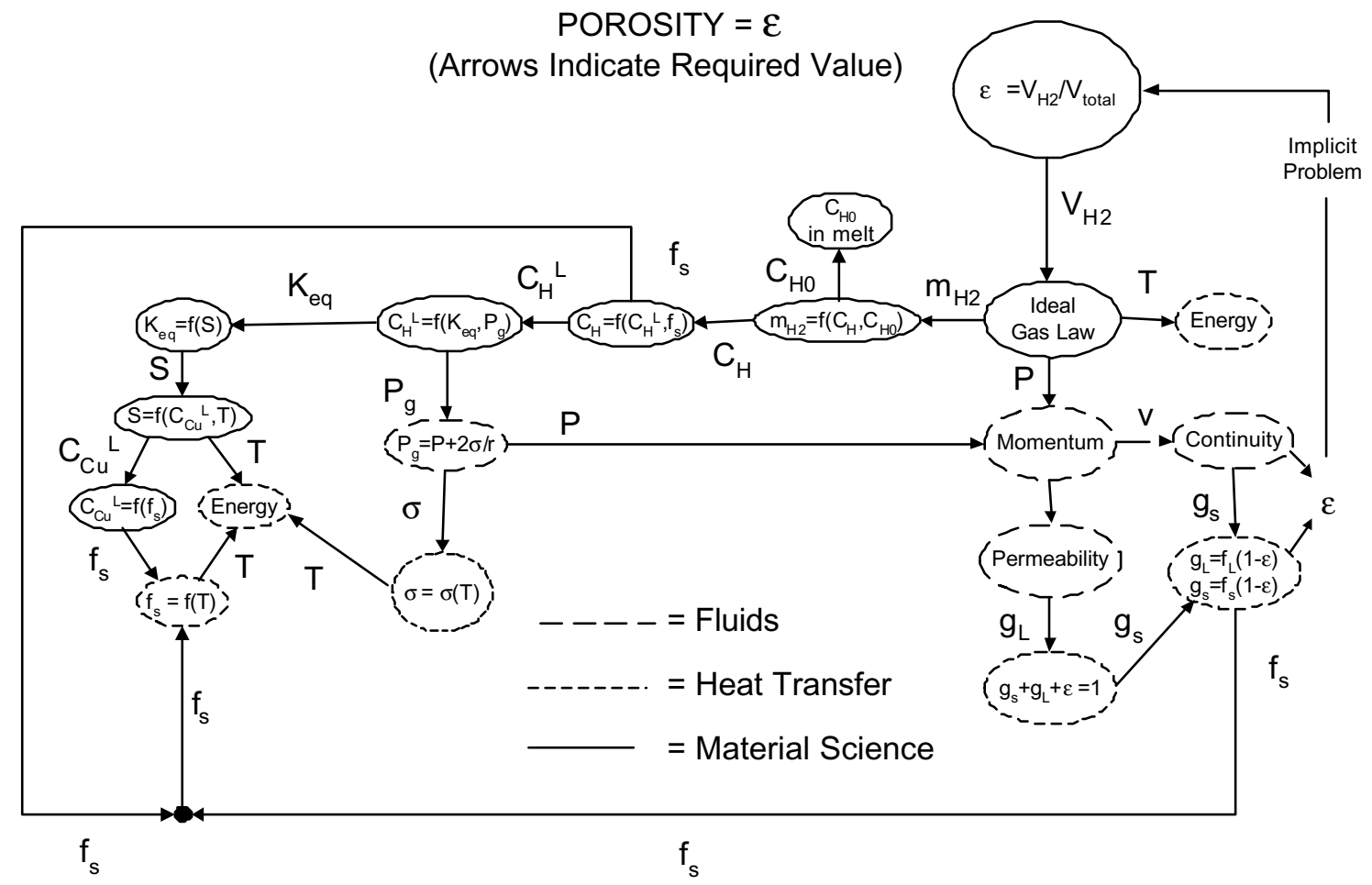

Figure 6: Microporosity Model. 